\title{
A new paravian dinosaur from the Late Jurassic of North America supports a late acquisition of avian flight
}

\author{
Scott Hartman ${ }^{\text {Corresp., }}{ }^{\text {, }}$, Mickey Mortimer $^{2}$, William R Wahl ${ }^{3}$, Dean Lomax ${ }^{4}$, Jessica Lippincott ${ }^{3}$, David M Lovelace ${ }^{5}$ \\ 1 Department of Geoscience, University of Wisconsin-Madison, Madison, Wisconsin, United States \\ 2 Independent, Maple Valley, Washington, United States \\ 3 Wyoming Dinosaur Center, Thermopolis, Wyoming, United States \\ 4 School of Earth and Environmental Sciences, The University of Manchester, Macnhester, United Kingdom \\ ${ }^{5}$ University of Wisconsin Geology Museum, University of Wisconsin-Madison, Madison, Wisconsin, United States \\ Corresponding Author: Scott Hartman \\ Email address: sahartman@wisc.edu
}

The last two decades have seen a remarkable increase in the known diversity of basal avialans and their paravian relatives. The lack of resolution in the relationships of these groups combined with attributing the behavior of specialized taxa to the base of Paraves has clouded interpretations of the origin of avialan flight. Here we describe Hesperornithoides miessleri gen. et sp. nov., a new paravian theropod from the Morrison Formation (Late Jurassic) of Wyoming, USA, represented by a single adult or subadult specimen comprising a partial, well-preserved skull and postcranial skeleton. Limb proportions firmly establish Hesperornithoides as occupying a terrestrial, non-volant lifestyle. Our phylogenetic analysis emphasizes extensive taxonomic sampling and robust character construction, recovering the new taxon most parsimoniously as a troodontid close to Daliansaurus, Xixiasaurus and Sinusonasus. Multiple alternative paravian topologies have similar degrees of support, but proposals of basal paravian archaeopterygids, avialan microraptorians, and Rahonavis being closer to Pygostylia than archaeopterygids or unenlagiines are strongly rejected. All parsimonious results support the hypothesis that each early paravian clade was plesiomorphically flightless, raising the possibility that avian flight originated as late as the Late Jurassic or Early Cretaceous. 


\section{A new paravian dinosaur from the Late Jurassic of North America supports a 2 late acquisition of avian flight}

3

4 Scott Hartman ${ }^{1}$, Mickey Mortimer ${ }^{2}$, William R. Wahl ${ }^{3}$, Dean Lomax ${ }^{4}$,

5 Jessica Lippincott ${ }^{3}$, David M. Lovelace ${ }^{5}$

6

$7 \quad{ }^{1}$ Department of Geoscience, University of Wisconsin-Madison, Madison, WI, USA

8

9 2Maple Valley, WA, USA

10

${ }^{3}$ Wyoming Dinosaur Center, 110 Carter Ranch Road, Thermopolis, WY, USA

12

${ }^{4}$ The University of Manchester, School of Earth and Environmental Sciences, Manchester, UK

14

15

${ }^{5}$ University of Wisconsin Geology Museum, University of Wisconsin-Madison, Madison,

16 Wisconsin, United States

17

18

19 Corresponding Author:

20

21 Scott A. Hartman ${ }^{1}$

22

23

24 Email address: sahartman@wisc.edu

25 
26

27

28

29

30

31

32

33

34

35

36

37

38

39

40

41

42

43

44

45

46

47

48

49

50

51

52

53

54

55

56

\section{Abstract}

The last two decades have seen a remarkable increase in the known diversity of basal avialans and their paravian relatives. The lack of resolution in the relationships of these groups combined with attributing the behavior of specialized taxa to the base of Paraves has clouded interpretations of the origin of avialan flight. Here we describe Hesperornithoides miessleri gen. et sp. nov., a new paravian theropod from the Morrison Formation (Late Jurassic) of Wyoming, USA, represented by a single adult or subadult specimen comprising a partial, well-preserved skull and postcranial skeleton. Limb proportions firmly establish Hesperornithoides as occupying a terrestrial, non-volant lifestyle. Our phylogenetic analysis emphasizes extensive taxonomic sampling and robust character construction, recovering the new taxon most parsimoniously as a troodontid close to Daliansaurus, Xixiasaurus and Sinusonasus. Multiple alternative paravian topologies have similar degrees of support, but proposals of basal paravian archaeopterygids, avialan microraptorians, and Rahonavis being closer to Pygostylia than archaeopterygids or unenlagiines are strongly rejected. All parsimonious results support the hypothesis that each early paravian clade was plesiomorphically flightless, raising the possibility that avian flight originated as late as the Late Jurassic or Early Cretaceous.

\section{Introduction}

Paravians are an important radiation of winged coelurosaurs more closely related to birds than to Oviraptor, that include dromaeosaurids, troodontids, unenlagiines, halszkaraptorines and archaeopterygids in addition to derived avialans. Despite robust support for their monophyly, the interrelationships and composition of these groups remains contentious with recent studies alternatively favoring joining troodontids and dromaeosaurids as Deinonychosauria (Hu et al., 2018; Lefèvre et al., 2017; Shen et al., 2017; Godefroit et al., 2013a; Senter et al., 2012; Turner et al., 2012), placing troodontids closer to Aves than dromaeosaurids (Gianechini et al., 2018; Cau et al., 2017; Foth and Rauhut, 2017; Lee et al., 2014a; Foth et al., 2014; Godefroit et al., 2013b), joining dromaeosaurids and avialans to form Eumaniraptora to the exclusion of 
57 troodontids (Agnolin and Novas, 2013) or merely recovering an unresolved trichotomy between

58 the three (Cau et al., 2015; Brusatte et al., 2014).

59

60 This lack of phylogenetic resolution has been attributed to a combination of rapid rates of

61 evolution at the base of Paraves (Brusatte, et al., 2014) and a lack of sampling of taxa from

62 outside the hugely prolific Late Jurassic and Early Cretaceous fossil beds of eastern China. In

63 particular, Middle and Late Jurassic taxa Archaeopteryx, Anchiornis, Aurornis, Eosinopteryx,

64 and Xiaotingia have been recovered variously as basal dromaeosaurids, basal troodontids,

65 archaeopterygids, or non-archaeopterygid avialans (e.g. Turner, et al., 2007; Xu, et al., 2011;

66 Senter et al., 2012; Godefroit, et al., 2013a, b). Incomplete taxonomic sampling and unresolved

67 relationships of basal avialans hinders tests of hypotheses for the origin of flight, and the order of

68 acquisition of flight-associated characters in stem avians.

69

70 Here we report a new paravian theropod, Hesperornithoides miessleri gen. et sp. nov., collected

71 from the Morrison Formation near Douglas, Wyoming, USA, based on a largely complete skull

72 and associated postcranial elements (Lovelace, 2006; Wahl, 2006). We also present a

73 significantly expanded and updated phylogenetic analysis of maniraptorans that clarifies

74 paravian relationships, as well as the acquisition of flight-related characters in stem avians.

77 Materials \& Methods

78

Specimen curation: WYDICE-DML-001 (formerly WDC DML-001) was collected on private property in 2001 (see Locality \& Geologic Context below). In 2005 it was donated to the Big Horn Basin Foundation, a research and educational non-profit 501(c)3 formed in 1995 to be curated and made available for research. In 2016 the Wyoming Dinosaur Center and the Big Horn Basin Foundation merged to form a new non-profit organization, renamed The Wyoming Dinosaur Center, Inc. At that point WYDICE-DML-001 was transferred to the new non-profit, where it will be accessible to researchers in perpetuity. If the Wyoming Dinosaur Center, Inc. 
86 should ever cease to exist the donation agreement requires the specimen be transferred to the

87 University of Wyoming's paleontological collections, ensuring it will always be available for

88 research.

89

90 The electronic version of this article in Portable Document Format (PDF) will represent a 91 published work according to the International Commission on Zoological Nomenclature (ICZN), 92 and hence the new names contained in the electronic version are effectively published under that

93 Code from the electronic edition alone. This published work and the nomenclatural acts it 94 contains have been registered in ZooBank, the online registration system for the ICZN. The

95 ZooBank LSIDs (Life Science Identifiers) can be resolved and the associated information viewed 96 through any standard web browser by appending the LSID to the prefix http://zoobank.org/. The 97 LSID for this publication is: urn:lsid:zoobank.org:pub:6325E8D2-0AAF-4ECD-9DF2-

98 87D73022DC93. The online version of this work is archived and available from the following 99 digital repositories: PeerJ, PubMed Central and CLOCKSS.

101 Preparation: Multiple cycles of mechanical micro-preparation have been performed on the 102 specimen since discovery. The specimen was collected in several blocks and later reassembled in the lab to reproduce the original in-field association. In 2004 the skull and body block were scanned at the University of Texas High-Resolution X-ray Computed Tomography Facility in Austin, Texas. Segmentation of the scan data was completed in Object Research System's Dragonfly v1.1 software to help visualize preserved elements and internal morphology. Internal

107 cavities, such as those seen in long bones and pleurocoels were filled with the mineral barite. The 108 high electron density of barite precluded segmentation of many of the postcranial elements due 
109 to poor visualization. During physical preparation most of the specimen was left in the minimal

110 amount of host matrix to preserve the original association but reveal as much morphology as

111 possible.

112

113 Systematic Palaeontology

114

115 Theropoda Marsh, 1881

116 Maniraptora Gauthier, 1986

117 Paraves Sereno, 1997

118 Deinonychosauria Gauthier, 1986

119 Troodontidae Gilmore, 1924

120 Hesperornithoides miessleri gen. et sp. nov.

121

122 Holotype: WYDICE-DML-001 (Wyoming Dinosaur Center, Thermopolis), a single, partially

123 articulated skeleton consisting of most of an articulated skull and mandibles missing the

124 anteriormost portions, hyoids, five cervical vertebrae, first dorsal vertebra, isolated anterior

125 dorsal rib, portions of twelve caudal vertebrae, five chevrons, partial left scapula and coracoid,

126 portions of the proximal left humerus and distal right humerus, left ulna and radius, radiale,

127 semilunate carpal, left metacarpals I-III, manual phalanges III-2 and 3, manual unguals I, II, and

128 III, ilial fragment, most of an incomplete femur, right and left tibiae and fibulae, left astragalus

129 and calcaneum, portions of right and left metatarsal packets2, left pedal phalanges III-1, III-2,

130 III-3, IV-1, IV-2, IV-3, IV-4, and pedal unguals II and III and the proximal portion of IV.

131

132 Etymology: 'Hesper', (Greek) referring to the discovery in the American West, 'ornis', (Greek)

133 for bird and 'oeides', (Greek) for similar, referring to the avian-like form of derived paravians.

134 The trivial epithet honors the Miessler family, who have been avid supporters of the project.

135

136 Occurrence: Douglas, Converse County, Wyoming, USA; middle portion of Morrison

137 Formation, which has been variously dated between Oxfordian and Tithonian in age (Trujillo, 
138 2006; Trujillo et a., 2014), associated vertebrate fossils include the sauropod Supersaurus, a 139 stegosaurid plate, and isolated large theropod teeth.

140

141 Diagnosis: A paravian with the following derived characters: pneumatic jugal (also in 142 Zanabazar and some eudromaeosaurs among maniraptorans); short posterior lacrimal process $143(<15 \%$ of ventral process length, measured from internal corner; also present in Zanabazar, 144 Archaeopteryx and Epidexipteryx); quadrate forms part of lateral margin of paraquadrate 145 foramen; small external mandibular fenestra ( $<12 \%$ of mandibular length; also in Zhenyuanlong 146 and Dromaeosaurus among non-avian paravians); humeral entepicondyle $>15 \%$ of distal 147 humeral width (also in some avialans); manual ungual III subequal in size to ungual II (also in 148 Daliansaurus, IGM 100/44 and Mahakala); mediodistal corner of tibia exposed anteriorly (also 149 in Archaeopteryx and Jeholornis).

150

151 Locality \& Geologic Context: In the summer of 2001, members of the Tate Geological Museum were excavating a large sauropod dinosaur (Supersaurus vivianae; see Lovelace et al., 2007) at the Jimbo Quarry in the Morrison Formation near Douglas, Wyoming (Fig 1). WYDICE-DML-001 (aka the 'Lori' specimen; see Wahl, 2006) was discovered during the 155 removal of overburden from the quarry. The accidental nature of the discovery directly impacted the recovery of the delicately preserved specimen, resulting in some portions being damaged or

157 lost during collection.

The Morrison Formation in central Wyoming is considered undivided adding to the difficulty in long distance correlation (Trujillo, 2006; Trujillo et al., 2006; Trujillo et al., 2014). Very fine $(100 \mu \mathrm{m})$ euhedral zircons have been observed in heavy mineral separates from a smectite rich mudstone within $0.5 \mathrm{~m}$ above and a mixed smectite-illite mudstone below the interval in which WYDICE-DML-001 was discovered.

The Jimbo Quarry (Unit 1 of Fig. 2) is an isolated discrete unit with an uneven upper and lower surface that is interpreted to be a hyperconcentrated flow resulting from post-fire soil destabilization (Lovelace, 2006). WYDICE-DML-001 was discovered in a fine grained muddy 
169 over 10-20 cm into the first $1.5 \mathrm{~m}$ of mixed smectite-illite mudstone of Unit 3 (Fig. 2). Unit 3

170 exhibits 6 discrete micritic limestone layers that overly the first $1.5 \mathrm{~m}$ of mudstone and are each

171 differentiated by $20-50 \mathrm{~cm}$ of mixed smectite-illite mudstones with abundant charophytes and

172 conchostraca (Lovelace, 2006).

173

174 The first four meters of strata overlying the Jimbo Quarry have been interpreted as representing a 175 cyclical rise and fall of the local water table in a marginal lacustrine or wetland environment 176 (Lovelace, 2006) similar to those seen in the Big Horn Basin of Wyoming (Jennings et al., 2011).

177 The concentrated presence of barite in long bones and pleurocoels is consistent with a saturated 178 microenvironment where free sulphur is available due to organic decay; this has been observed 179 elsewhere in marginal lacustrine and wetland environments within the Morrison of Wyoming 180 (Jennings \& Hasiotis, 2006; Jennings et al., 2011). The interpretation of a wetlands or marginal 181 lacustrine environment is supported by XRD of clay minerals, presence of freshwater algae and 182 arthropods, and the lack of sedimentary structures indicative of fluvial transport. 183

WYDICE-DML-001 is preserved in partial articulation with little evidence of dissociation. The 185 presence of organic material at the distal end of several manual and pedal unguals is consistent with the preservation of a keratinous sheath; no other soft-tissue preservation was observed. Much of the thoracic region is absent, although the relative positioning of the remaining elements (Fig. 3) suggests an animal in a resting position. Given the autochthonous nature of deposition it appears that Hesperornithoides was an inhabitant of wetland environments for at least a portion of its life history.

Description

WYDICE-DML-001 has an estimated length of $89 \mathrm{~cm}$ (Figs. 4 \& 5, Table 1). The hind legs are folded in a crouching or resting position, the head is turned to the side underneath the left manus, and the preserved mid-caudal series wraps around the torso, reminiscent of the sleeping posture preserved in Mei and Sinornithoides (Xu and Norell, 2004; Gao et al. 2012; Russell and Dong, 
199 200 201

202 203 204 205 206 207 208 209 210

211

212 213 214 215

216 217 218

1994). Hesperornithoides is compared below both to other paravians and to other small Morrison coelurosaurs.

Ontogenetic status: Visual inspection under 100x magnification showed neural arches are fused with fully obliterated synchondroses sutures on all preserved vertebrae, ruling out a hatchling or juvenile individual (sensu Hone, et al., 2016). Adult or subadult status is reinforced by general skeletal proportions (Fig. 5, Table $1 \&$ 2), as WYDICE-DML-001 lacks a relatively enlarged cranium or other allometric proportions associated with early ontogenetic stages. WYDICEDML-001 does not exhibit signs of advanced ageing, as the skull and proximal tarsal sutures lack evidence of obliteration by co-ossification. Without histological analysis the ontogenetic stage cannot be resolved beyond "adult or subadult", but either designation would result in minimal additional linear skeletal growth, making the estimated 1 meter total length (Table 1) of Hesperornithoides is therefore substantially smaller than other relatively complete theropods from the Morrison Formation (Foster, 2003). The same can be said about individual elements, for example the humerus of WYDICE-DML-001 is 29\% the length of the Coelurus holotype, $17 \%$ the length of the Tanycolagreus holotype and $28 \%$ the length of the Ornitholestes holotype.

Skull: Cranial elements are preserved in a separate "skull block" (Figs. $3 \& 4$ ) prepared so both the right and left skull elements are largely visible in lateral view; some palatal elements are visible on the right side of the block. The right jugal, lacrimal, and posterior process of the maxilla are articulated and well preserved; the right quadrate is also exposed (Fig. 6). The skull and mandible exhibit some lateral compression with the left side being dorsally displaced (Fig. 6). The braincase suffers from both inadvertent damage during collection (some natural molds of broken elements exist) and pre-depositional disruption of elements. Posterior skull roof elements are progressively displaced dorsally; the left jugal is dorsoventrally rotated out of position underlying the posterior process of the maxilla. A portion of the lower half of the left lacrimal is exposed in lateral view; a medial impression of the mid-lacrimal is also visible. The premaxillae, as well as anteriormost portions of the maxillae, nasals, and dentaries were unfortunately destroyed during discovery of the specimen. 
229 The skull is triangular in lateral aspect as seen in most basal paravians and enough of the snout is 230 preserved to show the external naris was not enlarged. The maxilla exhibits an extensive, sharp231 rimmed antorbital fossa containing a D-shaped antorbital fenestra, a large maxillary fenestra, and 232 the posterior margin of a promaxillary fenestra (Fig. 6). This rim is also found in derived 233 members of Sinovenatorinae (Xu et al., 2002: Fig. 1a; Xu et al., 2011: Fig. S1a; Xu et al., 2017:

234 Fig. 2a), Microraptoria (Xu and Wu, 2001: Fig. 4B; Pei et al., 2014: Fig. 2) and some 235 archaeopterygid specimens (Pei et al., 2017a: Fig. 5; Rauhut et al., 2018: Fig. 8A). Similar to 236 most dromaeosaurids and Halszkaraptor (Godefroit et al., 2008: Fig. 4; Lu and Brusatte, 2015 : 237 Fig. 2; Zheng et al., 2009: Fig. 2a; Cau et al., 2017: Fig. 3b), the maxillary fenestra is dorsally 238 displaced within the antorbital fossa (Fig. 7). The maxillary fenestra is positioned far from the 239 unpreserved anterior edge of the antorbital fossa and is not set within a concavity unlike some 240 dromaeosaurids. There is an accessory fossa posteroventral to the fenestra however, as in 241 Zhenyuanlong (Lu and Brusatte, 2005: Fig. 2) but less developed than in microraptorians. A 242 robust external ascending process separates the nasal and elongate antorbital fossa until the 243 anterior margin of the antorbital fenestra. Segmented CT data shows medially there is an 244 extensive palatal shelf placed more ventrally than in eudromaeosaurs (Fig. 7), and posteriorly the 245 jugal process is shallow. Both promaxillary and epiantral recesses are developed, the postantral 246 pila does not extend into the antorbital fenestra as it does in some dromaeosaurids, and the 247 palatal shelf does not extend dorsally to be visible laterally as it does in Saurornitholestes and 248 Atrociraptor (Fig. 7). Compared to Ornitholestes, the maxilla has a larger maxillary fenestra, a 249 medial fenestra for the maxillary antrum (Witmer, 1997:42) and an external dorsal process that 250 ends sooner so that the nasal contacts the antorbital fossa.

251

252 The incomplete nasals are unfused with smooth external surfaces which have no significant 253 transverse convexity. The portion adjacent to the antorbital fossa on the left nasal lacks accessory 254 pneumatic foramina. Both lacrimals are preserved, lacking horns but possessing the lateral 255 expansion on the dorsal edge typical of pennaraptorans. A foramen is present in the 256 posterodorsal corner of the antorbital fossa, here scored as pneumatic, but given similar 257 structures have been considered to house the lacrimal duct (e.g. Fig. 5A in Yin et al., 2018 for 258 Sinovenator), more objective criteria are needed. The posterior lacrimal process is short (Fig. 8), 259 unlike most long-tailed paravians, but also present in Zanabazar, Archaeopteryx and 
260 Epidexipteryx (Barsbold, 1974: plate 1 Fig. 1b; Rauhut, 2013: Fig. 1A; Zhang et al., 2008: Fig. 261 1c). The lacrimal differs from Tanycolagreus in lacking a dorsally projecting horn (Carpenter et 262 al., 2005a: Fig. 2.4G), and from Ornitholestes in having a laterally projecting antorbital process, 263 both more similar to maniraptoriforms. The ventral process is strongly expanded distally and has 264 a lateral lamina which never fully overlaps the medial lamina. The jugal is dorsoventrally low 265 but lateromedially compressed beneath the orbit and laterotemporal fenestra. Segmented CT data 266 indicates that unlike most maniraptorans (exceptions are Zanabazar, Velociraptor and

267 Deinonychus; Norell et al., 2009:34; Barsbold and Osmolska, 1999:200; Witmer, 1997:45) and 268 Ornitholestes (Witmer, 1997:45), the jugal is pneumatic (Fig. 9) with a large opening in the 269 antorbital fossa. The anterior end is only slightly expanded and there is no foramen medially at 270 the level of the postorbital process. Along its ventral edge, there is a longitudinal ridge extending 271 most of the way under the orbit. The jugal and postorbital contact completely separates the orbit 272 from the infratemporal fenestra.

273

274 The postorbital, squamosal, quadratojugal, palatine and perhaps pterygoid cannot be exposed via 275 mechanical preparation in sufficient detail to score characters from. Interference from barite 276 inclusions in the anterior cervical vertebrae have frustrated multiple CT scan attempts.

277 Proportions of suborbital bones suggest a parietal shorter than the frontal. Both quadrates are 278 preserved and partially exposed from surrounding matrix, showing a planar articulation with the 279 quadratojugal and bicondylar distal articulations. CT scans show the quadrate is pneumatized as 280 in troodontids but unlike Ornitholestes, with a fossa on the posterior surface. It partially encloses 281 the small paraquadrate foramen laterally unlike Tanycolagreus (Carpenter et al., 2005a: Fig. 282 2.4O) and other maniraptorans (Fig. 10; compare to e.g. Barsbold et al., 1987: plate 49 Fig. 4; Xu 283 and Wu, 2001: Fig. 4D; Burnham, 2004: Fig. 3.10B; Hu et al., 2009: Fig. S2d; Gao et al., 2012: 284 Fig. 2A; Xing et al., 2013: Fig. S1; Cau et al., 2017: Fig. 3a; Gianechini et al., 2017: Fig. 5; Yin 285 et al., 2018: Fig. 7A). Note in figure 10 there is a vertical suture at the top center of the closeup 286 image and that bone to the left of that is a fragment of quadratojugal adhering to the quadrate.

287

288 Mandible \& dentition: The left and right mandibles are complete save for the anterior portion 289 of the dentaries that were destroyed during discovery. The lateral surface of the posterior left 290 mandible is well exposed, however the dorsolateral dentary is largely obscured by the overlying 
291 maxillary teeth and associated matrix and must be described from segmented CT scan data. The

292 posteriormost right mandible is laterally exposed and the medial surface of the dentary is visible 293 on the left side of the skull block. The labial dentary groove widening posteriorly is clearly 294 visible; initially described as a troodontid character (Hartman et al., 2005; Wahl, 2006) it is here 295 resolved as a symplesiomorphy seen also in some microraptorians, unenlagiines, Halszkaraptor 296 and most archaeopterygids (Xu and Wu, 2001: Fig. 6; Paul, 2002: plate 7A; Gianechini and 297 Apesteguia, 2011: Fig. 2Ag; Pei et al., 2014: Fig. 2; Cau et al., 2017:S23; Gianechini et al., 2017: 298 Fig. 1-2; Lefèvre et al., 2017: Fig. 2; Pei et al., 2017a: Fig. 5). The groove is absent in 299 Ornitholestes however, and the dentary differs from that referred to Coelurus in not being 300 downturned (Carpenter, et al., 2005b: Fig. 3.3). Whether the new taxon's dentaries are entirely 301 straight or slightly upturned anteriorly is uncertain due to the missing anterior tips. The slender 302 dentaries lack a posterolateral shelf and have a deep Meckelian groove positioned at 303 approximately midheight. Hesperornithoides has a small external mandibular fenestra $(<11 \%$ of 304 mandibular length; Fig. 5B) unlike most other maniraptorans except for Zhenyuanlong and 305 Dromaeosaurus (Currie, 1995: Fig. 7A; Lu and Brusatte, 2015: Fig. 2). No coronoid is obvious 306 despite a well preserved in situ mandible, but we conservatively score the taxon unknown given 307 the reduced state of this element in some maniraptoriforms. Posteriorly, the surangular is 308 shallower than the dentary at the anterior border of the external mandibular fenestra (Fig. 6A), 309 has a very long suture with the dentary anterior to this fenestra, and lacks a pronounced coronoid 310 eminence and or a process invading the fenestra.

311

312 The lack of anteriormost portions of the mandible and maxilla prevent determination of changes 313 in size or spacing of alveoli, but in both elements the posterior teeth are smallest and the left 314 maxilla preserves an anterior crown base smaller than the next tooth, the largest in the series. At 315 least ten maxillary teeth and eleven dentary teeth were present, with the total count being perhaps $316 \sim 14$ and $\sim 17$. Teeth are relatively large and recurved and possess well developed mesial 317 serrations as in most dromaeosaurids, Troodon and Caihong (Hu et al., 2018:4). The serrations 318 on the mesial carinae of maxillary teeth are smaller than the distal serrations as in basal 319 dromaeosaurids. Mesial serrations are restricted to the apical third of the crown and appear 320 absent in some teeth. Serrations are small (5.5 per mm distally) as in Sinusonasus, 321 Liaoningvenator and some sinovenatorines, and not apically hooked. Similar to the condition 
322 described for Serikornis, the maxillary teeth are anisodont with crown height of the largest

323 exposed teeth twice the size of others (Lefèvre, et al., 2017: Fig. 2). There is a slight mesiodistal 324 constriction between tooth root and crown in fully erupted teeth (Fig. 11G) unlike Ornitholestes 325 and most dromaeosaurids except some microraptorians (Xu et al., 2000: Fig. 2d; Xu and Li, 326 2016: Fig. 3), although no proximal expansion of the root is present. Both root and crown are 327 labiolingually compressed, and the enamel shows no trace of longitudinal grooves. Chure (1994) 328 previously described an isolated tooth from the Morrison Formation of Utah as the troodontid 329 Koparion douglassi. This tooth differs from Hesperornithoides teeth in being more recurved, 330 labiolingually wide (Basal Width / FABL .72 compared to $\sim .45$ ), possessing large serrations as 331 in derived troodontids, exhibiting mesial serrations that extend to within two serration lengths of 332 the crown base, and possessing blood pits (Fig. 11). While it may belong to a derived troodontid, 333 serration size and extent was extremely homoplasic in our phylogenetic results suggesting caution should be applied. Paired hyoids are preserved as thin parallel rod-like structures on the left side of the skull block; posteriorly the hyoids overlie the medioposterior surface of the right mandible.

Axial skeleton: The axial skeleton is distributed across three blocks (Fig. 4). Six presacral vertebrae are preserved on the "body block", three anterior cervicals, two mid-cervicals and a cervicodorsal (Fig. 12). Three articulated mid-anterior caudals are found on the skull block, and the remaining caudal vertebrae are preserved on the "hand block", some as natural molds.

342 Cervical centrum measurements indicate a cervicofemoral ratio $(\sim 0.95)$ similar to anchiornithines (0.81-1.01), troodontids (0.83-1.08) and dromaeosaurids (1.02-1.04) but shorter 344 than Halszkaraptor (2.65) or Archaeopteryx (1.21-1.37). The axis is partially preserved, possessing epipophyses that extend past the postzygapophyseal tips. The third cervical centrum is over four times longer than tall posteriorly extending past the neural arch, with amphicoelous articular surfaces, a transversely convex ventral surface and a single pair of pleurocoels posterior to the parapophysis (Fig. 12B). CT cross sections and broken surfaces reveal additional cavities, including those extending into the zygapophyses (Fig. 12C). The neural spines are long and low, centered on the neural arch. Contra initial reports (Hartman et al., 2005; Wahl, 2006) some of the cervical ribs extend beyond the posterior margin of the centra. Cervical ribs begin broad in crosssection but thin rapidly in length to an almost hair-like diameter (Fig. 12E). Initial mechanical 
353 preparation missed this thinning, and it appears that other paravians described as having short

354

355

356

357

358

359

360

361

362

363

364

365

366

367

368

369

370

371

372

373

374

375

376

377

378

379

380

381

382

383

cervical ribs may also be in need of additional preparation to ensure accurate scoring of this character (S.H., personal observation). Two cervical vertebrae are preserved with fused cervical ribs, consistent with a subadult or adult individual.

A single anterior dorsal vertebra is preserved (Fig. 12F). Its centrum is longer than wide or tall, posteriorly concave and has a pleurocoel behind the parapophysis with no lateral fossa. The anteroventral centrum is hidden by matrix, preventing determination of hypapophyseal height. Separated hyposphenes are present posteriorly. The transverse processes are short according to our newly quantified version of this classic TWiG character. It has a fan-shaped and moderately tall neural spine.

Portions of at least 3 caudals are preserved on the hand skull block, an additional 9 caudals are preserved on the hand block, several as natural molds. The 12 caudals provide good representation from mid and distal portions of the tail (Fig. $5 \&$ 8G-H). Caudal morphology suggests a distinct transition from shorter proximal caudals to elongate mid and distal caudal centra. The neural spines transition from well-developed on more proximal caudals to absent in mid-caudals, whereas Coelurus has low spines even on distal caudal vertebrae (Makovicky, 1995). The distal caudals have transversely flat dorsal surfaces between the zygapophyses, and while the distalmost elements develop a negligible concavity, it is never comparable to the sulcus found in other troodontids. Distal caudal prezygapophyses are between $33-100 \%$ of central length (Fig. 12H, Fig. 13), as in Scansoriopteryx, some troodontids, Caihong and jeholornithids (Currie and Dong, 2001: Fig. 5A; Czerkas and Yuan, 2002: Fig. 13; Zhou and Zhang, 2002: Fig. 1b-c; Xu and Wang, 2004: Fig. 1; Norell et al., 2009: Fig. 32A-B; Hu et al., 2018: Fig. 2e) but unlike the shorter prezygapophyses of Coelurus (Carpenter et al., 2005b: Fig. 3.6C). Unlike microraptorians and eudromaeosaurs, these processes lack bifurcation. The mid and distal caudals have a longitudinal sulcus on the lateral surface where centra meet neural arches, which is primitive for paravians, being present in unenlagiines, Liaoningovenator, archaeopterygids and Jeholornis (Motta et al., 2017:174; Shen et al., 2017: Fig. 4A). CT scans reveal pneumatopores within a fossa on the lateral surface of some caudal vertebrae. Ventrally, distal caudal centra exhibit a deep longitudinal groove. Mid-caudal chevrons are dorsoventrally flat but without

Peer) reviewing PDF | (2018:08:30731:1:2:NEW 20 May 2019) 
384 highly elongate processes, and bifid anteriorly and posteriorly unlike those of Ornitholestes 385 (Carpenter et al., 2005b: Fig. 3.6B") or other non-paravians.

386

387 Pectoral girdle $\&$ forelimb: The pectoral girdle is poorly preserved, but a large and robust 388 furcula was preserved in association with the cervicodorsal vertebra on the body block. The 389 boomerang-shaped furcula has an angle of approximately 80 degrees and curves posteriorly in

390

391

392

393

394

395

396

397

398

399

400

401

402

403

404

405

406

407

408

409

410

411

412

413

414

lateral view. No hypocleidium or posterior groove are evident, and the furcula lacks strong anteroposterior compression unlike most paravians besides Velociraptor (Norell and Makovicky, 1999:7). Remaining pectoral girdle elements include a portion of a strap-like scapula without a dorsal flange (preserved in part as natural mold on the body and skull blocks), and most of an enlarged coracoid, consistent with the pectoral girdle of other paravians. The coracoid possesses a posterior fossa and supracoracoid foramen but lacks signs of proximal pneumaticity.

The left forelimb is largely complete, missing the distal portion of the humeral shaft and the nonungual phalanges of digits I and II; these elements are distributed across the skull, body, and hand blocks. The proximal half of the left humerus has been mechanically prepared to be fully free of matrix. The distal half of the right humerus is preserved on the body block, providing a nearly complete composite humerus. The ulna and radius are shorter than the humerus, and the resulting forearm is proportionately short (estimated forelimb to hindlimb ratio of .58, Table 1) as seen in Mahakala, Mei, Tianyuraptor, Caihong, Zhenyuanlong, Austroraptor and Halszkaraptor (Xu and Norell, 2004: supp. table 4; Novas et al., 2008: table 1; Zheng et al., 2009: table 1; Turner et al., 2011: table 1; Lu and Brusatte, 2015: supp. info. 1; Cau et al., 2017: supp. table 1; Hu et al., 2018: supp. table 1), and was clearly incapable of flapping flight.

The humerus is significantly shorter than the femur $(0.63)$ and slender. The deltopectoral crest is proximally restricted, roughly triangular and projects closer to perpendicular to the head's long axis (Fig. 14E). Hesperornithoides' crest lacks the fenestra found in some microraptorians and the distinct lateral scar (Fig. 14F) seen in Coelurus, attributed to the m. pectoralis superficialis by Carpenter et al., (2005:60, Fig. 3.8B). The humeral head is anteriorly concave and proximally convex, and not separated from the bicipital crest by a capital groove. Well projected medially but unprojected anteriorly, this crest is proximodistally short but has a straight inner edge. There

Peer) reviewing PDF | (2018:08:30731:1:2:NEW 20 May 2019) 
415 is no trace of a pneumatricipital fossa or foramen in the proximal humerus. Distally the humerus

416 is well expanded and exhibits an enlarged entepicondyle, over 15\% of distal humeral width (Fig.

417 14D). Among maniraptorans, this is otherwise only seen in avialans such as Zhongjianornis,

418 Sapeornis, Jixiangornis, Confuciusornis and various ornithothoracines (Chiappe et al., 1999: Fig.

419 38; Zhou and Zhang, 2003: Fig. 7a).

420

421 Unlike any of the three well preserved Morrison basal coelurosaurs, the distal ulna is highly 422 compressed dorsoventrally to be over twice as wide as tall. It is also dissimilar from Coelurus 423 and Tanycolagreus in being straight in side view (Carpenter et al., 2005a: Fig. 2.10B-C;

424 Carpenter et al., 2005b: Fig. 3.8C-D). The distal end lacks significant proximoventral

425 development of the articular surface, is roughly straight in dorsal perspective and has no well 426 defined radial sulcus. The radius itself is over $70 \%$ of ulnar width at midshaft, exhibits no 427 obvious groove or scaring posterodorsally on the shaft but does possess a distodorsal flange 428 typical of pennaraptorans.

429

430 The semilunate carpal is preserved next to, but slightly displaced from the metacarpal packet on 431 the skull block. It is not well exposed on the surface of the block, but CT scans reveal a well432 developed semilunate morphology with a transverse trochlear groove (Fig. 14A). This is unlike 433 the unfused distal carpal I of the much larger Coelurus specimen YPM 2010 which is more 434 oblong than semilunate (Carpenter et al., 2005b: Fig. 3.9A). Tanycolagreus fuses the distal 435 carpals but the resulting structure is very flat instead of semilunate (Carpenter et al., 2005a: Fig.

$4362.11 \mathrm{E}-\mathrm{F}$; note the radiale is mistakenly identified as the semilunate). The size of the semilunate 437 shows it covered most or all of the proximal ends of metacarpals I and II. A well-developed 438 mediodorsal process was present for articulation with the first metacarpal.

439

440 Metacarpal (MC) I is complete, while MC II-III are both missing the distal-most articular 441 condyles; the left MC's can be seen on the right side of the skull block. An isolated distal MC III 442 is also preserved from the other manus. Preserved phalanges are located on the hand block, with 443 the exception of an isolated manual ungual. MC I is the shortest and most robust metacarpal (Fig. 444 14B), featuring an extensor flange as in paravians (Gishlick, 2002) but unlike Ornitholestes or 445 Tanycolagreus. Its distal end is deeply ginglymoid, with the lateral condyle extending further 
446 ventrally. The metacarpals become progressively less robust laterally and there is no bowing of

447 MC III. Metacarpal III is more robust than in Tanycolagreus however, where it is much narrower 448 than half the width of metacarpal II (Carpenter et al., 2005a: Fig. 2.12B). Metacarpal II exhibits a 449 dorsal scar for the $\mathrm{m}$. extensor carpi ulnaris longus equivalent to the intermetacarpal process in 450 some Aves, which Gishlick (2002) recovered as exclusive to Pennaraptora.

451

452 The articulated digit III is exposed on the hand block in medial view, along with phalanx II-1 and 453 manual ungual II in lateral view. Phalanx III-3 is longer than the combined lengths of III-1 and 454 III-2. Manual unguals are large, raptorial, and trenchant. They have well-developed, proximally 455 placed flexor tubercles and lack a proximodorsal lip (Fig. 15). An isolated ungual reported as an 456 enlarged pes ungual II by Hartman et al. (2005) is reinterpreted as manual ungual I, as the dorsal 457 margin arches significantly above the articular facet when the latter is held vertically, and the 458 large flexor tubercle extends significantly beyond the palmar side of the articular facet (cf. 459 Senter, 2007b). Manual ungual III is subequal in size to ungual II (Fig. 15B-C) unlike 460 Tanycolagreus (Carpenter et al., 2005a: Fig. 2.12A) and most paravians except Daliansaurus, 461 troodontid IGM 100/44 and Mahakala (Barsbold et al., 1987: plate 50 Fig. 2-4; Turner et al., 462 2011: Fig. 29; Shen et al., 2017: Table 1).

463

464 Pelvic girdle \& hind limb: An isolated block contains much of the ilial postacetabular process, 465 partly as an impression that can nonetheless be reconstructed precisely via CT scans. Unlike the 466 condition in Ornitholestes (Carpenter et al., 2005b: fig. 3.10A; note the ilium is photographed at 467 a slight ventral angle and that the postacetabular process is blunt if viewed perpendicular to the 468 blade- M.M. pers. obs., AMNH 619), the postacetabular process is distally pointed in lateral 469 view, has only a shallow brevis fossa and possesses a laterally projecting ventral lobe like some 470 basal dromaeosaurids and troodontids. Hesperornithoides possesses a concavity along the dorsal 471 edge of its postacetabular process. Originally considered an unenlagiine synapomorphy 472 (Makovicky et al., 2005:S15), the condition has proven to be widespread among theropods. 473

474 Hind limb elements are all preserved on the body block. The hind limbs are elongate relative to 475 individual vertebrae, as in most coelurosaurs including Archaeopteryx and Jeholornis (Dececchi 476 \& Larsson, 2013). The left femur has been entirely prepared off of the block prior to 
477 reattachement, and is missing only the head and proximal-most portion; enough of the shaft is

478 preserved to establish the absence of a fourth trochanter as in the vast majority of pennaraptorans

479 but unlike Coelurus and Tanycolagreus (Carpenter et al., 2005b:66; Carpenter et al., 2005a: Fig.

480 2.14B). Notable among previously described Morrison paravian postcrania, proximal femur

481 BYU 2023 (Jensen and Padian, 1989) only overlaps with WYDICE-DML-001 at midshaft where

482 it also lacks a fourth trochanter. Our analysis recovered BYU 2023 as a deinonychosaur that

483 could belong to a troodontid or dromaeosaurid Hesperornithoides without an increase in tree

484 length (see Positions of taxa pruned a posteriori in the supplementary information), but further

485 comparison is limited. Distally, our specimen lacks a significant extensor groove or medial

486 epicondyle, and has a lateral condyle which is not projected distally and is separated from both

487 the medial condyle and ectocondylar tuber.

488

489 The left tibia and fibula are exposed almost completely, with the anterior portion of the shafts

490 buried in the the body block. Proximally the tibia is longer than wide, with a deep incisura

491 tibialis and anteriorly projected cnemial crest that diverges from the shaft at a high angle. No

492 medial cnemial crest is developed. Hesperornithoides is similar to Sinovenator, the Almas

493 holotype and Achillobator among paravians in having a lateral tibial condyle that extends

494 anteriorly to overlap the incisura tibialis (Perle et al., 1999: plate XII Fig. 12C; Xu et al., 2002:

495 Fig. 1h; Pei et al., 2017b: Fig. 9). This is unlike the condition in Tanycolagreus (Carpenter et al.,

496 2005a: Fig. 2.14K). The proximally placed fibular crest is separated from the proximal condyles

497 and has a longitudinal groove on its posterior edge. Distally, the lateral malleolus is covered by

498 the proximal tarsals but the medial malleolus is distally exposed.

499

500 The fibula extends the full length of the tibia but is extremely reduced in diameter. Most of the

501 shaft is less than $1 \mathrm{~mm}$ at maximum thickness. Broken portions reveal the fibula lacks trabecular

502 bone, being hollow and exceptionally thin walled. Hesperornithoides also differs from

503 Tanycolagreus in that its fibula is subequal in transverse width anteriorly and posteriorly,

504 whereas the latter genus exhibits a posterior tapering (Carpenter et al., 2005a: Fig. 2.14K).

505

506 The astragalus and calcaneum are tightly appressed to the distal ends of the tibia and fibula but

507 are not co-ossified to them or each other. The ascending process of the astragalus is elongate 
508 unlike Coelurus (Carpenter et al., 2005b: Fig. 3.12A), though narrow unlike most paravians

509 except for Anchiornis and Scansoriopteryx (Czerkas and Yuan, 2002: Fig. 20; Hu et al., 2009:

510 Fig. S4d). It is separated from the astragalar body by a transverse groove and contacts the fibula

511 at its lateral edge. Similar to avialans and most troodontids (Xu, 2002: Fig. 47D; Ji et al., 2011:

512 Fig. 3F; Zanno et al., 2011: Fig. 9D; Xu et al., 2012: Fig. 1K; Brusatte et al., 2013:67) but in

513 contrast to Coelurus and Tanycolagreus (Carpenter et al., 2005b: Fig. 3.12E; Carpenter et al.,

514 2005a: Fig. 2.14L), the astragalocalcanear anterior intercondylar groove is deep (over 20\% of

515 tarsal depth).

516

517 The left metatarsus is preserved in articulation with the zeugopod and is almost completely

518 exposed on the body block. Distal tarsals are not fused to the metatarsals, which are themselves

519 also unfused. Although the left metatarsus is incomplete distally, it clearly displays a sub-

520 arctometatarsalian condition (Fig. 16A, B, \& D) unlike Tanycolagreus and Ornitholestes

521 (Carpenter et al., 2005a: Fig. 2.15B; Carpenter et al., 2005: Fig. 3.13A), with metatarsal III being

522 constricted along the shaft but not excluded in anterior view. The metatarsus is quite different

523 from Ornitholestes, being slender and closely appressed with transversely compressed

524 metatarsals (Fig. 16D; compare to Fig. 13C in Holtz, 1994). Metatarsal III further differs from all

525 three well preserved Morrison basal coelurosaurs in being straight in proximal view instead of L-

526 shaped (Carpenter et al., 2005a: Fig. 2.15C; Carpenter et al., 2005b: Fig. 3.13A, D- based on

527 medial margin of proximal metatarsal IV for Coelurus). Posteriorly, metatarsal III is exposed as

528 a narrow sliver along its proximal length. MT II is not slender as in derived troodontids, and it

529 and MT III lack tubercles for the m. cranialis tibialis. Only a posterior portion of the distal

530 metatarsals is mechanically exposed, and they are not well resolved in the CT data. Metatarsal I

531 is straight with no torsion, and has a slightly constricted neck just before the incompletely

532 preserved distal condyles (Fig. 16C). A slender metatarsal V is preserved in articulation at the

533 posterolateral edge of metatarsal IV (Fig. 16A, D). Due to distal breakage it is uncertain if the

534 element is elongated as in dromaeosaurids.

535

536 Left pes digits III and IV are preserved in articulation with the plantar and lateral surface

537 exposed at the base of the body block. As in Archaeopteryx, toes III and IV are subequal in

538 length, proportions that appear less specialized for functional didactyly, with digit IV being 
539 substantially shorter and less robust than digit III (Mayr, et al., 2007: Fig. 13). Pedal phalanx IV-

5404 is shorter than IV-3, associated with cursoriality more than arboreality or grasping. Proximal

541 portions of pedal unguals III and IV are preserved; they are compressed in section, do not appear

542 to be strongly curved and lack enlarged flexor tubercles. An isolated ungual was found that is

543 strongly recurved and trenchant, exhibiting an intermediately expanded flexor tubercle (Fig.

544 15D). The isolated ungual differs from manual unguals in having a dorsal margin that does not

545 arch above the articular facet when the facet is vertical. Given the differences from the manual

546 unguals and the articulated III \& IV pedal unguals, we interpret this as an enlarged semi-raptorial

547 pedal ungual II. It also preserves a filagree of organic material that is consistent with previously

548 published remnants of keratin sheaths (Fig. 14E; Schweitzer, 2011).

549

550

Phylogenetic analysis

551

552 Phylogenetic methods: Almost every large-scale coelurosaur analysis from the past two decades

553 is ultimately a derivative of Norell et al. (2001) and have come to be known as Theropod

554 Working Group (TWiG) analyses. While TWiG can refer to the core group of AMNH affiliated

555 researchers, we use it more inclusively to encompass the myriad analyses and derivatives based

556 on their dataset (Supplemental figure S1). This widespread adoption has made the TWiG dataset

557 arguably the most successful lineage of dinosaur phylogenetic analyses to date. Most subsequent

558 iterations add one to several taxa and a few to several characters to a preexisting version of the

559 matrix. While this practice has resulted in character and taxon list stability between coelurosaur

560 analyses, it has also led to endemic issues in the compilation of data matrices. Jenner (2004)

561 identified similar concerns for metazoan cladistics, finding that taxon selection and sampling,

562 uncritical copying of scores, and poorly formed character states have been overlooked and can

563 compromise the validity of topologies recovered by phylogenetics programs that use these as

564 their primary data. In light of this, rather than adding Hesperornithoides to an existing TWiG

565 matrix we have instead begun an overhaul of the TWiG dataset to comply with modern ideals of

566 data matrix construction.

567

568 Subsequent TWiG analyses and derivatives have not added characters and taxa in a single

569 "lineage" of analyses, but instead have formed "clades" of analyses that increasingly diverge in 
570 content (see Fig. S1). So for example modern analyses derived from Senter (2007a) such as

571 Senter et al. (2012), and those derived from Turner (2008) such as Brusatte et al. (2014) have

572 over a hundred characters not found in the other. A similar pattern occurs with taxonomic

573 sampling; most new paravians are added individually or in small groups to a version of the

574 TWiG matrix but these additions are frequently not propagated to subsequent analyses. To date

575 no analysis has added all, or even most, newly discovered taxa to a single matrix. We follow the

576 advice of Jenner (2004) that authors should attempt to include all previously proposed characters

577 and terminal taxa, while explicitly justifying omissions. To this end we have attempted to include

578 every character from all TWiG papers published through 2012, with the goal to continually add

579 characters from other analyses in future iterations. Each excluded character from these studies is

580 justified under Excluded Characters in the Supplementary Information.

581

582 We have also scored almost every named Mesozoic maniraptoromorph known from more than

583 single elements or teeth (the seven exceptions are noted under Excluded Taxa in the

584 Supplementary Information), as well as twenty-eight unnamed specimens. Five recent examples

585 of Aves were included, the palaeognath Struthio and the neognaths Chauna, Anas, Meleagris and

586 Columba. The Tertiary Lithornis and Qinornis were also included as both have been suggested to

587 be outside Aves by some authors, as were Palaeotis, Anatalavis, Presbyornis, Sylviornis,

588 Gallinuloides, Paraortygoides and Foro as basal representatives of modern clades. Historically,

589 TWiG analyses have focused on coelurosaurs while using Sinraptor dongi and Allosaurus as

590 outgroups. As some taxa have been alternatively recovered as ceratosaurs or coelurosaurs (e.g.

591 Deltadromeus, Afromimus), we tested the current character list against an exhaustive sample of

592 Mesozoic averostrans with Dilophosaurus as the outgroup. This enabled us to test the content of

593 Maniraptoromorpha and provided us with a more representative outgroup sample than merely

594 Sinraptor and Allosaurus. However, while the coelurosaur characters utilized do recover many

595 traditional clades outside Maniraptoromorpha, the topology of this section should not be viewed

596 as well supported since characters specific to e.g. ceratosaurs, megalosauroids and carnosaurs are 597 lacking.

598

599 One issue is that many TWiG analyses (a notable exception being Senter [2007a]) reuse scorings 600 from prior analyses they were derived from, even when additional data has been published. This 
601 can perpetuate errant scores and fails to account for more recent discoveries, publications and

602 interpretations. As an example, Harpymimus has been scored identically for only three cranial 603 characters in every TWiG analysis not derived from Senter (2007a) since Norell et al.'s (2001)

604 original up through Turner et al. (2012). Even analyses which focused on basal

605 ornithomimosaurs (e.g. Makovicky et al., 2010) sometimes failed to utilize Kobayashi and

606 Barsbold's (2005) redescription of Harpymimus for updated scorings. We address this by

607 reexamining and rescoring each character for every taxon based on direct personal examination,

608 high resolution photographs and/or literature published through 2018.

609

610 Perhaps more importantly, we have set out to improve character selection and construction. It is

611 often unappreciated that accurate character scores are only useful if the characters and states

612 themselves are objective, independent and formed so that phylogenetics programs will correctly

613 interpret proposed homology. Existing TWiG state definitions are often unquantified, which

614 hinders future authors from scoring taxa consistently or objectively determining accuracy of

615 published scores. Composite characters, which score multiple variables in a single character, are

616 also common. Correlated characters have increasingly become an issue in analysis lineages as

617 authors add data from other analyses that are not independent of characters already in their

618 matrix. Other issues we addressed included eliminating the use of "absent" as a state in a

619 transformational character (Sereno, 2007:582-584), character traits constructed with

620 discontinuous quantified states (so that certain ranges of values aren't covered by any state) and

621 those that include a state merely scoring for any condition except those specified by the other

622 states (Jenner, 2004:301-302). We have begun the process of resolving these issues by

623 quantifying 163 characters, isolating 240 composite states into single variables (often using the

624 other variables to form new characters), and excluding 36 correlated characters (see Excluded

625 Characters in the Supplementary Information). Our character list includes details of how each

626 character has been changed from previously published versions. When possible, newly

627 quantified character states have been formulated to best match the taxon distribution for each

628 originally subjective character. All characters have been rewritten in the logical structure

629 advocated by Sereno (2007) to reduce ambiguity and variability between analyses.

630

631 The resulting matrix includes 700 characters and 501 OTUs. Ten characters are parsimony- 
632 uninformative among our 389 maniraptoromorphs (excluding the possibly tyrannosauroid

633 megaraptorans, coelurids and proceratosaurids in this and the following taxon totals, to ensure

634 similar content). These are retained pending future expansions of the analysis, leaving 690

635 parsimony-informative characters among our taxon sample of maniraptoromorphs. This makes it

636 the second largest character sample and the largest taxonomic sample in a TWiG analysis of

637 maniraptoromorphs to date, compared to other recent iterations of each TWiG lineage-

638 Gianechini et al. (2018) (700 parsimony-informative characters for their 135 maniraptoromorph

639 OTUs), Foth and Rauhut (2017) (534 such characters and 120 such OTUs), Brusatte et al. (2014)

640 (666 such characters and 127 such OTUs), Agnolin and Novas (2013) (405 such characters and

64180 such OTUs) and Senter et al. (2012) (367 such characters and 98 such OTUs).

642

643 The data matrix was analyzed with TNT 1.5 (Goloboff and Catalano, 2016). After increasing the

644 'Max. trees' under 'Memory' in 'Settings' to 99999, an initial 'New Technology search' using

645 'Sect. Search', 'Ratchet', 'Drift' and 'Tree fusing' was run, as a 'Driven search' to 'Find min. length'

64615 times. The level was checked every 3 hits, and Sect. Search settings were changed to 'For

647 selections of size ... ' ' . . . above' 45 and RSS settings to 'Factor for number of selections' 84 and

648 'Max. sector size' 267. This search was stopped after 100 hours at a length of 12132 steps. A

649 series of 'New Technology search'es using 'Sect. Search' (with 'CSS' unchecked), 'Ratchet',

650 'Drift' and 'Tree fusing' were run from 'RAM' which located trees 12128 steps in length.

651 Constraint analyses were run using a file containing one shortest tree, unchecking 'Settings'

652 'Lock trees', checking 'Trees' 'View' and moving OTUs (left click, right click) to fulfill the

653 constraint. An initial 'Traditional search' of 'trees from RAM' with 100 'Max. trees' and

654 'enforce constraints' was then run, followed by a 'New Technology search' with 10000 'Max

655 trees' using 'Sect. Search' (with 'CSS' unchecked), 'Ratchet', 'Drift' and 'Tree fusing' from

656 'RAM' using 'Enforce constraints.' These traditional and new technology searches were

657 alternated until the length was unchanged for three searches. Constraint analysis results which

658 were shorter than 12128 steps were combined as the only trees in a new file which was itself

659 analyzed as a 'New Technology search' with 99999 'Max trees' using 'Sect. Search' (with 'CSS'

660 unchecked), 'Ratchet', 'Drift' and 'Tree fusing' from 'RAM' until no shorter trees were recovered.

661 A 'Traditional search' of 'trees from RAM' with default parameters was then performed to more

662 fully explore the final treespace. 
663

664 Phylogenetic Results: The analysis resulted in $>99999$ most parsimonious trees with a length of 66512123 steps. The recovered trees had a Consistency Index of 0.073, and a Retention Index of 6660.589 . Fig. 17 presents a summary of the strict consensus tree after the a posteriori pruning of 667 several taxa with multiple possible positions (see Supplementary Information for complete 668 results). Megaraptorans and a clade of proceratosaurids and coelurids branch first after 669 tyrannosauroids, yet both groups are often recovered as members of the latter clade in analyses 670 sampling more characters relevant rootward of Maniraptoromorpha. Indeed, megaraptorans or 671 the coelurid-proceratosaurid group can be constrained to Tyrannosauroidea in only four steps, 672 while it takes 10 steps to move the next closest taxon to birds, Ornitholestes. As Ornitholestes 673 has never been recovered as a tyrannosauroid either, it is considered the most basal well 674 supported member of Maniraptoromorpha here.

675

676 Compsognathids emerge closer to maniraptoriforms than Ornitholestes, and several taxa usually 677 considered members of that family (e.g. Huaxiagnathus, Juravenator, Mirischia,

678 Sinocalliopteryx) branch off more basally. As all previously suggested characters (e.g. Peyer, 679 2006:880; Brusatte, 2013:559) connecting these taxa to Compsognathus were utilized, our 680 increased data sampling supports the more reduced Compsognathidae recovered here. This 681 version of the family includes several controversial taxa. As described in the Supplementary 682 Information, Sciurumimus ' placement away from Compsognathus in the analyses used by 683 Rauhut et al. (2012) was due almost entirely to misscorings in the original versions of those 684 analyses and only one of its characters unexpected in a basal maniraptoromorph is not used in 685 our analysis. As it requires seven steps to move to Megalosauroidea, the compsognathid 686 identification is better supported. Aorun was recently recovered as an alvarezsauroid by Xu et al. 687 (2018) based on four characters, one of which we include (our 29) and another (proximodistal 688 oblique ridge on tibia bracing astragalar ascending process) seemingly present in 689 Compsognathus as well (Peyer, 2006: Fig. 10; scored unknown by Xu et al.). Constraining it to 690 be an alvarezsauroid in our matrix adds 17 steps, so seems to be highly unlikely. Similarly, 691 Haplocheirus falls out in Compsognathidae instead of its traditional position as a basal 692 alvarezsauroid. Eight characters used by Choiniere et al. (2010) to place it in the latter clade were 693 not included, but it also requires nine steps to constrain there in our analysis even with the 
694 inclusion of the supposedly intermediate Xiyunykus and Bannykus. This suggests neither a 695 compsognathid nor an alvarezsauroid identification is well supported and more study is needed.

696

697 Another area with less support than suggested by consensus is the base of Maniraptoriformes, 698 where we recover alvarezsauroids and therizinosaurs as the first branching maniraptorans as in 699 most recent studies. However, only four steps are required to get a result similar to Sereno's

700

701

702

703

704

705

706

707

708

709

710

711

712

713

714

715

716

717

718

719

720

721

722

723

724

(1999) where alvarezsauroids are sister to ornithomimosaurs and therizinosaurs sister to that pair. Similarly, while we recover a pairing of alvarezsauroids and therizinosaurs to the exclusion of pennaraptorans, placing therizinosaurs closer to the latter clade merely needs three additional steps. Positioning alvarezsauroids sister to Pennaraptora or putting therizinosaurs just outside Maniraptoriformes are slightly less parsimonious at six steps each, but the once popular topology of a therizinosaur-oviraptorosauria clade is much less likely at 13 steps longer.

Among ornithomimosaurs, Deinocheirus and the odd Hexing form the first branching clade unlike Lee et al. (2014b) where the former is well nested sister to Garudimimus. As we use all valid characters from that analysis placing Deinocheirus close to Garudimimus and Beishanlong, and it takes 14 steps to constrain that result, it is here rejected. However, the Mongolian giant can be placed within the toothless ornithomimosaur clade using merely four additional steps, so its basal position may change as the referred material is more fully described. Early Cretaceous American Arkansaurus and Nedcolbertia are both resolved as ornithomimosaurs for the first time. Few characters have been proposed to organize taxa within Ornithomimosauria and many taxa lack detailed descriptions or justified alpha taxonomy. Thus our topology should be be regarded as tentative (e.g. the placement of Harpymimus within toothed ornithomimosaurs can be changed with only two steps), but the consensus pairing of Anserimimus with Gallimimus and Struthiomimus with Dromiceiomimus requires eight more steps, so deserves additional scrutiny.

Therizinosauroidea retains standard relationships among basal taxa, with Falcarius, Jianchangosaurus, Beipiaosaurus and Alxasaurus successively closer to therizinosaurids.

Martharaptor has several equally parsimonious positions as a therizinosaur less closely related to Therizinosaurus than Alxasaurus, matching the position recovered by Senter et al. (2012). The topology is similar to the latest major study, Zanno's 2010 TWiG analysis whose data was fully

Peer) reviewing PDF | (2018:08:30731:1:2:NEW 20 May 2019) 
725 utilized, in that Suzhousaurus, Erliansaurus and Neimongosaurus are outside a clade including

726 Nanshiungosaurus, Nothronychus spp., Erlikosaurus and Segnosaurus.

727

728 Fukuivenator has a poorly specified position at the base of Maniraptora, emerging as the first

729 branching alvarezsauroid, but moving to a basal therizinosauroid position with only two steps. A

730 more stemward position seems more likely than a relationship with dromaeosaurids as suggested

731 in its original description or Cau (2018), as it can be a coelurid with only four more steps, but

732 takes seven steps to be sister to Pennaraptora and 11 steps to be paravian. The next branching

733 alvarezsauroid is Nqwebasaurus, as also recovered by Dal Sasso and Maganuco (2007), which

734 requires six steps to be an ornithomimosaur or seven steps to be closer to Pennaraptora. All but

735 two characters recovered by Choiniere et al. (2012) as supporting an ornithomimosaurian

736 placement were included, so the alvarezsauroid alternative is stronger. A compsognathid position

737 as in Novas et al. (2012) is ten steps longer so even less likely. Rounding out the controversial

738 basal ornithomimosaurs is Pelecanimimus, recovered as the first branching alvarezsauroid based

739 on characters such as an elongate anterior maxillary ramus (311:1), posterior tympanic recess in

740 the otic recess (27:1), lateral teeth set in grooves (302:1), over 30 dentary teeth (90:3) and a

741 proximally expanded metacarpal II (370:0). Constraining it as an ornithomimosaur only requires

742 two additional steps however, where it emerges just above Shenzhousaurus as in MacDonald and

743 Currie (2018). As only two of their characters supporting an ornithomimosaurian identification

744 were not used by us, and only one from Brusatte et al. (2014), its true position is unclear pending

745 a detailed osteology such as Perez-Moreno’s (2004) unreleased description.

746

747 As in Xu et al.'s (2018) new analysis, Patagonykus and Bonapartenykus are outside

748 Alvarezsauridae, but unlike that study Xiyunykus and Bannykus join them as patagonykines.

749 Alvarezsaurid Patagonykus requires four steps, and Xu et al.'s new genera follow, while placing

750 the new genera more stemward than Patagonykus only takes two steps. Thus neither of these

751 arrangements should be viewed as heavily favored until Xu et al.'s taxa are described in detail.

752 Within Parvicursorinae, not all characters from Longrich and Currie's (2009) alvarezsaurid

753 analysis were included, but we recovered a clade including only Mononykus, Shuvuuia,

754 Parvicursor and the Tugrik taxon as in derivatives of that study. Heptasteornis is recovered as an

755 alvarezsaurid, supporting Naish and Dyke (2004). Note while the controversial Kinnareemimus

Peer] reviewing PDF | (2018:08:30731:1:2:NEW 20 May 2019) 
756 fell out as a tyrannosauroid in the shortest trees, only three steps move it to Ornithomimosauria

757 and four to Alvarezsauroidea. Similarly, while Kol resolves as a relative of Avimimus as

758 suggested by Agnolin et al. (2012), a single step places it in Alvarezsauridae.

759

760 Protarchaeopteryx emerges as the sister group of Pennaraptora, but changes to the first

761 branching oviraptorosaur with merely two steps and the first branching paravian with three steps,

762 suggesting no strong signal for this poorly preserved specimen. Placing it in Archaeopterygidae

763 as originally proposed and supported by Paul (2002) requires 11 additional steps however, which

764 strongly outnumber the few valid published characters for such an arrangement. Oviraptorosaurs

765 include Similicaudipteryx as their first branching member and unusually places Incisivosaurus

766 closer to caenagnathoids than Caudipteryx and within Oviraptoridae itself. It only requires a

767 single step to make Incisivosaurus the sister taxon of Caenagnathoidea, and three steps to make

768 the first branching oviraptorosaur, so any of these positions are plausible. Forcing Incisivosaurus

769 and Protarchaeopteryx to be sister taxa as in Senter et al. (2004) requires six steps, and the duo

770 resolves as the first branching oviraptorosaur clade. Within Caenagnathoidea, our results should

771 be considered incomplete pending incorporation of characters from Maryanska et al. (2002) and

772 its derivatives. Notable similarities to (Lee et al., 2019) include Nomingia as an oviraptorid and a

773 clade of Nemegtomaia and Heyuannia. Major differences include non-caenagnathoid

774 Ganzhousaurus (1 step needed to make oviraptorid; emerges sister to Heyuannia), caenagnathid

775 Avimimus (3 steps to place outside Caenagnathoidea) and Machairasaurus (2 steps needed to

776 make oviraptorid; emerges basalmost), and oviraptorid Microvenator (1 step needed to make

777 caenagnathid, 3 steps to move it outside Caenagnathoidea), Gigantoraptor (4 steps needed to

778 make caenagnathid; emerges basalmost) and Beibeilong ( 2 steps needed to make caenagnathid;

779 second branching after Microvenator). Maryanska et al.'s heterodox hypothesis of avialan

780 oviraptorosaurs requires 12 additional steps despite the inclusion of proposed intermediates such

781 as Epidexipteryx and Sapeornis. As we use a far greater maniraptoromorph taxon and character

782 sample (Maryanska et al., 2002 includes 16 such taxa and 162 parsimony-informative

783 characters), and only lack two characters they use to support avialan oviraptorosaurs, the

784 traditional content for Paraves is significantly more parsimonious. 
786 A Deinonychosauria including troodontids and dromaeosaurids was recovered as in many recent

787 analyses. Positioning troodontids closer to Aves than dromaeosaurids only requires a single

788 additional step, but non-eumaniraptoran troodontids are less parsimonious at six more steps.

789 Scansoriopterygids form the first branch of Avialae, matching their stratigraphic placement, and

790 constraining them as basal paravians instead is only one step longer. Their other suggested

791 position as oviraptorosaurs requires 12 more steps though, so is unlikely. While Pedopenna

792 emerges as a scansoriopterygid in the MPTs, one step moves the fragmentary specimen to

793 Archaeopterygidae instead. The juvenile Zhongornis branches next, with alternative positions in

794 Scansoriopterygidae or Confuciusornithiformes being four and five steps longer respectively.

795 Balaur follows and only moves to Dromaeosauridae with eight additional steps, supporting its

796 placement in Avialae by Cau et al., 2015. The branching order of Jehol non-ornithothoracine

797 birds has been contentious, with our matrix supporting Sapeornis branching first, followed by

798 jeholornithids then confuciusornithiforms. Jeholornithids branching first is only three steps

799 longer, but Sapeornis branching last as in some recent analyses requires twelve more steps. Note

800 Changchengornis moves one node to Confuciusornithiformes in merely two steps and

801 Jinguofortis joins Chongmingia in only three steps. Our analysis supports the latter's position

802 close to Ornithothoraces as in p2 of Wang et al.'s (2016) figure 7, whereas moving it to their p1

803 more stemward of Jeholornis and Sapeornis requires 11 more steps.

804

805 Characters supporting enantiornithine monophyly and phylogeny are not strongly sampled,

806 making this portion of the tree provisional. Despite this, several proposed clades were recovered

807 including Pengornithidae, Liaoningornis plus Eoalulavis, Sinornis plus Cathayornis, and

808 Longipterygidae with Longipteryx outside a clade containing Longirostravis, Shanweiniao and

809 Rapaxavis. One proposed clade which is strongly rejected is Bohaiornithidae, requiring 16

810 additional steps to make monophyletic using Wang et al.'s (2014) content. Among controversial

811 taxa, Evgenavis and Qiliania can move to Confuciusornithiformes using only three steps and one

812 step respectively, Liaoningornis and Hollanda can move to Ornithuromorpha in four steps each,

813 and Vorona requires six steps to move to that clade. The proposed pairings of Aberratiodontus

814 and Yanornis (Zhou et al., 2008) and Ambiortus and Otogornis (Kurochkin, 1999) are

815 unparsimonious at eight and 17 additional steps. Among taxa closer to crown Aves, the grade of 816 taxa stemward of Bellulornis are usually resolved as enantiornithines and can move there in one 
817 to five steps depending on the OTU. Thus, their position may be revised given the inclusion of 818 more enantiornithine characters, whereas e.g. Bellulornis and Archaeorhynchus would take 14 819 and 17 steps to move to Enantiornithes respectively so are solidly closer to Aves.

820

821 Our analysis includes all of Clarke's lineage of ornithuromorph characters (originating from 822 Clarke, 2002) as incorporated into Turner et al.'s (2012) TWiG analysis, so should be a good test 823 for this portion of the tree. Bellulornis is the sister taxon to Ornithuromorpha, followed by a 824 pairing of Archaeorhynchus and Patagopteryx as in Zheng et al. (2018). Placing the latter genus 825 closer to carinates than Gansus as in some recent analyses requires nine more steps.

826 Songlingornithidae is recovered, but Hongshanornithidae forms a grade and requires 10 more 827 steps to constrain with Wang et al.'s (2015) content. With Field et al.'s (2018) new Ichthyornis 828 data included, it falls out sister to hesperornithines, but the alternatives with either toothed taxon 829 being closer to Aves only need four additional steps each. Eogranivora and the poorly described 830 Xinghaiornis form the first branching carinates, followed by Iaceornis and Apsaravis. Lithornis 831 is just outside Aves, but can be a palaeognath in five additional steps. While the character list 832 was not designed to resolve Aves, consensus clades are largely recovered, including the recently 833 recognized Vegaviidae and an anseriform Teviornis.

834

835 Incorporating the new data from Rauhut et al. (2018) on Archaeopteryx and Pei et al. (2017a) on 836 Anchiornis nests the former genus in the clade usually called Anchiornithinae, making this entire 837 group Archaeopterygidae. As in Xu et al. (2011) we recover archaeopterygids as

838 deinonychosaurs, but both the traditional Archaeopteryx position closer to Aves and the common 839 Anchiornis position sister to troodontids require a single additional step each. Even making 840 archaeopterygids sister to dromaeosaurids requires merely four more steps, but placing them on 841 the paravian stem as Lefevre et al. (2017) recovered for anchiornithines is 15 steps longer. As 842 only two of their characters supporting this stemward placement were unused by us, that position 843 is rejected here. Among complete archaeopterygids Caihong is notably labile and can be a 844 dromaeosaurid with only two more steps, given its mesially serrated teeth and unreduced distal 845 caudal prezygapophyses. 
847 As in Senter et al. (2012) and Cau (2018) our trees pair unenlagiines and halszkaraptorines, but 848 uniquely places this Unenlagiidae sister to the dromaeosaurid plus troodontid clade. Unenlagiids 849 can take their traditional position sister to other dromaeosaurids in trees one step longer where 850 archaeopterygids pair with troodontids, or can be placed closer to Aves as in Agnolin and Novas 851 (2013) in trees one step longer where archaeopterygids are in this position as well. Mahakala is 852 only weakly connected to Halszkaraptor, becoming a basal paravian in one step, but eight new 853 characters proposed as halszkaraptorine synapomorphies by Cau et al. (2017) were not used so 854 this may be an artifact. Hulsanpes emerges as a dromaeosaurine in the shortest trees, but only 855 takes two steps to move to Halszkaraptorinae. The briefly described taxon Ningyuansaurus 856 resolves as the sister taxon to Mahakala but becomes a basal paravian in one more step and an 857 oviraptorosaur as originally proposed in four steps. It should be reexamined, but characters such 858 as the low iliofemoral ratio (261:1), low ischiopubic ratio (187:3) and enlarged pedal ungual II 859 (224:1) are more like paravians than oviraptorosaurs. For the first time the European Pyroraptor 860 and Ornithodesmus are recovered as unenlagiines, which would match biostratigraphically with 861 the presence of traditionally Gondwanan clades such as spinosaurids, carcharodontosaurids and 862 abelisaurs in the Cretaceous of Europe. Giant Dakotaraptor also falls out in this group instead of 863 sister to Dromaeosaurus as in DePalma et al. (2015), but the latter study did not provide their 864 scorings for the genus although we used all their characters. Moving it to Dromaeosauridae only 865 takes three steps, but it resolves as a basal taxon instead of a eudromaeosaur. The unenlagiine 866 Rahonavis had previously been recovered by Agnolin and Novas (2013) and trees based on 867 Cau's analysis as closer to Aves in a similar position to Jeholornis. We recover it nested in 868 Unenlagiinae, and it takes ten additional steps to move closer to Aves than archaeopterygids and 869 other unenlagiines. We analyzed every character supporting this in Agnolin and Novas' matrix, so the unenlagiine consensus seems strong, especially as four of their characters connecting 872

873 Tianyuraptor is recovered as the most basal dromaeosaurid but can be placed in Microraptoria 874 with one step and closer to eudromaeosaurs in two steps. Similarly, Zhenyuanlong is a 875 microraptorian in the shortest trees, but can be nearer to eudromaeosaurs in two steps as well. 876 Constraining the two to be sister taxa to simulate the synonymy suggested by Makovicky et al. 877 (2018) is only four steps longer, and the pair emerge on the eudromaeosaur branch. We recover 
878 Bambiraptor as an early branching microraptorian as in Senter et al. (2004), with Variraptor as

879 its sister taxon. However, Bambiraptor moves closer to eudromaeosaurs as in Senter et al. (2012)

880 and Cau et al. (2017) with the addition of a single step, and Variraptor can join Unenlagiinae

881 with the other European taxa in only three steps. Fragmentary Yurgovuchia is sister to

882 Eudromaeosauria and requires four steps to place close to Utahraptor and Achillobator as in

883 Senter et al. (2012) despite using all of their characters supporting this. Deinonychus joins

884 Utahraptor and Achillobator to form a large dromaeosaurid clade not previously hypothesized,

885 which is most parsimoniously outside Dromaeosaurinae plus Velociraptorinae, but can be moved 886 to either subfamily in two steps. This group also includes the controversial Yixianosaurus, which

887 takes seven steps to move to a more stemward position in Maniraptora as in Dececchi et al.

888 (2012), 10 steps to be a basal paravian as in Foth et al. (2014) and 13 steps to place by 889 scansoriopterygids as originally proposed by its describers. Another new coalition is a

890 Dromaeosaurinae including Saurornitholestes, Atrociraptor, Tsaagan, Linheraptor and Itemirus, 891 though the first two were recovered as close relatives by Longrich and Currie (2009) and 892 Tsaagan and Linheraptor have been proposed to be synonymous by several authors and were 893 resolved as sister taxa by Cau et al. (2017). Our results agree with most recent studies in placing 894 Adasaurus in Velociraptorinae, along with the newly analyzed Luanchuanraptor and unnamed 895 Djadochta specimen IGM 100/980. Although Acheroraptor and Velociraptor? osmolskae resolve 896 as microraptorians, a single step nests the former in Eudromaeosauria, and two steps joins the 897 latter to $V$. mongoliensis, so these jaw-based taxa are not strong evidence of Late Cretaceous 898 microraptorians. Conversely, the Campanian Hesperonychus holotype emerges as an avialan at 899 least as close to Aves as Balaur despite all of its microraptorian-like characters being used. Three 900 steps are needed to constrain it to Microraptoria. Agnolin and Novas (2013) uniquely proposed 901 microraptorians to be in Avialae (under their junior synonym Averaptora), but as we included all 902 their characters supporting this arrangement and still find it takes 14 additional steps to constrain, 903 we strongly reject the hypothesis.

904

905 The recently named Sinovenatorinae are the first branching troodontids, including not only $\mathrm{Mei}$ 906 and the eponymous Sinovenator, but also Xiaotingia, Jianianhualong and unnamed IGM 907 100/140 described by Tsuijhiji et al. (2015). Troodontid characters present in Xiaotingia but not 908 anchiornithines include distally positioned obturator process (183:2), and characters shared with 
909 sinovenatorines include large posterior surangular foramen (80:2), capital groove in humerus 910 (458:1), metacarpal III extending distally past metacarpal II (640:1), laterally ridged ischium 911 (182:2) and enlarged pedal ungual II (224:1). Forcing Xiaotingia into Archaeopterygidae

912 requires nine more steps, which strongly suggests it is not a member considering we included all

913 of the TWiG data originally used to place it there. Alternative placements as a non-

914 anchiornithine avialan (Lee et al., 2014a), a dromaeosaurid (Senter et al., 2012) and a

915 scansoriopterygid relative (Lefevre et al., 2017) are eight, five and 26 more steps respectively.

916 Jianianhualong and IGM 100/140 were originally recovered as closer to troodontines by their 917 describers, and both can move there with a single step. One node closer to troodontines are 918 Almas, possibly referrable perinates IGM 100/972 and 100/974, and a clade of Liaoningvenator 919 and unnamed Ukhaa Tolgod specimen IGM 100/1128. Almas and IGM 100/1128 were recovered 920 as jinfengopterygines by Turner et al. (2012) but the eponymous Jinfengopteryx has a highly 921 unstable position in our analysis, equally capable of joining with these taxa or falling out in 922 Sinovenatorinae. Even a position in Archaeopterygidae as in Ji et al. (2005) is only three steps 923 longer, and a basal paravian position as in Foth et al. (2014) is just four steps longer. In 924 comparison, moving Liaoningvenator to group with anchiornithines as in Shen et al. (2017a) 925 requires 10 steps. Zanabazar, Linhevenator, Talos and Troodon sensu lato form a derived group 926 of troodontines, with Saurornithoides, Urbacodon, Gobivenator and Byronosaurus successively 927 more distant sister taxa. The classic Early Cretaceous specimen IGM 100/44 branches first in the 928 final troodontid clade, with Daliansaurus and a pairing of Xixiasaurus and Sinusonasus 929 successively closer to our new taxon Hesperornithoides. Daliansaurus and Sinusonasus were 930 recovered as sinovenatorines by Shen et al. (2017b) and can be constrained there in four and six 931 steps respectively.

932

933 Finally, constraint analyses were used to test alternative placements for Hesperornithoides. In 934 order to quantify the likelihood of it being a juvenile Ornitholestes, Coelurus or Tanycolagreus, 935 we constrained trees pairing Hesperornithoides with each Morrison OTU. These were 11, 15 and 93616 steps longer respectively than the most parsimonious trees, corroborating the abundant 937 character evidence described above that Hesperornithoides is not referable to a Morrison non938 maniraptoriform. While not unique, troodontid synapomorphies such as the pneumatic quadrate 939 (60:1), anterior cervical centra which extend posterior to their neural arches (104:1), and the deep 
940 tibiotarsal intercondylar groove (206:1) place Hesperornithoides within that clade. Characters

941 like the small dental serrations (92:1), elongate but not hypertrophied distal caudal

942 prezygapophyses (127:1), straight ulna (367:0), dorsally projected curve on manual ungual I

943 (378:1) and enlarged manual ungual III (391:1) are homoplasic but combine to position the new

944 taxon with Daliansaurus, Xixiasaurus and Sinusonasus. Yet like its contemporary

945 Archaeopteryx, Hesperornithoides can easily move to different positions in the paravian tree. A

946 placement as the first branching dromaeosaurid is just two steps longer, supported by the

947 dorsally placed maxillary fenestra (321:1), mesial dental serrations (89:0) and large lateral teeth

948 (91:0). This may be more compatible stratigraphically, but moving Hesperornithoides' clade to a 949 more stemward position in Troodontidae outside Sinovenatorinae, the Liaoningvenator-like taxa

950 and derived troodontids is also only two steps longer. Similarly, in trees two steps longer than the 951 MPTs where troodontids are avialans, Hesperornithoides can be the first branching taxon closer

952 to Aves than troodontids based on homoplasic characters such as the short posterodorsal lacrimal 953 process (44:0/1). Two additional steps also place the taxon in contemporaneous

954 Archaeopterygidae, sister to Caihong which shares character states 89:0, 91:0 and 127:1. Despite 955 the uncertainty of its position within Paraves however, Hesperornithoides is strongly supported 956 as a member of the Deinonychosauria plus Avialae clade, as even constraining it to the paravian 957 stem requires 15 additional steps.

958

\section{Discussion}

960

961 Hesperornithoides miessleri adds another small-bodied theropod to the list of dinosaur taxa from 962 the well-studied Morrison Formation (e.g. Foster, 2003), reinforcing the importance of continued 963 exploration and excavation of well-sampled formations. Regardless of its position within

964 Paraves, Hesperornithoides is significant given the previous lack of Jurassic troodontids or 965 dromaeosaurids known from non-dental remains, or of Jurassic avialans and/or archaeopterygids 966 from the Americas. If it is a troodontid as the most parsimonious trees suggest, it would establish 967 the presence of multiple species in the Jurassic of North America in conjunction with Koparion 968 douglassi (though see Holtz, Brinkman \& Chandler, 1998).

969 
970 Our phylogenetic analysis and constraint tests suggest that the appearance of consensus in TwiG 971 derivatives may often be one of multiple equally plausible alternatives, from the topology of 972 early maniraptoriform clades to the structure of Paraves. Indeed, a single step separates several 973 different paravian phylogenies including such heterodox concepts as an archaeopterygid-

974 troodontid sister group and a pairing of troodontids and dromaeosaurids exclusive of unenlagiids.

975 Yet this does not mean anything goes, as multiple proposed topologies were rejected by our data.

976 These include alvarezsauroid Aorun, paravian Fukuivenator, deinocheirid Garudimimus, the

977 therizinosaur-oviraptorosaur clade, avialan oviraptorosaurs, oviraptorosaurian

978 scansoriopterygids, Yixianosaurus or Xiaotingia sister to scansoriopterygids, basal paravian

979 archaeopterygids, avialan microraptorians, Rahonavis closer to Pygostylia than archaeopterygids

980 or unenlagiines, pygostylian Sapeornis and Bohaiornithidae with its original content. This realm

981 of plausibility has not always been made obvious in prior TWiG analyses, as few explicitly test

982 alternative topologies. When alternatives are tested, the likelihood of their reality may be

983 understated such as when Turner et al. (2012) reported as we do that only one step is necessary

984 to recover troodontids in Avialae instead of Deinonychosauria. Yet they still stated

985 "Deinonychosaurian monophyly is well supported in the present cladistic analysis and has been

986 consistently recovered in all TWiG analyses after the original Norell et al. (2001) analysis". This

987 illustrates the importance of viewing cladograms as a network of more or less likely relationships

988 instead of a new "correct" topology. Given the propensity of authors to reuse previous scorings

989 and character constructions, repeated phylogenetic results may result in a false impression of

990 confidence not justified by constraint analysis. We urge authors going forward to be vigilant in

991 checking old character scorings, to formulate uncorrelated and quantifiable new characters

992 scoring for single variables when expanding past analyses, and to check alternative topologies'

993 strength.

994

995 Even considering the range of parsimonious maniraptoran topologies, our phylogenetic results

996 provide important observations on the origin of avian flight. Basal maniraptoran clades such as

997 alvarezsauroids and therizinosaurs are unambiguously non-volant. Short-armed

998 Protarchaeopteryx lies near the divergence of oviraptorosaurs and paravians, while basal

999 oviraptorosaurs exhibit a grade of short-armed basal taxa including Similicaudipteryx,

1000 Caudipteryx and Avimimus (Table 3). Within Paraves we find unambiguously non-flying taxa at 
1001 the base of all clades regardless of topology. Archaeopteryx (humerofemoral ratio 112-124\%) is 1002 nested within shorter-armed Tiaojishan taxa (78-104\%) that lack feathers adapted for advanced 1003 aerodynamic locomotion (Saitta, Gelernter \& Vinther, 2017; Pan, et al., 2019) whether Caihong 1004 is an archaeopterygid or a dromaeosaurid. Halszkaraptorines are short-armed, and if Mahakala 1005 and/or Ningyuansaurus are basal paravians instead these support the hypothesis even further. 1006 Long-armed Rahonavis is deeply nested in Unenlagiinae, as is Microraptor within 1007 Dromaeosauridae even if Tianyuraptor, Zhenyuanlong and Bambiraptor are allowed several 1008 steps to be closer to eudromaeosaurs. All troodontids have humeri 70\% or less of femoral length 1009 with the exception of Xiaotingia (Table 3), including the early Hesperornithoides if it is a 1010 member. Moving the latter to Dromaeosauridae or Avialae would only cement the pattern 1011 further.

1012

1013 This pattern of short-armed basal members of paravian outgroups and subclades (Fig. 18) is 1014 important for understanding the timing of avian flight acquisition, as individuals with 1015 humerofemoral ratios of $70 \%$ or less lack the wing-loading to generate significant horizontal or 1016 vertical thrust (Dececchi et al. 2016). This contradicts hypotheses of neoflightlessness in 1017 oviraptorosaurs (Maryanska, Osmolska, \& Wolsan, 2002; Feduccia \& Czerkas, 2015) or 1018 paravians in general (Paul, 2002), and also contradicts plesiomorphically volant dromaeosaurids 1019 (Xu, et al., 2003). The recently discovered $Y i$ suggests that at least some scansoriopterygids 1020 developed a divergent, parallel form of aerial locomotion (Xu, et al., 2015), but given the 1021 significant epidermal and morphological differences between $Y i$ 's forelimb anatomy and avian 1022 wings it seems most likely to have occurred independently of avian flight. This holds true 1023 whether scansoriopterygids are early branching avialans or basal paravians. The most 1024 parsimonious interpretation of our results is a series of parallel appearances of non-avian 1025 aerodynamic locomotion within microraptorians, unenlagiids, archaeopterygids and 1026 scansoriopterygids.

1028 Traditional attempts to understand the origin of avian flight have centered on the use of well1029 known, supposedly intermediary taxa such as Archaeopteryx and Microraptor to serve as key 1030 evolutionary stages (e.g. Ostrom, 1979; Xu, Zhou, \& Wang, 2003). Our results (Fig. 18) suggest 1031 that whatever aerial locomotion these taxa may have engaged in, they did not give rise to avialan 
1032 flight. Models of avian flight origins based on these taxa may be misinterpreting the sequence of 1033 character acquisition that resulted in crown avian flight. The embedding of putatively flighted 1034 Rahonavis, Archaeopteryx (though see Federico, et al., 2019), and Microraptor within clades 1035 that lack evidence of aerial locomotion is consistent with prior students that found the 1036 morphology of most non-avialan paravians as functionally more similar to terrestrial than 1037 arboreal birds and mammals (e.g. Dececchi \& Larsson, 2011; Angolin, et al., 2019; Federico, et 1038 al., 2019). This supports a non-volant terrestrial ecomorph as the basal condition for the major 1039 paravian clades, supporting numerous previous studies demonstrating that key flight 1040 preadaptations up to and including vaned feathers and well-developed wings evolved in 1041 terrestrial contexts millions of years prior to the origin of crown avian flight (e.g. Makovicky \& 1042 Zanno, 2011; Brusatte, et al., 2014; Dececchi, et al., 2016; Cau, 2018).

1043

1044 With the morphologically divergent and potentially volant $Y i$ (Xu, et al., 2015) nested within a 1045 non-flying clade of basal avialans, one counter-intuitive result is that even avialans may have 1046 been plesiomorphically flightless. Though not a novel hypothesis (e.g. Ostrom, 1979; Speakman 1047 \& Thompson, 1994; Dececchi \& Larsson, 2011), it suggests the possibility for a surprisingly late 1048 acquisition of avian flight. Though new Jurassic fossils have the potential to push the origin of 1049 avian flight deeper in time, at the moment our first branching preserved examples are the Early 1050 Cretaceous Zhongjianornis, Sapeornis and possibly Zhongornis (Fig. 18). Investigating the 1051 differences in flight capabilities and mode of life between them, confuciusornithids and more 1052 crownward avialans may be the most fruitful line of inquiry for understanding the transition to 1053 true avian flight.

1054

1055 The pattern of character acquisition, adult body reduction size (Bensen, et al., 2014), and parallel 1056 emergences of aerodynamic locomotion within Paraves suggests one possible solution to the 1057 traditional dichotomy of arboreal vs. terrestrial habitats in the origin of avian flight. While short1058 armed, non-arboreal alvarezsauroids, oviraptorosaurs, troodontids, and dromaeosaurs 1059 demonstrate that wings and other key characters associated with avian flight evolved in a 1060 terrestrial context, it is notable that clearly volant avialans like Zhongjianornis, and clades with 1061 putatively aerial behavior such as microraptorians, some archaeopterygids and 1062 scansoriopterygids exhibit the strongest evidence among paravians for arboreal or semi-arboreal 
1063 behavior. This suggests a model wherein small size and increasing approximations of the flight

1064 stroke allowed some clades of terrestrial paravians to utilize wing assisted incline running to 1065 access trees or other subvertical substrates previously not accessible (Tobalske \& Dial, 2007;

1066 Dececchi et al., 2016). From there the utility of gliding or flap-descent (Norberg, 1985; Rayner, 1067 1988) provides a logical selective pressure that could generate several parallel experiments with 1068 aerial behavior, only one of which led directly to avian flight.

1069

1070 Conclusions

1071

1072 We have described Hesperornithoides miessleri, a new paravian theropod from the Late Jurassic 1073 of North America. We ran a phylogenetic analysis based on previous TWiG datasets with 1074 expanded taxonomic sampling and recovered it as a troodontid, the oldest diagnostic specimen 1075 from North America known from more than teeth. Hesperornithoides was clearly a non-volant, 1076 terrestrial theropod that spent at least a portion of its life in a marginal lacustrine or wetland 1077 environment. The terrestrial and flightless lifestyle is consistent with the base of Paraves, and 1078 with the base of paravian subclades, suggesting that avian flight evolved within Avialae, most 1079 likely in the Late Jurassic or Early Cretaceous.

1080

1081 Acknowledgements

1082

1083 We would like to thank Howard and Helen Miessler for their support and generosity. We also 1084 thank volunteers from both the Tate Geological Museum and the Wyoming Dinosaur Center who 1085 aided the excavation. Thanks are due to Levi Shinkle for additional photography of WYDICEDML-001 NS to Dan Chure for supplying photographs of Koparion. High resolution CT scans were carried out at UT-Austin, with additional CT work provided by the UW-Madison WIMR and Hot Springs County Memorial Hospital. We would like to thank Alexander Averianov, Hebert Bruno Campos, Andrea Cau, Gareth Dyke, Federico Gianechini, Michael Habib, Jaime Headden, Rutger Jansma, Zhiheng Li, Heinrich Mallison, Phil Senter, Lindsay Zanno and others who provided unpublished data on specimens, and the AMNH staff for allowing access to their collections. A final thanks is due to Oliver Rauhut and an anonymous reviewer, whose feedback greatly improved the manuscript. 
1094

1095

1096

1097

1098

1099

1100

1101

1102

1103

1104

1105

1106

1107

1108

1109

1110

1111

1112

1113

1114

1115

1116

1117

1118

\section{References}

Agnolin, Federico, \& Novas, Fernando E. 2013. Avian ancestors: A review of the phylogenetic relationships of the theropods Unenlagiidae, Microraptoria, Anchiornis and Scansoriopterygidae. Springer Netherlands. 96 pp. DOI: 10.1007/978-94-007-5637-3_1

Agnolin, Powell, Novas and Kundrat, 2012. New alvarezsaurid (Dinosauria, Theropoda) from uppermost Cretaceous of north-western Patagonia with associated eggs. Cretaceous Research. 35, 33-56. DOI: 10.1016/j.cretres.2011.11.014

Agnolin, F., Motta, M.J., Brisson, F., Lo Coco, G. and Novas, F.E., 2018. Paravian phylogeny and the dinosaur-bird transition: An Overview. Frontiers in Earth Science, 6, p.252. DOI: $10.3389 /$ feart.2018.00252

Barsbold, 1974. Saurornithoididae, a new family of small theropod dinosaurs from Central Asia and North America. Palaeontologia Polonica. 30, 5-22.

Barsbold and Osmólska, 1999. The skull of Velociraptor (Theropoda) from the Late Cretaceous of Mongolia. Acta Palaeontologica Polonica. 44(2), 189-219.

Barsbold, Osmolska and Kurzanov, 1987. On a new troodontid (Dinosauria, Theropoda) from the Early Cretaceous of Mongolia. Acta Palaeontologica Polonica. 32(1-2), 121-132. 
1119

1120 Benson, R.B., Campione, N.E., Carrano, M.T., Mannion, P.D., Sullivan, C., Upchurch, P. and

1121 Evans, D.C., 2014. Rates of dinosaur body mass evolution indicate 170 million years of

1122 sustained ecological innovation on the avian stem lineage. PLoS Biology, 12, 5, DOI:

1123 10.1371/journal.pbio.1001853

1124

1125 Brusatte, 2013. The phylogeny of basal coelurosaurian theropods (Archosauria: Dinosauria) and

1126 patterns of morphological evolution during the dinosaur-bird transition. $\mathrm{PhD}$ thesis, Columbia

1127 University. 944 pp.

1128

1129 Brusatte, S. L., Lloyd, G. T., Wang, S. C., \& Norell, M. A. 2014. Gradual assembly of avian

1130 body plan culminated in rapid rates of evolution across the dinosaur-bird transition. Current

1131 Biology, 24, 2386-2392. DOI: 10.1016/j.cub.2014.08.034

1132

1133 Burnham, 2004. New information on Bambiraptor feinbergi (Theropoda: Dromaeosauridae)

1134 from the Late Cretaceous of Montana. In Currie, Koppelhus, Shugar and Wright (eds.).

1135 Feathered Dragons. Studies on the transition from dinosaurs to birds. Indiana University Press.

1136 67-111.

1137

1138 Carpenter, Miles and Cloward, 2005a. New small theropod from the Upper Jurassic Morrison

1139 Formation of Wyoming. In Carpenter (ed.). The Carnivorous Dinosaurs. Indiana University

1140 Press. 23-48.

1141 
1142 Carpenter, K., Miles, C., Ostrom, J.H. and Cloward, K., 2005b. Redescription of the small

1143 maniraptoran theropods Ornitholestes and Coelurus from the Upper Jurassic Morrison Formation

1144 of Wyoming. In Carpenter (ed.). Carnivorous Dinosaurs. Indiana University Press. 49-71.

1145

1146 Cau, 2018. The assembly of the avian body plan: A 160-million-year long process. Bollettino

1147 della Società Paleontologica Italiana. 57(1), 1-25. DOI: 10.4435/BSPI.2018.01

1148

1149 Cau, A., Brougham, T., \& Naish, D. 2015. The phylogenetic affinities of the bizarre Late

1150 Cretaceous Romanian theropod Balaur bondoc (Dinosauria, Maniraptora): dromaeosaurid or

1151 flightless bird? PeerJ 3, e1032. DOI: 10.7717/peerj.1032

1152

1153 Cau A., Beyrand, V., Voeten, D. F. A. E., Fernandez, V., Tafforeau, P., Stein, K., Barsbold, R.,

1154 Tsogtbaatar, K., Currie, P. J. \& Godefroit, P. 2017. Synchrotron scanning reveals amphibious

1155 ecomorphology in a new clade of bird-like dinosaurs. Nature, 552, 395-399. DOI:

1156 10.1038/nature24679

1157

1158 Chiappe, Ji, Ji and Norell, 1999. Anatomy and systematics of the Confuciusornithidae

1159 (Theropoda: Aves) from the Late Mesozoic of northeastern China. Bulletin of American

1160 Museum of Natural History. 242, 1-89. DOI: 10.1642/0004-

$1161 \quad 8038(2000) 117[0836: A A S O T C] 2.0 . C O ; 2$

1162

1163 Choiniere, Forster and de Klerk, 2012. New information on Nqwebasaurus thwazi, a

1164 coelurosaurian theropod from the Early Cretaceous (Hauteriverian?) Kirkwood Formation in 
1165 South Africa. Journal of African Earth Sciences. 71-72, 1-17. DOI:

1166 10.1016/j.jafrearsci.2012.05.005

1167

1168 Choiniere, Xu, Clark, Forster, Guo and Han, 2010. A basal alvarezsauroid theropod from the

1169 Early Late Jurassic of Xinjiang, China. Science. 327, 571-574. DOI: 10.1126/science.1182143

1170

1171 Chure, D. J. 1994. Koparion douglassi, a new dinosaur from the Morrison Formation (Upper

1172 Jurassic) of Dinosaur National Monument; the oldest troodontid (Theropoda:

1173 Maniraptora). Brigham Young University Geology Studies, 40(1), 11-15.

1174

1175 Clarke, 2002. The morphology and systematic position of Ichthyornis Marsh and the

1176 phylogenetic relationships of basal Ornithurae. Ph.D. dissertation, Yale University. 532 pp.

1177

1178 Currie, 1995. New information on the anatomy and relationships of Dromaeosaurus albertensis

1179 (Dinosauria: Theropoda). Journal of Vertebrate Paleontology. 15(3), 576-591. DOI:

$1180 \quad 10.1080 / 02724634.1995 .10011250$

1181

1182 Currie and Dong, 2001. New information on Cretaceous troodontids (Dinosauria, Theropoda)

1183 from the People's Republic of China. Canadian Journal of Earth Sciences. 38(12), 1753-1766.

1184 DOI: $10.1139 / \mathrm{e} 01-065$

1185

1186 Czerkas and Yuan, 2002. An arboreal maniraptoran from Northeast China. Feathered Dinosaurs 1187 and the Origin of Flight. The Dinosaur Museum Journal. 1, 63-95. 
1188

1189 Dal Sasso and Maganuco, 2011. Scipionyx samniticus (Theropoda: Compsognathidae) from the 1190 Lower Cretaceous of Italy: Osteology, ontogenetic assessment, phylogeny, soft tissue anatomy, 1191 taphonomy, and palaeobiology. Memorie della Società Italiana di Scienze Naturali e del Museo 1192 Civico di Storia Naturale di Milano. $281 \mathrm{pp}$.

1193

1194 Dececchi, T. A. \& Larsson, H. C. 2013. Body and limb size dissociation at the origin of birds:

1195 uncoupling allometric constraints across a macroevolutionary transition. Evolution, 67, 27411196 2752. DOI: $10.1111 /$ evo.12150

1197

1198 Dececchi, T. A., Larsson, H. C., \& Habib, M. B. 2016. The wings before the bird: an evaluation 1199 of flapping-based locomotory hypotheses in bird antecedents. PeerJ, 4, e2159. DOI:

$1200 \quad 10.7717 /$ peerj.2159

1201

1202 Dececchi, Larsson and Hone, 2012. Yixianosaurus longimanus (Theropoda: Dinosauria) and its 1203 bearing on the evolution of Maniraptora and ecology of the Jehol fauna. Vertebrata PalAsiatica. $120459(2), 111-139$.

1205

1206

DePalma, Burnham, Martin, Larson and Bakker, 2015. The first giant raptor (Theropoda:

1207 Dromaeosauridae) from the Hell Creek Formation. Paleontological Contributions. 14, 16 pp.

1208 DOI: $10.17161 /$ paleo.1808.18764

1209 
1210 Feduccia, A. and Czerkas, S.A., 2015. Testing the neoflightless hypothesis: propatagium reveals

1211 flying ancestry of oviraptorosaurs. Journal of ornithology, 156(4), pp.1067-1074.

1212

1213 Field, Hanson, Burnham, Wilson, Super, Ehret, Ebersole and Bhullar, 2018. Complete

1214 Ichthyornis skull illuminates mosaic assembly of the avian head. Nature. 557, 96-100. DOI:

1215 10.1038/s41586-018-0053-y

1216

1217 Foster, J.R., 2003. Paleoecological Analysis of the Vertebrate Fauna of the Morrison Formation

1218 (Upper Jurassic), Rocky Mountain Region, USA: Bulletin 23 (Vol. 23). New Mexico Museum of 1219 Natural History and Science.

1220

1221 Foth, C., \& Rauhut, O.W.M. 2017. Re-evaluation of the Haarlem Archaeopteryx and the 1222 radiation of maniraptoran theropod dinosaurs. BMC Evolutionary Biology. 17:236. DOI:

$1223 \quad 10.1186 / \mathrm{s} 12862-017-1076-\mathrm{y}$

1224

1225 Foth, C., Tischlinger, H., \& Rauhut, O.W.M. 2014. New specimen of Archaeopteryx provides 1226 insights into the evolution of pennaceous feathers. Nature. 511, 79-82. DOI:

$1227 \quad 10.1038 /$ nature 13467

1228

1229 Gao, C., Morschhauser, E.M. , Varricchio, D.J., Liu, J., \& Zhao, B. 2012. A second soundly

1230 sleeping dragon: New anatomical details of the Chinese troodontid Mei long with implications

1231 for phylogeny and taphonomy. PLoS ONE, 7, e45203. DOI: 10.1371/journal.pone.0045203

1232 
1233 Gauthier, J. A. 1986. Saurischian monophyly and the origin of birds. Memoirs of the California 1234 Academy of Sciences, 8, 1-55.

1235

1236 Gianechini and Apesteguiia, 2011. Unenlagiinae revisited: Dromaeosaurid theropods from South 1237 America. Anais da Academia Brasileira de Ciências. 83(1), 163-195.

1238

1239 Gianechini, Makovicky and ApesteguÍa, 2017. The cranial osteology of Buitreraptor

1240 gonzalezorum Makovicky, ApesteguÍa, and AgnolÍn, 2005 (Theropoda, Dromaeosauridae), from 1241 the Late Cretaceous of Patagonia, Argentina. Journal of Vertebrate Paleontology. e1255639.

1242 DOI: $10.1080 / 02724634.2017 .1255639$

1243

1244 Gianechini, Makovicky, Apesteguía and Cerda, 2018. Postcranial skeletal anatomy of the 1245 holotype and referred specimens of Buitreraptor gonzalezorum Makovicky, Apesteguía and 1246 Agnolín 2005 (Theropoda, Dromaeosauridae), from the Late Cretaceous of Patagonia. PeerJ. 1247 6:e4558. DOI: $10.7717 /$ peerj.4558

1248

1249 Gilmore, 1924. On Troodon validus, an orthopodous dinosaur from the Belly River Cretaceous 1250 of Alberta, Canada. Department of Geology, University of Alberta Bulletin. 1, 1-43. 1251

1252 Gishlick, 2002. The functional morphology of the forelimb of Deinonychus antirrhopus and its 1253 importance for the origin of avian flight. PhD thesis, Yale University. $142 \mathrm{pp}$.

1254 
1255 Goloboff, P. A. \& Catalano, S. A. 2016. TNT version 1.5, including a full implementation of 1256 phylogenetic morphometrics. Cladistics, 32, 221-238. DOI: 10.1111/cla.12160

1257

1258 Godefroit, Currie, Li, Shang and Dong, 2008. A new species of Velociraptor (Dinosauria:

1259 Dromaeosauridae) from the Upper Cretaceous of northern China. Journal of Vertebrate

1260 Paleontology. 28(2), 432-438. DOI: 10.1671/0272-4634(2008)28[432:ANSOVD]2.0.CO;2

1261

1262 Godefroit, P., Cau, A., Dong-Yu, H., Escuillié, F., Wenhao, W. \& Dyke, G. 2013b. A Jurassic 1263 avialan dinosaur from China resolves the early phylogenetic history of birds. Nature, 498, 3591264 362. DOI: $10.1038 /$ nature 12168

1265

1266 Godefroit, P., Demuynck, H., Dyke, G., Hu, D., Escuillie, F. \& Claeys, P. 2013a. Reduced 1267 plumage and flight ability of a new Jurassic paravian theropod from China. Nature 1268 Communications, 4, 1394. DOI: 10.1038/ncomms2389

1269

1270 Hartman, S., Lovelace, D. \& Wahl, W. 2005. Phylogenetic assessment of a maniraptoran from 1271 the Morrison Formation. In: Journal of Vertebrate Paleontology, 25, 3, pp. 67A-68A. DOI:

$1272 \quad 10.1080 / 02724634.2005 .10009942$

1273

1274 Holtz, 1994. The arctometatarsalian pes, an unusual structure of the metatarsus of Cretaceous

1275 Theropoda (Dinosauria: Saurischia). Journal of Vertebrate Paleontology. 14(4), 480-519. DOI: $1276 \quad 10.1080 / 02724634.1995 .10011574$

1277 
1278 Holtz Jr, T.R., Brinkman, D.L. and Chandler, C.L., 1998. Denticle morphometrics and a possibly

1279 omnivorous feeding habit for the theropod dinosaur Troodon. Gaia, 15, pp.159-166.

1280

1281 Hone, D.W., Farke, A.A. and Wedel, M.J., 2016. Ontogeny and the fossil record: what, if 1282 anything, is an adult dinosaur?. Biology letters, 12(2), p.20150947. DOI: 10.1098/rsbl.2015.0947 1283

$1284 \mathrm{Hu}, \mathrm{Hou}$, Zhang and $\mathrm{Xu}, 2009$. A pre-Archaeopteryx troodontid theropod from China with long 1285 feathers on the metatarsus. Nature. 461, 640-643. DOI: $10.1038 /$ nature08322

1286

1287 Hu, D., Clarke, J. A., Eliason, C. M., Qiu, R., Li, Q., Shawkey, M. D., Zhao, C., D'Alba, L., 1288 Jiang, J., \& Xu, X. 2018. A bony-crested Jurassic dinosaur with evidence of iridescent plumage 1289 highlights complexity in early paravian evolution. Nature Communications. 9, 217. DOI: $1290 \quad 10.1038 / \mathrm{s} 41467-017-02515-\mathrm{y}$

1291

1292 Jenner, 2004. The scientific status of metazoan cladistics: Why current research practice must

1293 change. Zoologica Scripta. 33, 293-310. DOI: 10.1111/j.0300-3256.2004.00153.x

1294

1295 Jennings, D. \& Hasiotis, S. 2006. Taphonomic analysis of a dinosaur feeding site using 1296 Geographic Information Systems (GIS), Morrison Formation, southern Bighorn Basin, 1297 Wyoming, USA. Palaios, 21, 480-492. DOI: 10.2110/palo.2005.P05-062R

1298

1299 Jennings, D. S., Lovelace, D. M. \& Driese, S. G. 2011. Differentiating paleowetland 1300 subenvironments using a multi-disciplinary approach: An example from the Morrison formation, 
1301 South Central Wyoming, USA. Sedimentary Geology, 238, 23-47. DOI:

$1302 \quad 10.1016 /$ j.sedgeo.2011.03.005

1303

1304 Jensen and Padian, 1989. Small pterosaurs and dinosaurs from the Uncomphagre fauna (Brushy

1305 Basin Member, Morrison Formation: ?Tithonian), Late Jurassic, western Colorado. Journal of

1306 Paleontology. 63(3), 364-373. DOI: 10.1017/S0022336000019533

1307

1308

Ji, Ji, Lu, You, Chen, Liu and Liu, 2005. First avialan bird from China (Jinfengopteryx elegans

1309 gen. et sp. nov.). Geological Bulletin of China. 24(3), 197-205.

1310

1311

Ji, Atterholt, O'Connor, Lammana, Harris, Li, You and Dodson, 2011. A new, three-

1312 dimensionally preserved enantiornithine bird (Aves: Ornithothoraces) from Gansu Province, 1313 north-western China. Zoological Journal of the Linnean Society. 162, 201-219. DOI:

1314 10.1111/j.1096-3642.2010.00671.x

1315

1316 Kirkland, J. I., Zanno, L. E., Sampson, S. D., Clark, J. M., \& DeBlieux, D. D. 2005. A primitive 1317 therizinosauroid dinosaur from the Early Cretaceous of Utah. Nature. 435, 84-87. DOI:

$1318 \quad 10.1038 /$ nature03468

1319

1320 Kobayashi and Barsbold, 2005. Anatomy of Harpymimus okladnikovi Barsbold and Perle 1984

1321 (Dinosauria; Theropoda) of Mongolia. In Carpenter (ed.). The Carnivorous Dinosaurs. 97-126. 1322 
1323 Kurochkin, 1999. The relationships of the Early Cretaceous Ambiortus and Otogornis (Aves:

1324 Ambiortiformes). Smithsonian Contributions to Paleobiology. 89, 275-284.

1325

1326 Lee, M, S, Cau, A., Naish, D., \& Dyke, G. J. 2014a. Sustained miniaturization and anatomical 1327 innovation in the dinosaurian ancestors of birds. Science. 345(6196), 562-566. DOI:

$1328 \quad 10.1126 /$ science. 1252243

1329

1330 Lee, Lee, Chinsamy, Lu, Barsbold and Tsogtbaatar, 2019. A new baby oviraptorid dinosaur 1331 (Dinosauria: Theropoda) from the Upper Cretaceous Nemegt Formation of Mongolia. PLoS 1332 ONE. 14(2), e0210867. DOI: 10.1371/journal.pone.0210867

1333

1334 Lee, Barsbold, Currie, Kobayashi, Lee, Godefroit, Escuillie and Tsogtbaatar, 2014b. Resolving 1335 the long-standing enigmas of a giant ornithomimosaur Deinocheirus mirificus. Nature. 515, 2571336 260. DOI: $10.1038 /$ nature 13874

1337

1338 Lefèvre, U., Cau, A., Cincotta, A., Hu, D., Chinsamy, A., Escuillié, F. \& Godefroit, P. 2017. A 1339 new Jurassic theropod from China documents a transitional step in the macrostructure of 1340 feathers. The Science of Nature, 104, 74. DOI: 10.1007/s00114-017-1496-y 1341

1342 Longrich and Currie, 2009. Albertonykus borealis, a new alvarezsaur (Dinosauria: Theropoda) 1343 from the Early Maastrichtian of Alberta, Canada: Implications for the systematics and ecology of 1344 the Alvarezsauridae. Cretaceous Research. 30(1), 239-252. DOI: 10.1016/j.cretres.2008.07.005 
1346 Lovelace, D. M. 2006. An Upper Jurassic Morrison Formation fire-induced debris flow:

1347 Taphonomy and paleoenvironment of a sauropod (Sauropoda: Supersaurus vivianae) locality, 1348 east-central Wyoming. Paleontology and Geology of the Upper Jurassic Morrison Formation, 36, $1349 \quad 47-56$.

1350

1351 Lovelace, D. M., Hartman, S. A., \& Wahl, W. R. 2007. Morphology of a specimen of 1352 Supersaurus (Dinosauria, Sauropoda) from the Morrison Formation of Wyoming, and a re1353 evaluation of diplodocid phylogeny. Arquivos do Museu Nacional, Rio de Janeiro, 65, 527-544. 1354

Lu and Brusatte, 2015. A large, short-armed, winged dromaeosaurid (Dinosauria: Theropoda) 1356 from the Early Cretaceous of China and its implications for feather evolution. Scientific Reports. 1357 5, 11775. DOI: 10.1038/srep11775

1358

1359

Macdonald and Currie, 2018. Description of a partial Dromiceiomimus (Dinosauria: Theropoda)

1360

skeleton with comments on the validity of the genus. Canadian Journal of Earth Sciences. 56(2),

1361

129-157. DOI: $10.1139 /$ cjes-2018-0162

1362

1363

Makovicky, 1995. Phylogenetic aspects of the vertebral morphology of Coelurosauria

1364 (Dinosauria: Theropoda). M.S. thesis, University of Copenhagen. $311 \mathrm{pp.}$

1365

1366 Makovicky, P.J. and Zanno, L.E., 2011. Theropod diversity and the refinement of avian

1367 characteristics. In Living Dinosaurs (pp. 9-29). Wiley, Hoboken. 
1369 Makovicky, Gorscak and Zhou, 2018. A new specimen of the large-bodied dromaeosaurid 1370 Tiuanyuraptor provides new insights on microraptorine anatomy, taxonomy, and plumage 1371 evolution. Journal of Vertebrate Paleontology. Program and Abstracts, 2018. 174.

1372

1373 Makovicky, Li, Gao, Lewin, Erickson and Norell, 2010. A giant ornithomimosaur from the Early 1374 Cretaceous of China. Proceedings of the Royal Society B. 277, 191-198. DOI:

$1375 \quad 10.1098 / \mathrm{rspb} .2009 .0236$

1376

1377 Marsh, O. C., 1881. Principal characters of American Jurassic dinosaurs. Part V. American 1378 Journal of Science, 21, 417-423.

1379

1380 Maryanska, T., Osmolska, H., \& Wolsan, M. 2002. Avialan status for Oviraptorosauria. Acta 1381 Palaeontologica Polonica. 47 (1), 97-116.

1382

1383 Matthew, W. D., \& Brown, B. 1922. The family Deinodontidae, with notice of a new genus from 1384 the Cretaceous of Alberta. Bulletin of the American Museum of Natural History. 46(6), 367-385. 1385

1386 Mayr, G., Pohl, B., Hartman, S. \& Peters, D. S. 2007. The tenth skeletal specimen of

1387 Archaeopteryx. Zoological Journal of the Linnean Society, 149, 97-116. 10.1111/j.1096$1388 \quad 3642.2006 .00245 . x$ 
1390 Motta, Egli and Novas, 2017. Tail anatomy of Buitreraptor gonzalezorum (Theropoda, 1391 Unenlagiidae) and comparisons with other basal paravians. Cretaceous Research. 83, 168-181. 1392 DOI: $10.1016 /$ j.cretres.2017.09.004

1393

1394 Naish, D., \& Dyke, G. J. 2004. Heptasteornis was no ornithomimid, troodontid, 1395 dromaeosaurid or owl: The first alvarezsaurid (Dinosauria: Theropoda) from 1396 Europe. Neus Jahrbuch für Geologie und Paläontologie. 7 , 385-401.

1397

1398 Norberg, U.M., 1985. Evolution of vertebrate flight: an aerodynamic model for the transition 1399 from gliding to active flight. The American Naturalist, 126(3), pp.303-327. DOI:

$1400 \quad 10.1086 / 284419$

1401

1402 Norell and Makovicky, 1999. Important features of the dromaeosaurid skeleton II: Information 1403 from newly collected specimens of Velociraptor mongoliensis. American Museum Novitates. $14043282,45 \mathrm{pp}$.

1405

1406 Norell, M. A., Clark, J. M. \& Makovicky, P. J. 2001. Phylogenetic relationships among 1407 coelurosaurian theropods. In: Gauthier, J. \& Gall, L. F. (eds.). New Perspectives on the Origin 1408 and Early Evolution of Birds. Proceedings of the International Symposium in Honor of John H. 1409 Ostrom, 49-67. 
1411 Norell, Makovicky, Bever, Balanoff, Clark, Barsbold and Rowe, 2009. A review of the

1412 Mongolian Cretaceous dinosaur Saurornithoides (Troodontidae: Theropoda). American Museum 1413 Novitates. 3654, 63 pp. DOI: 10.1206/648.1

1414

1415 Novas, Ezcurra, Agnolin, Pol and Ortiz, 2012. New Patagonian Cretaceous theropod sheds light 1416 about the early radiation of Coelurosauria. Revista del Museo Argentino de Ciencias Naturales. 1417 14(1), 57-81.

1418

1419 Novas, Pol, Canale, Porfiri and Calvo, 2008. A bizarre Cretaceous theropod dinosaur from 1420 Patagonia and the evolution of Gondwanan dromaeosaurids. Proceedings of the Royal Society B. 1421 276(1659), 1101-1107. DOI: 10.1098/rspb.2008.1554

1422

1423 Ostrom, J.H., 1979. Bird Flight: How Did It Begin? Did birds begin to fly "from the trees down" 1424 or "from the ground up"? Reexamination of Archaeopteryx adds plausibility to an" up from the 1425 ground" origin of avian flight. American Scientist, 67(1), pp.46-56.

1426

1427 Padian, K., Hutchinson, J. R. \& Holtz Jr, T. R. 1997. Phylogenetic definitions and nomenclature 1428 of the major taxonomic categories of the theropod dinosaurs. Journal of Vertebrate Paleontology. 1429 17(3), 68A. DOI: 10.1080/02724634.1997.10011028

1430

1431 Pan, Y., Zheng, W., Sawyer, R.H., Pennington, M.W., Zheng, X., Wang, X., Wang, M., Hu, L., 1432 O'Connor, J., Zhao, T. and Li, Z., 2019. The molecular evolution of feathers with direct evidence 
1433 from fossils. Proceedings of the National Academy of Sciences, p.3018-3023. DOI:

1434 10.1073/pnas.1815703116

1435

1436 Paul, 2002. Dinosaurs of the Air. The Johns Hopkins University Press, Baltimore. 460 pp.

1437

1438 Pei, Li, Meng, Gao and Norell, 2014. A new specimen of Microraptor (Theropoda:

1439 Dromaeosauridae) from the Lower Cretaceous of western Liaoning, China. American Museum

1440 Novitates. 3821,28 pp. DOI: $10.1206 / 3821.1$

1441

1442 Pei, Li, Meng, Norell and Gao, 2017a. New specimens of Anchiornis huxleyi (Theropoda:

1443 Paraves) from the Late Jurassic of northeastern China. Bulletin of the American Museum of

1444 Natural History. 411, 66 pp. DOI: 10.1206/0003-0090-411.1.1

1445

1446 Pei, Norell, Barta, Bever, Pittman and Xu, 2017b. Osteology of a new Late Cretaceous

1447 troodontid specimen from Ukhaa Tolgod, Ömnögovi Aimag, Mongolia. American Museum

1448 Novitates. 3889,47 pp. DOI: $10.1206 / 3889.1$

1449

1450 Perez-Moreno, 2004. Pelecanimimus polyodon: Anatomía, sistemática y paleobiología de un

1451 Ornithomimosauria (Dinosauria: Theropoda) de Las Hoyas (Cretácico Inferior; Cuenca, España).

$1452 \mathrm{PhD}$ thesis. Universidad Autónoma de Madrid. 149 pp.

1453 
1454 Perle, Norell and Clark, 1999. A new maniraptoran theropod - Achillobator giganticus

1455 (Dromaeosauridae) - from the Upper Cretaceous of Burkhant, Mongolia. Contribution no. 101 of 1456 the Mongolian-American Paleontological Project. 1-105.

1457

1458 Peyer, 2006. A reconsideration of Compsognathus from the Upper Tithonian of Canjuers,

1459 southeastern France. Journal of Vertebrate Paleontology. 26(4), 879-896. DOI: 10.1671/0272-

1460 4634(2006)26[879:AROCFT]2.0.CO;2

1461

1462 Rauhut, 2013. New observations on the skull of Archaeopteryx. Paläontologische Zeitschrift. 1463 88(2), 211-221. DOI: 10.1007/s12542-013-0186-0

1464

1465 Rauhut, Foth and Tischlinger, 2018. The oldest Archaeopteryx (Theropoda: Avialiae): A new 1466 specimen from the Kimmeridgian/Tithonian boundary of Schamhaupten, Bavaria. PeerJ.

1467 6:e4191. DOI: 10.7717/peerj.4191

1468

1469 Rauhut, Foth, Tischlinger and Norell, 2012. Exceptionally preserved juvenile megalosauroid 1470 theropod dinosaur with filamentous integument from the Late Jurassic of Germany. Proceedings 1471 of the National Academy of Sciences. 109(29), 11746-11751. DOI: 10.1073/pnas.1203238109\ 1472

1473 Rayner, J.M., 1988. The evolution of vertebrate flight. Biological Journal of the Linnean Society, 1474 34(3), pp.269-287. DOI:10.1111/j.1095-8312.1988.tb01963.x 1475 
1476 Russell, D. A., \& Dong, Z-M. 1994. A nearly complete skeleton of a new troodontid dinosaur

1477 from the Early Cretaceous of the Ordos Basin, Inner Mongolia, People's Republic of China.

1478 Canadian Journal of Earth Sciences. 30(10), 2163-2173. DOI: 10.1139/e93-187

1479

1480 Saitta, E.T., Gelernter, R. and Vinther, J., 2018. Additional information on the primitive contour

1481 and wing feathering of paravian dinosaurs. Palaeontology, 61, 273-288. DOI:

1482 10.1111/pala.12342

1483

1484 Schweitzer, M. H. 2011. Soft tissue preservation in terrestrial Mesozoic vertebrates. Annual 1485 Review of Earth and Planetary Sciences, 39, 187-216. DOI: 10.1146/annurev-earth-040610$1486 \quad 133502$

1487

1488 Sears, K. E., Behringer, R. R., Rasweiler, J. J. \& Niswander, L. A. 2006. Development of bat 1489 flight: morphologic and molecular evolution of bat wing digits. Proceedings of the National 1490 Academy of Sciences, 103, 6581-6586. DOI: 10.1073/pnas.0509716103

1491

1492 Senter, P. 2007a. A new look at the phylogeny of Coelurosauria. Journal of Systematic

1493 Palaeontology, 5, 429-463. DOI: 10.1017/S1477201907002143

1494

1495 Senter, P. 2007b. A method for distinguishing dromaeosaurid manual unguals from pedal "sickle 1496 claws". Bulletin of the Gunma Museum of Natural History, 11, 1-6.

1497 
1498 Senter, P. 2011. Using creation science to demonstrate evolution 2: Morphological continuity

1499 within Dinosauria. Journal of Evolutionary Biology, 24, 2197-2216. DOI: 10.1111/j.1420-

1500 9101.2011.02349.x

1501

1502 Senter, Barsbold, Britt and Burnham, 2004. Systematics and evolution of Dromaeosauridae.

1503 Bulletin of Gunma Museum of Natural History. 8, 1-20.

1504

1505 Senter, P., Kirkland, J. I., DeBlieux, D. D., Madsen, S \& Toth, N. 2012. New dromaeosaurids

1506 (Dinosauria: Theropoda) from the Lower Cretaceous of Utah, and the evolution of the

1507 dromaeosaurid tail. PLoS ONE, 7, e36790. DOI: 10.1371/journal.pone.0036790

1508

1509 Sereno, P.C. 1997. The origin and evolution of dinosaurs. Annual Review of Earth and Planetary

1510 Sciences, 25, 435-489. DOI: 10.1146/annurev.earth.25.1.435

1511

1512 Sereno, 1999. The evolution of dinosaurs. Science. 284, 2137-2147. DOI:

1513 10.1126/science.284.5423.2137

1514

1515 Sereno, 2007. Logical basis for morphological characters in phylogenetics. Cladistics. 23, 565-

1516 587. DOI: 10.1111/j.1096-0031.2007.00161.x

1517

1518 Shen, Zhao, Gao, Lü and Kundrát, 2017a. A new troodontid dinosaur (Liaoningvenator curriei

1519 gen. et sp. nov.) from the Early Cretaceous Yixian Formation in western Liaoning province. Acta

1520 Geoscientica Sinica. 38(3), 359-371. DOI: 10.3975/cagsb.2017.03.06 
1521

1522 Shen, C., Lü, J., Kundrát, M., Brusatte, S. L. \& Gao, H. 2017b. A new troodontid dinosaur from 1523 the Lower Cretaceous Yixian Formation of Liaoning Province, China. Acta Geologica Sinica, 1524 91, 763-780. DOI: 10.1111/1755-6724.13307

1525

1526 Speakman, J.R. and Thomson, S.C., 1994. Flight capabilities of Archaeopteryx. Nature, 1527 370(6490), 514. DOI: 10.1038/370514a0

1528

1529 Tobalske, B. W., \& Dial, K. P. 2007. Aerodynamics of wing-assisted incline running in birds. 1530 Journal of Experimental Biology, 210, 1742-1751. DOI: 10.1242/jeb.001701

1531

1532 Trujillo, K. 2006. Clay mineralogy of the Morrison Formation and its use in long distance 1533 correlation and paleoenvironmental analysis. In: Foster, J. R. \& Lucas, S. G. (Eds.), Paleontology 1534 and Geology of the Upper Jurassic Morrison Formation. New Mexico Museum of Natural 1535 History and Science Bulletin, 17-24.

1536

1537 Trujillo, K., Chamberlain, K. \& Strickland, A. 2006. Oxfordian Park: U/Pb ages from SHRIMP 1538 analysis for the Upper Jurassic Morrison Formation of southeastern Wyoming with implications 1539 for biostratigraphic correlations. Journal of Vertebrate Paleontology, Suppl. 26:3, 132. DOI: $1540 \quad 10.1080 / 02724634.2006 .10010069$ 
1542 Trujillo, K., Foster, J., Hunt-Foster, R. \& Chamberlain, K. A. 2014. U/Pb age for the Mygatt-

1543 Moore Quarry, Upper Jurassic Morrison Formation, Mesa County, Colorado. Volumina

1544 Jurassica, 12, 107-114. DOI: 10.5604/17313708 .1130132

1545

1546 Tsuihiji, Barsbold, Watabe, Tsogtbaatar, Suzuki and Hattori, 2015. New material of a troodontid

1547 theropod (Dinosauria: Saurischia) from the Lower Cretaceous of Mongolia. Historical Biology.

1548 28(1-2), 128-138. DOI: 10.1080/08912963.2015.1005086

1549

1550 Turner, 2008. Phylogenetic relationships of paravian theropods. PhD Thesis. Columbia

1551 University. 666 pp.

1552

1553 Turner, A. H., Makovicky, P. J. \& Norell, M. 2012. A review of dromaeosaurid systematics and 1554 paravian phylogeny. Bulletin of the American Museum of Natural History, 371, 1-206.

1555

1556 Turner, Pol and Norell, 2011. Anatomy of Mahakala omnogovae (Theropoda:

1557 Dromaeosauridae), Tögrögiin Shiree, Mongolia. American Museum Novitates. 3722, 66 pp.

1558 DOI: $10.1206 / 3722.2$

1559

1560 Turner, A. H., Pol, D., Clarke, J. A., Erickson, G. M. \& Norell, M. A. 2007. A basal

1561 dromaeosaurid and size evolution preceding avian flight. Science, 317, 1378-1381. DOI:

$1562 \quad 10.1126 /$ science. 1144066

1563 
1564 Wahl, W. R. 2006. Osteology and phylogenetic relationships of a new small maniraptoran from 1565 the Upper Jurassic of Wyoming. Master's thesis, Fort Hays State University. 97 pp.

1566

1567 Wang, Zhou, O'Connor and Zelenkov, 2014. A new diverse enantiornithine family

1568 (Bohaiornithidae fam. nov.) from the Lower Cretaceous of China with information from two new 1569 species. Vertebrata PalAsiatica. 52(1), 31-76.

1570

1571 Wang, Wang, Wang and Zhou, 2016. A new basal bird from China with implications for 1572 morphological diversity in early birds. Scientific Reports. 6, 19700. DOI: 10.1038/srep19700 1573

1574 Wang, Zheng, O'Connor, Lloyd, Wang, Wang, Zhang and Zhou, 2015. The oldest record of 1575 Ornithuromorpha from the Early Cretaceous of China. Nature Communications. 6:6987. DOI: $1576 \quad 10.1038 /$ ncomms 7987

1577

1578 Witmer, 1997. The evolution of the antorbital cavity of archosaurs: A study in soft-tissue 1579 reconstruction in the fossil record with an analysis of the function of pneumaticity. Journal of 1580 Vertebrate Paleontology. Memoir 3. 17(1), 1-73. DOI: 10.1080/02724634.1997.10011027 1581

1582 Xing, Persons, Bell, Xu, Zhang, Miyashita, Wang and Currie, 2013. Piscivory in the feathered 1583 dinosaur Microraptor. Evolution. 67(8), 2441-2445. DOI: 10.1111/evo.12119

1584

$1585 \mathrm{Xu}, 2002$. Deinonychosaurian fossils from the Jehol Group of Western Liaoning and the 1586 coelurosaurian evolution. PhD Thesis. Chinese Academy of Sciences. 325 pp. 
1587

$1588 \mathrm{Xu}$ and Li, 2016. A new microraptorine specimen (Theropoda: Dromaeosauridae) with a brief 1589 comment on the evolution of compound bones in theropods. Vertebrata PalAsiatica. 54(4), 1531590169.

1591

1592

Xu, X., \& Norell, M.A. 2004. A new troodontid dinosaur from China with avian-like sleeping 1593 posture. Nature. 431, 838-841. DOI: 10.1038/nature02898

1594

1595 Xu and Wang, 2004. A new troodontid (Theropoda: Troodontidae) from the Lower Cretaceous 1596 Yixian Formation of Western Liaoning, China. Acta Geologica Sinica. 78(1), 22-26. DOI:

1597 10.1111/j.1755-6724.2004.tb00671.x

1598

$1599 \mathrm{Xu}$ and $\mathrm{Wu}, 2001$. Cranial morphology of Sinornithosaurus millenii Xu et al. 1999 (Dinosauria: 1600 Theropoda: Dromaeosauridae) from the Yixian Formation of Liaoning, China. Canadian Journal 1601 of Earth Sciences. 38, 1739-1752. DOI: 10.1139/e01-082

1602

$1603 \mathrm{Xu}$, Zhou and Wang, 2000. The smallest known non-avian theropod dinosaur. Nature, 408, 7051604 708. DOI: $10.1038 / 35047056$

1605

1606 Xu, X., You, H., Du, K. \& Han, F. 2011. An Archaeopteryx-like theropod from China and the 1607 origin of Avialae. Nature, 475, 465-470. DOI: 10.1038/nature10288

1608 
1609 Xu, Norell, Wang, Makovicky and Wu, 2002. A basal troodontid from the Early Cretaceous of

1610 China. Nature. 415, 780-784. DOI: 10.1038/415780a

1611

1612 Xu, Zhao, Sullivan, Tan, Sander and Ma, 2012. The taxonomy of the troodontid IVPP V 10597

1613 reconsidered. Vertebrata PalAsiatica. 50(2), 140-150.

1614

1615 Xu, Currie, Pittman, Xing, Meng, Lu, Hu and Yu, 2017. Mosaic evolution in an asymmetrically

1616 feathered troodontid dinosaur with transitional features. Nature Communications. 8:14972. DOI:

$1617 \quad 10.1038 /$ ncomms 14972

1618

1619 Xu, Kobayashi, Lu, Lee, Liu, Tanaka, Zhang, Jia and Zhang, 2011. A new ornithomimid

1620 dinosaur with North American affinities from the Late Cretaceous Qiupa Formation in Henan

1621 Province of China. Cretaceous Research. 32(2), 213-222. DOI: 10.1016/j.cretres.2010.12.004

1622

1623 Xu, X., Zheng, X., Sullivan, C., Wang, X., Xing, L., Wang, Y., Zhang, X., O’Connor, J.K.,

1624 Zhang, F. and Pan, Y., 2015. A bizarre Jurassic maniraptoran theropod with preserved evidence 1625 of membranous wings. Nature, 521(7550), p.70.

1626

1627 Xu, Choiniere, Tan, Benson, Clark, Sullivan, Zhao, Han, Ma, He, Wang, Xing and Tan, 2018.

1628 Two Early Cretaceous fossils document transitional stages in alvarezsaurian dinosaur evolution.

1629 Current Biology. 28, 1-8. DOI: 10.1016/j.cub.2018.07.057

1630 
1631 Yin, Pei and Zhou, 2018. Cranial morphology of Sinovenator changii (Theropoda: Troodontidae)

1632 on the new material from the Yixian Formation of western Liaoning, China. PeerJ 6:e4977. DOI:

1633 10.7717/peerj.4977

1634

1635 Zanno, 2010. A taxonomic and phylogenetic re-evaluation of Therizinosauria (Dinosauria:

1636 Maniraptora). Journal of Systematic Palaeontology. 8(4), 503-543. DOI:

$1637 \quad 10.1080 / 14772019.2010 .488045$

1638

1639 Zanno, Varricchio, O'Connor, Titus and Knell, 2011. A new troodontid theropod, Talos

1640 sampsoni gen. et sp. nov., from the Upper Cretaceous western interior basin of North America.

1641 PLoS ONE. 6(9), e24487. DOI: 10.1371/journal.pone.0024487

1642

1643 Zhang, Zhou, Xu, Wang and Sullivan, 2008. A bizarre Jurassic maniraptoran from China with

1644 elongate ribbon-like feathers. Nature. $455,1105-1108$. DOI: $10.1038 /$ nature 07447

1645

1646 Zheng, O'Connor, Wang, Wang and Zhou, 2018. Reinterpretation of a previously described

1647 Jehol bird clarifies early trophic evolution in the Ornithuromorpha. Proceedings of the Royal

1648 Society B. 285, 20172494. DOI: 10.1098/rspb.2017.2494

1649

1650 Zheng, Xu, You, Zhao and Dong, 2009. A short-armed dromaeosaurid from the Jehol Group of

1651 China with implications for early dromaeosaurid evolution. Proceedings of the Royal Society B.

1652 277, 211-217. DOI: 10.1098/rspb.2009.1178

1653

Peer] reviewing PDF | (2018:08:30731:1:2:NEW 20 May 2019) 
1654 Zhou and Zhang, 2002. A long-tailed, seed-eating bird from the Early Cretaceous of China.

1655 Nature. 418, 405-409. DOI: 10.1038/nature00930

1656

1657 Zhou and Zhang, 2003. Anatomy of the primitive bird Sapeornis chaoyangensis from the Early 1658 Cretaceous of Liaoning, China. Canadian Journal of Earth Sciences. 40, 731-747. DOI:

$1659 \quad 10.1139 / \mathrm{e} 03-011$

1660

1661 Zhou, Clarke and Zhang, 2008. Insight into diversity, body size and morphological evolution 1662 from the largest Early Cretaceous enantiornithine bird. Journal of Anatomy. 212, 565-577. DOI: $166310.1111 / \mathrm{j} .1469-7580.2008 .00880 . \mathrm{x}$ 
Figure 1

Geographic relationship of the Jimbo Quarry and the majority of the Morrison Formation, Late Jurassic, USA.

Formation outcrop and map data based on paleobiodb.org.

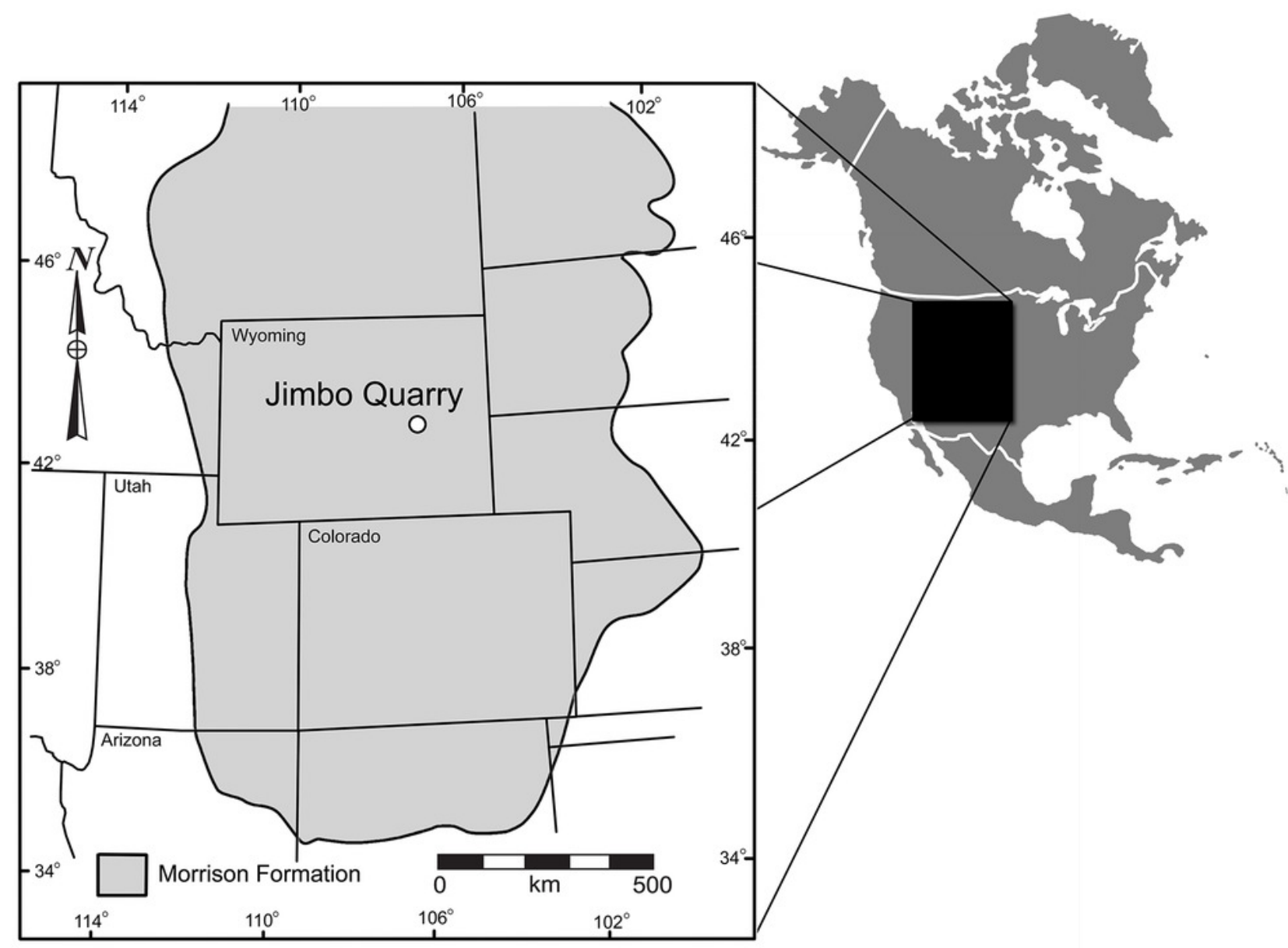


Figure 2

Condensed stratigraphic sections demonstrating the lateral variability near the Jimbo Quarry.

'?' indicate loss of direct lateral correlation due to covered section. 1=Jimbo Quarry; 2=Lori locality; $3=$ marginal wetland deposits .

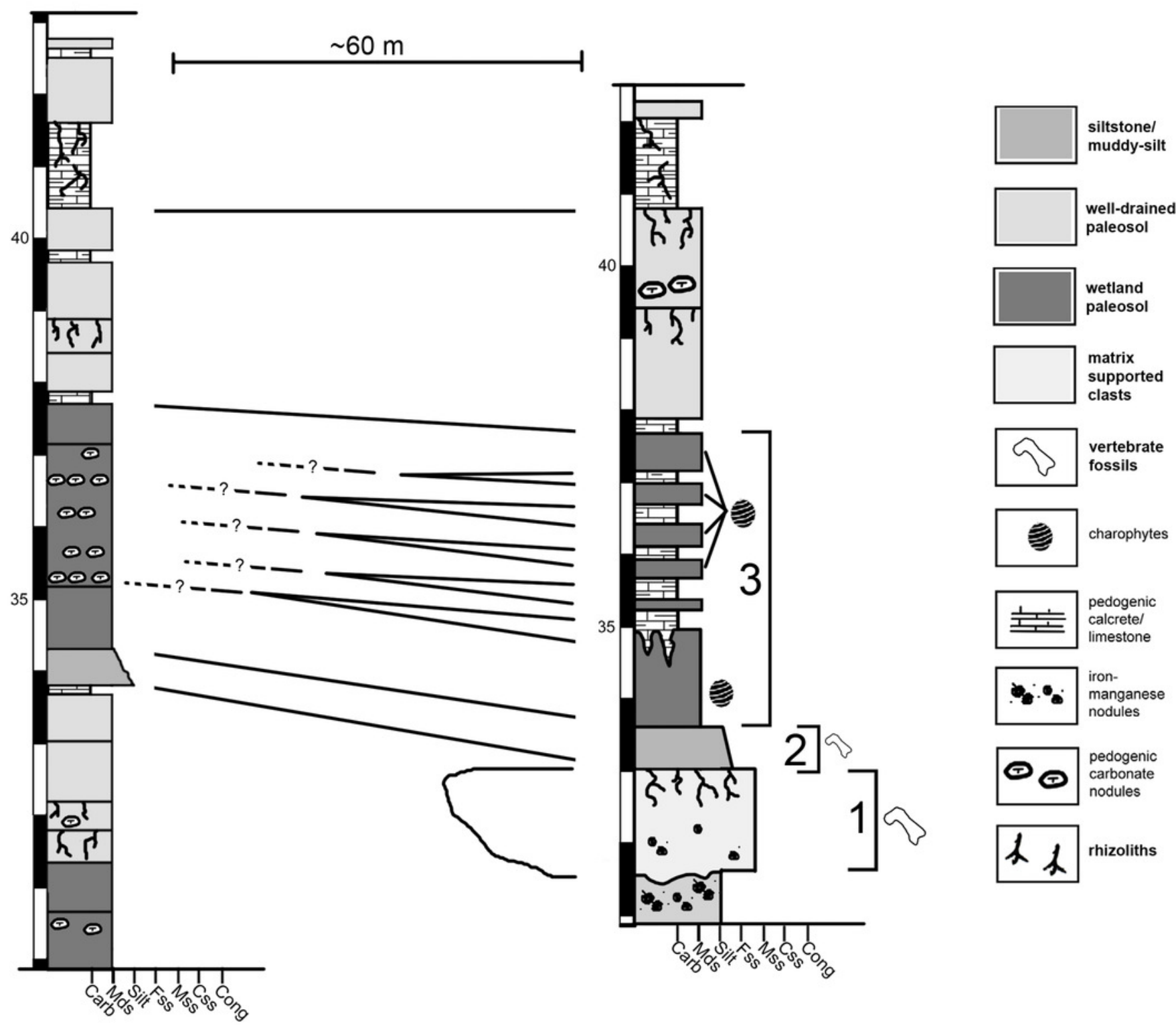


Figure 3

Reconstructed quarry map of WDC DML-00.

Association of skeletal elements assembled from 3D scans of specimen blocks prior to final mechanical preparation. 


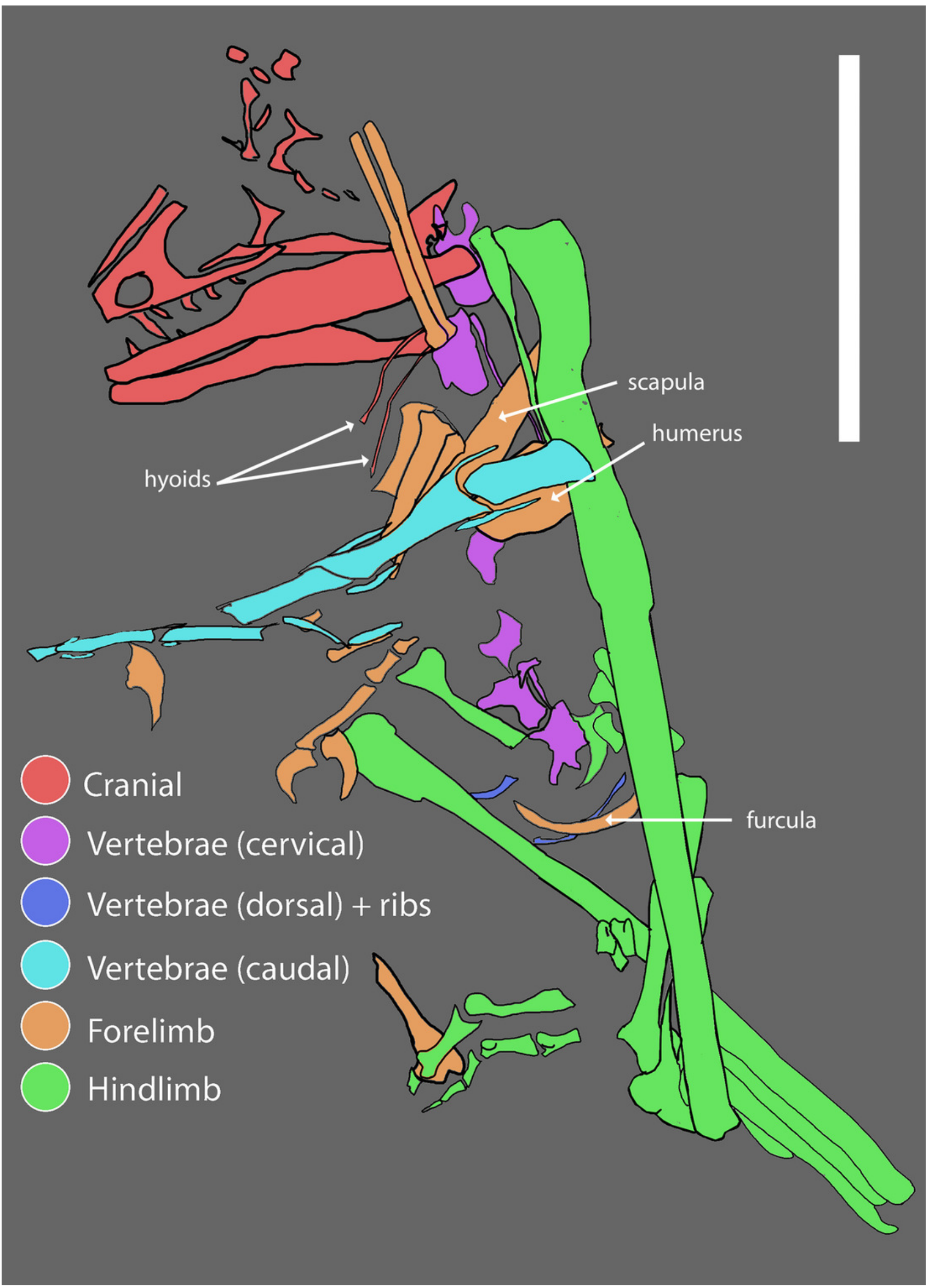


Figure 4

Primary blocks of WDC DM-001.

"Left" (A) and "right" (B) sides of the blocks after final preparation (B). Scale bar $=1 \mathrm{~cm}$.

Images taken by Levi Shinkle, used with permission 


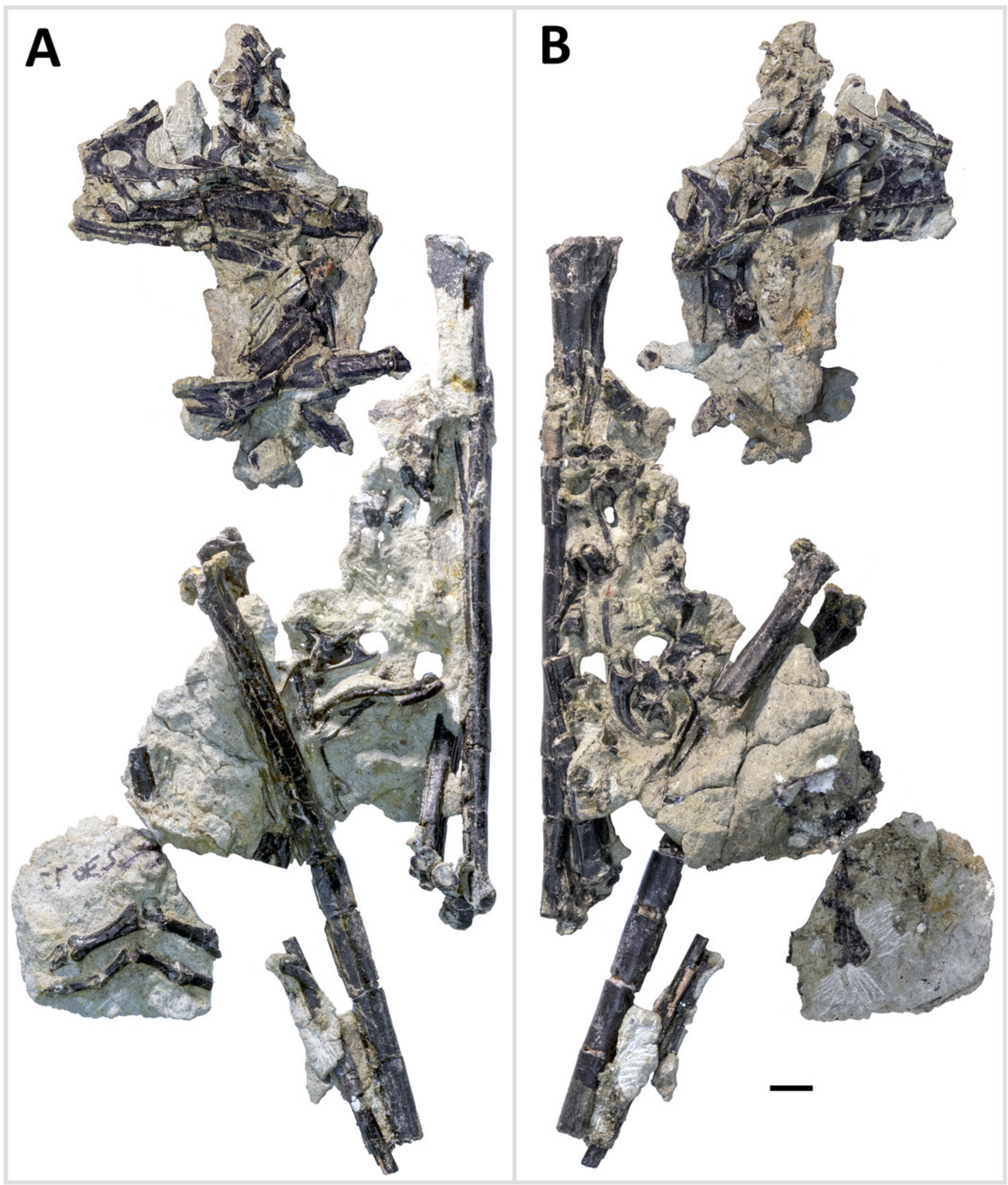


Figure 5

Rigorous skeletal reconstruction of WDC DML-001.

Scale bar $=25 \mathrm{~cm}$.

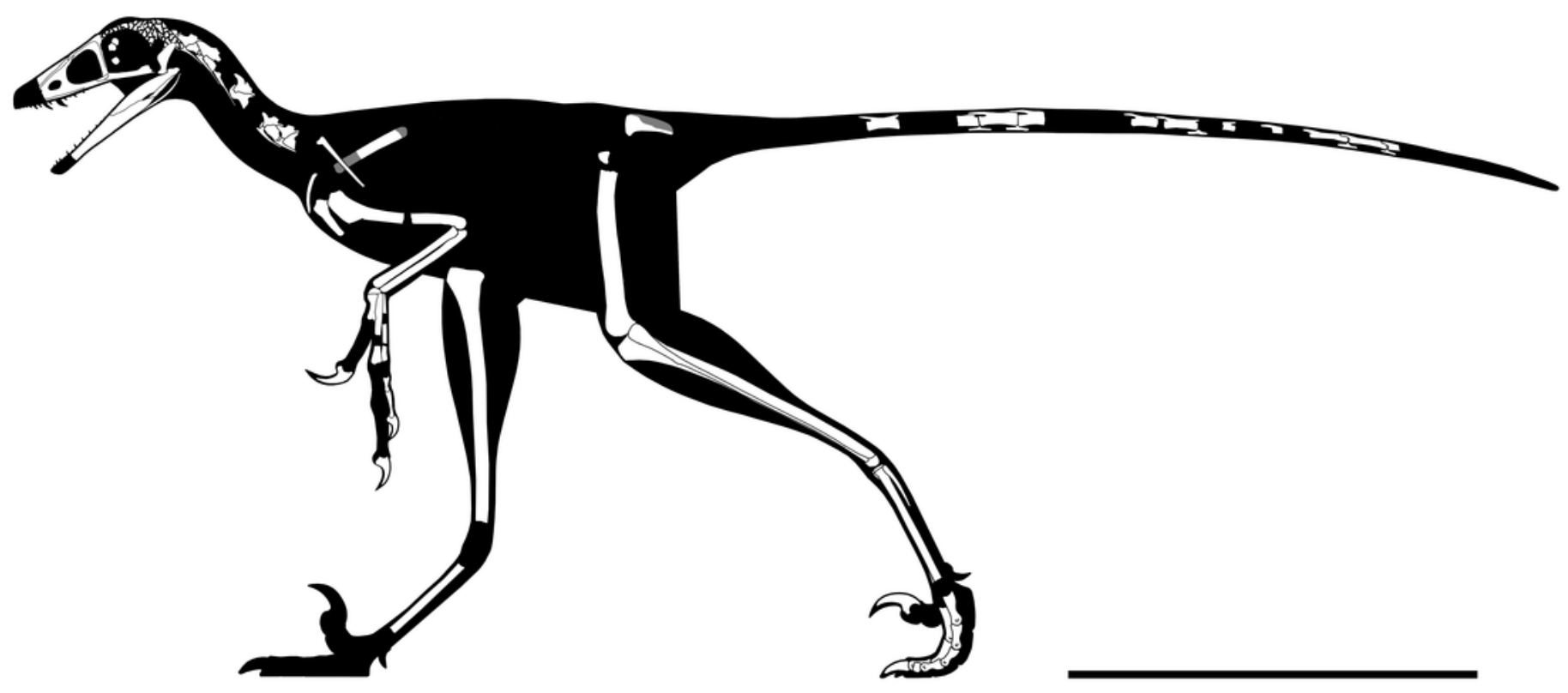




\section{Figure 6}

Skull block and interpretive drawing.

Skull block in left lateral (A, B) and right lateral (C, D) views. Abbreviations: An, angular; Aof, antorbital fenestra; $\mathrm{Cd}$, mid caudal vertebrae; $\mathrm{CV}$, cervical vertebra; Den, dentary; Emf, external mandibular fenestra; Hyo, hyoids; Hum, humerus; Lju, left jugal; LIc, left lacrimal; Max, maxilla; Mc2, metacarpal II; Mxf, maxillary fenestra; Pal, palatine; Pmf, promaxillary fenestra; Qd, quadrate; Qj, quadratojugal; Raf, ridge under antorbital fossa; Rju, right jugal; $\mathrm{RIc}$, right lacrimal; Rn, right nasal; Sa, surangular. Scale bar $=5 \mathrm{~cm}$. Photo credit Levi Shinkle, used with permission. 


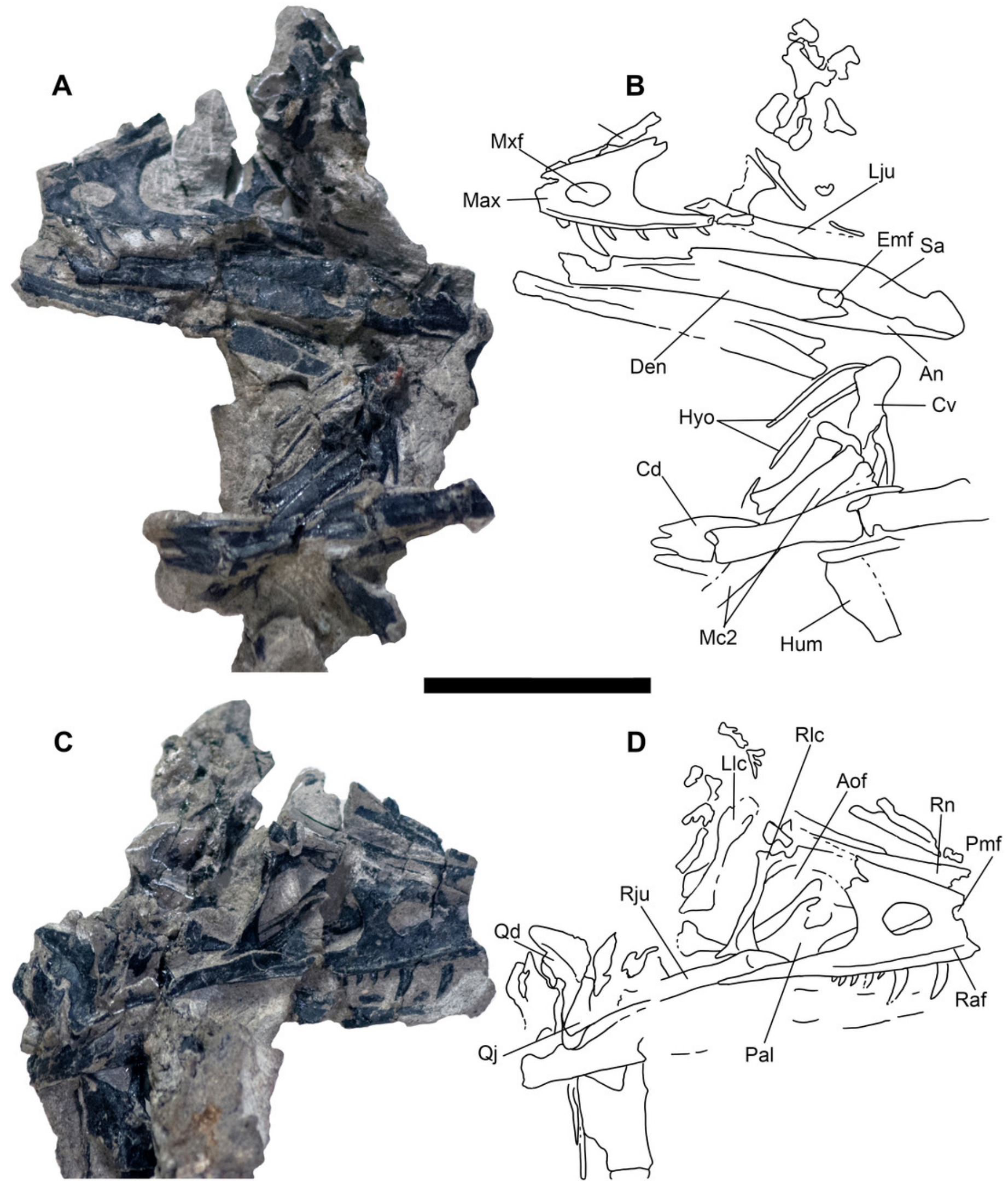


Figure 7

Segmented left maxilla of WDC DML-001.

Shown in lateral (A) and medial (B) views. 

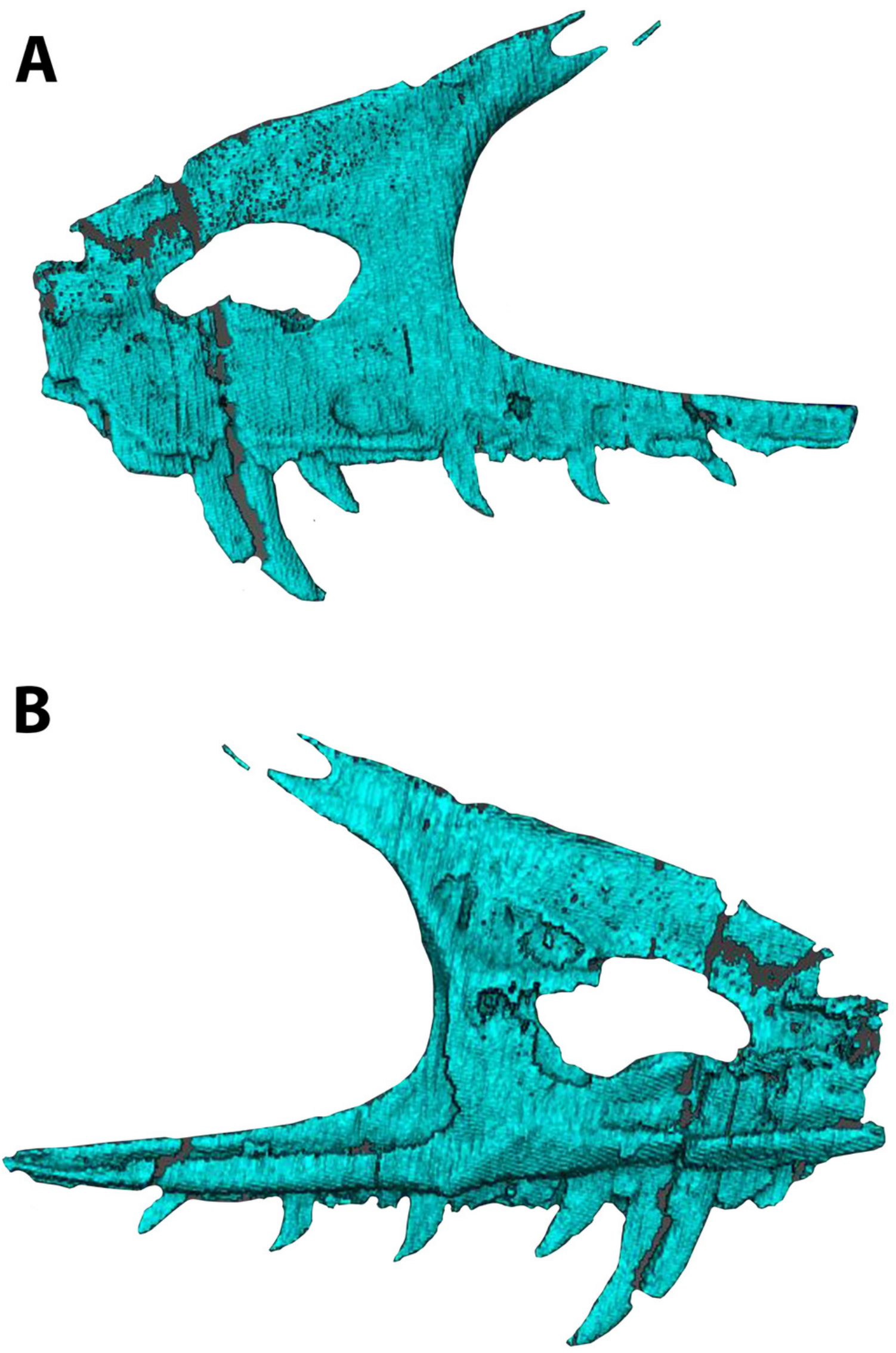
Figure 8

Segmented right lacrimal of WDC DML-001.

Shown in lateral (A), posterior (B) and medial (C) views.

A

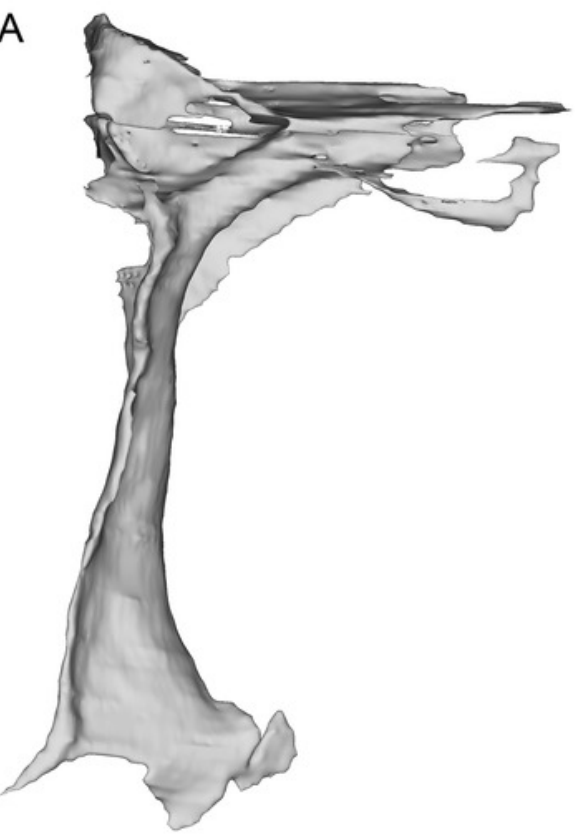

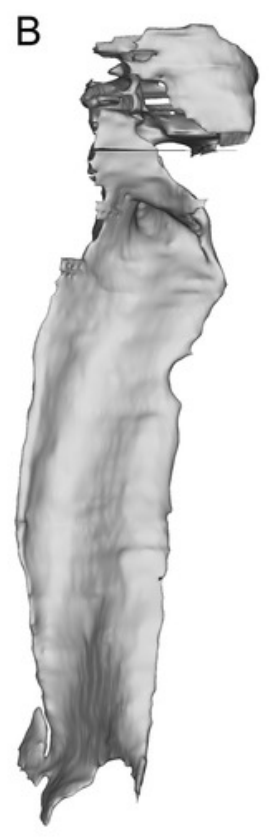

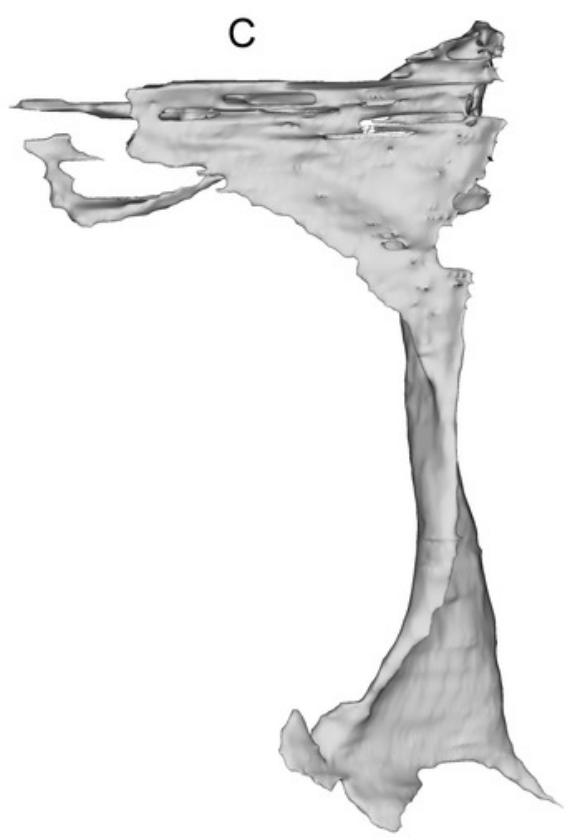


Figure 9

Segmented left jugal of WDC DML-001.

Shown in medial (A), lateral (B) and anterolateral oblique (C) views.
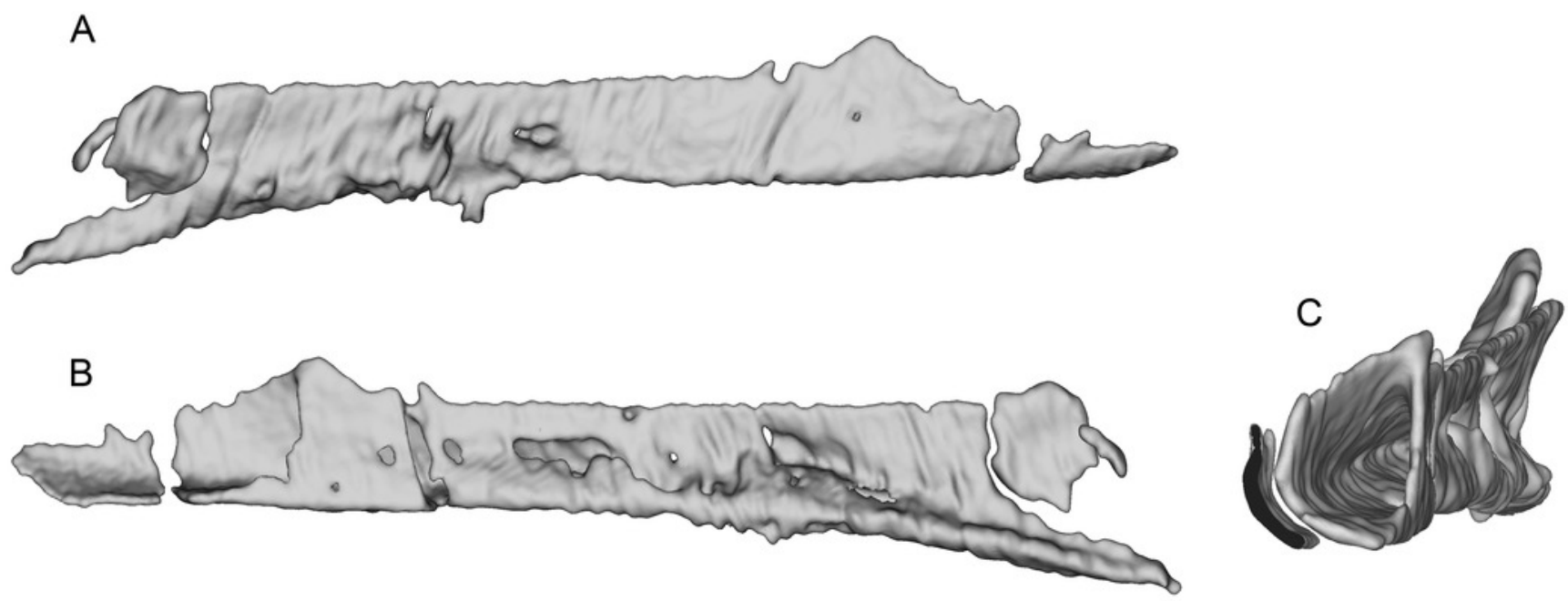


\section{Figure 10}

Paraquadrate foramen of WDC DML-001.

Paraquadrate foramen and inset detail showing the contribution of the quadrate to the paraquadrate foramen. Abbreviations: Pqf, paraquadrate foramen; Qd, quadrate; Qj, quadratojugal. 


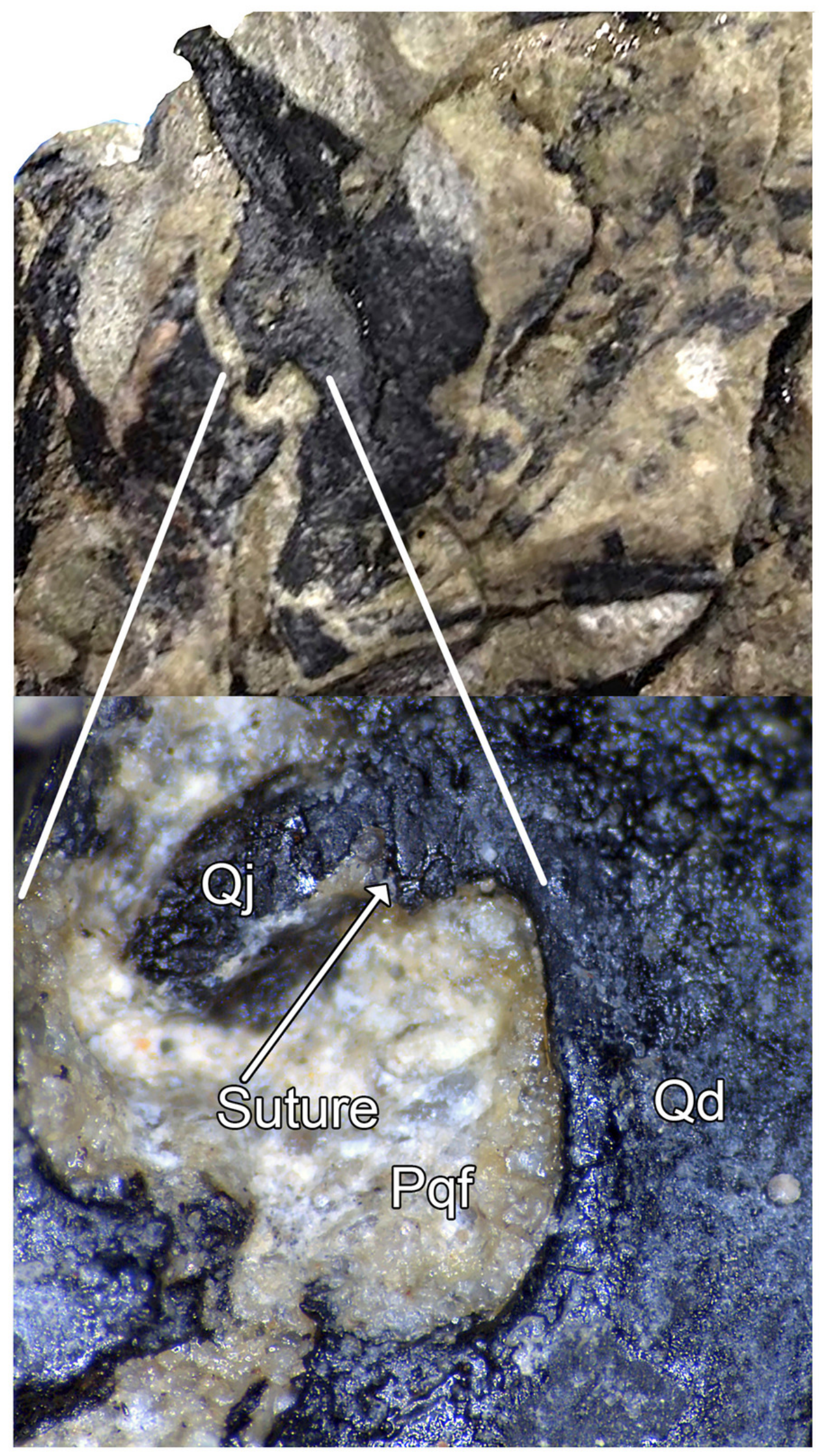




\section{Figure 11}

Mandible and comparative tooth morphology of Koparion and Hesperornithoides.

Tooth of Koparion in 'side' (A) and mesial (B) views, and a detail of the distal serrations (C). Hesperornithoides maxillary tooth in labial view $(\mathrm{E})$, rendered from $\mathrm{CT}$ data in mesial view $(F)$, inset details of segmented tooth and segmented oblique view of anterior mandibular elements of Hesperornithoides (G). Photo credit (A-C): Dan Chure. 

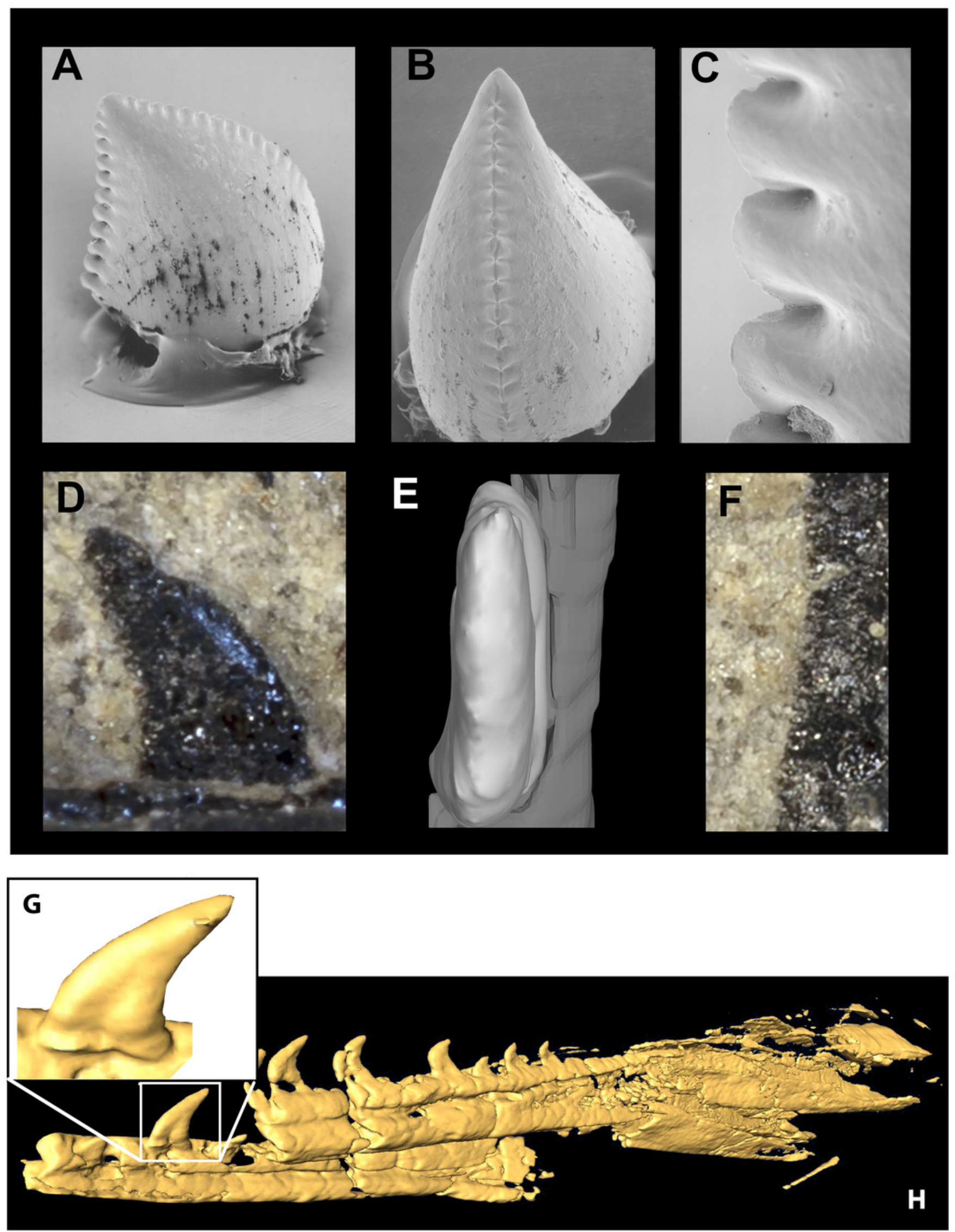
Figure 12

Select axial elements of WDC DML-001.

Cervical vertebra three in dorsal (A) and right lateral (B) views. (C) Mid-cervical vertebra in cross-section. Photo and schematic of association between axis and cervical three (D, E). (F) Cervicodorsal in right lateral view. Articulated middle $(G)$ and distal $(H)$ caudal vertebrae in right lateral views. 

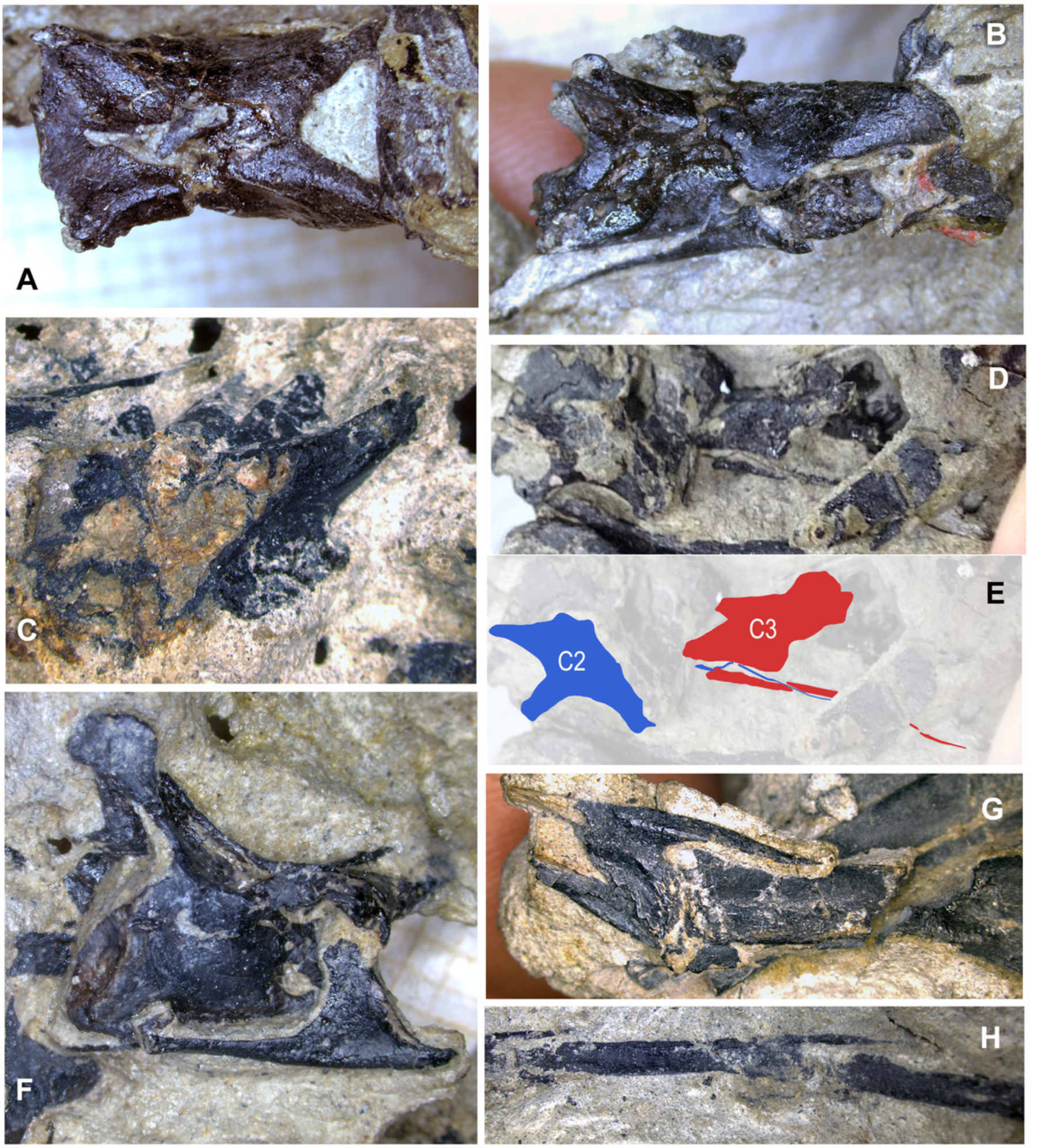
Figure 13

Segmented and interpretive drawing of mid caudal vertebrae of WDC DML-001.

In dorsal (A), right lateral (B) and ventral (C) view. Anterior is to the right in all views. Abbreviations: Chv, chevron; Przg, prezygapophysis; Pszg, postzygapophysis. Scale bar = $1 \mathrm{~cm}$. 


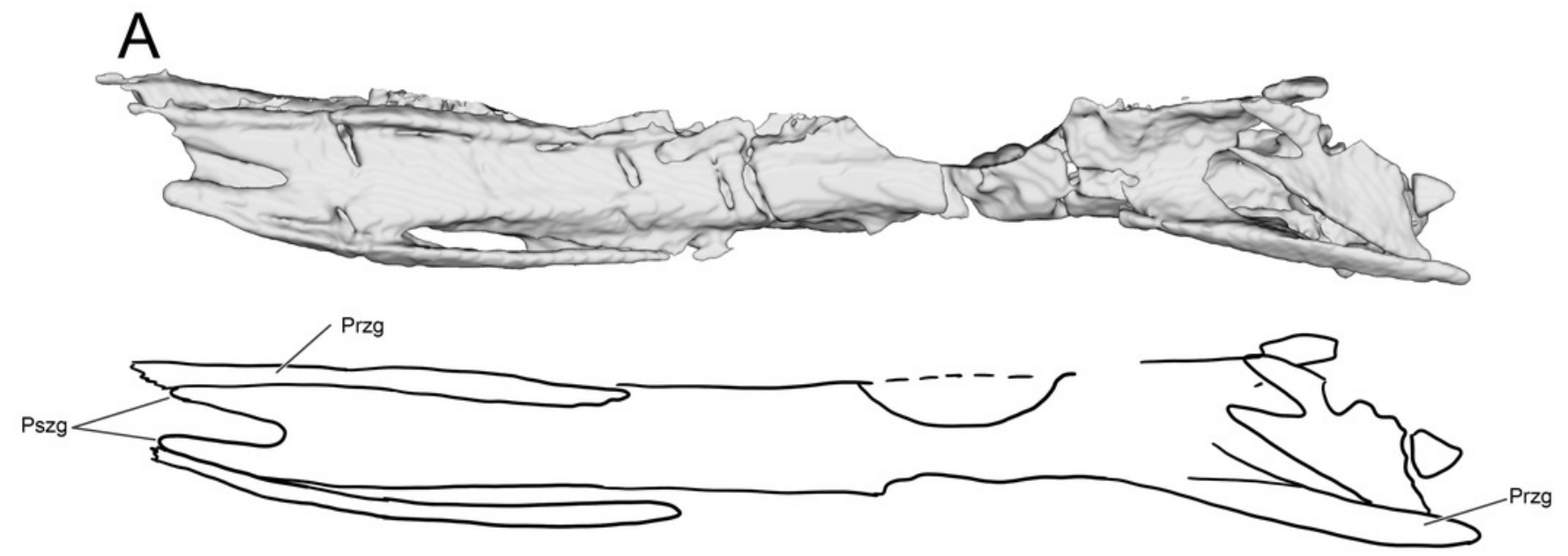

\section{B}
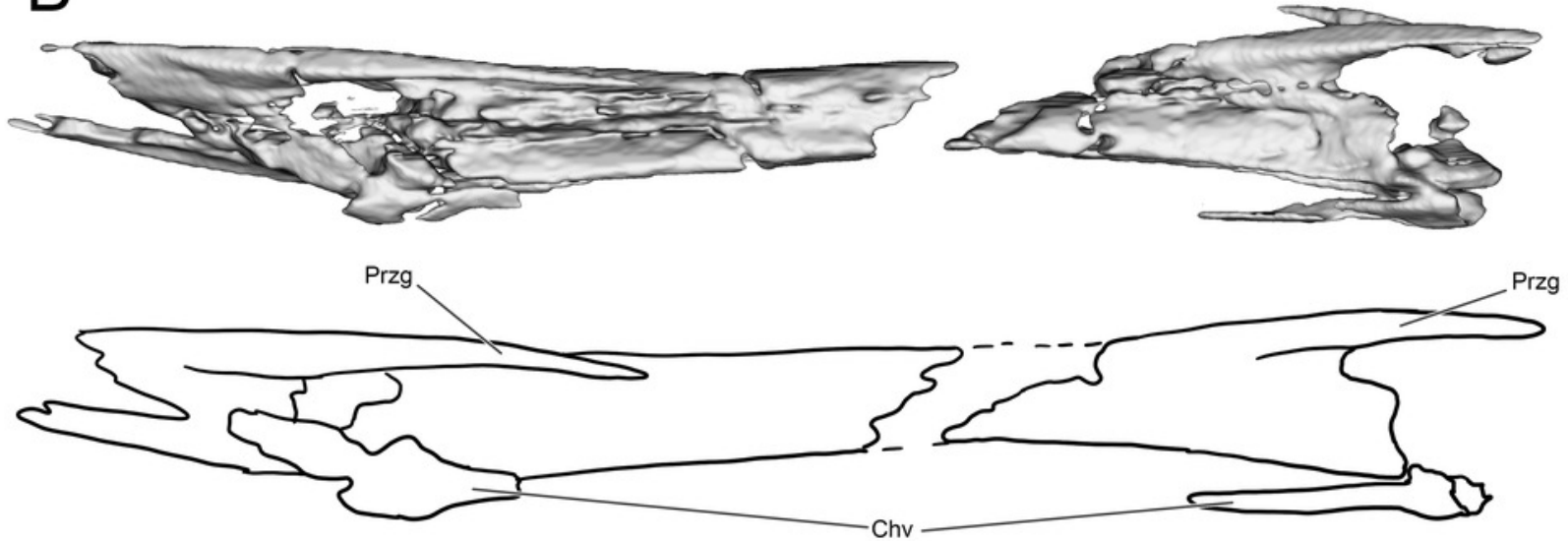

\section{C}
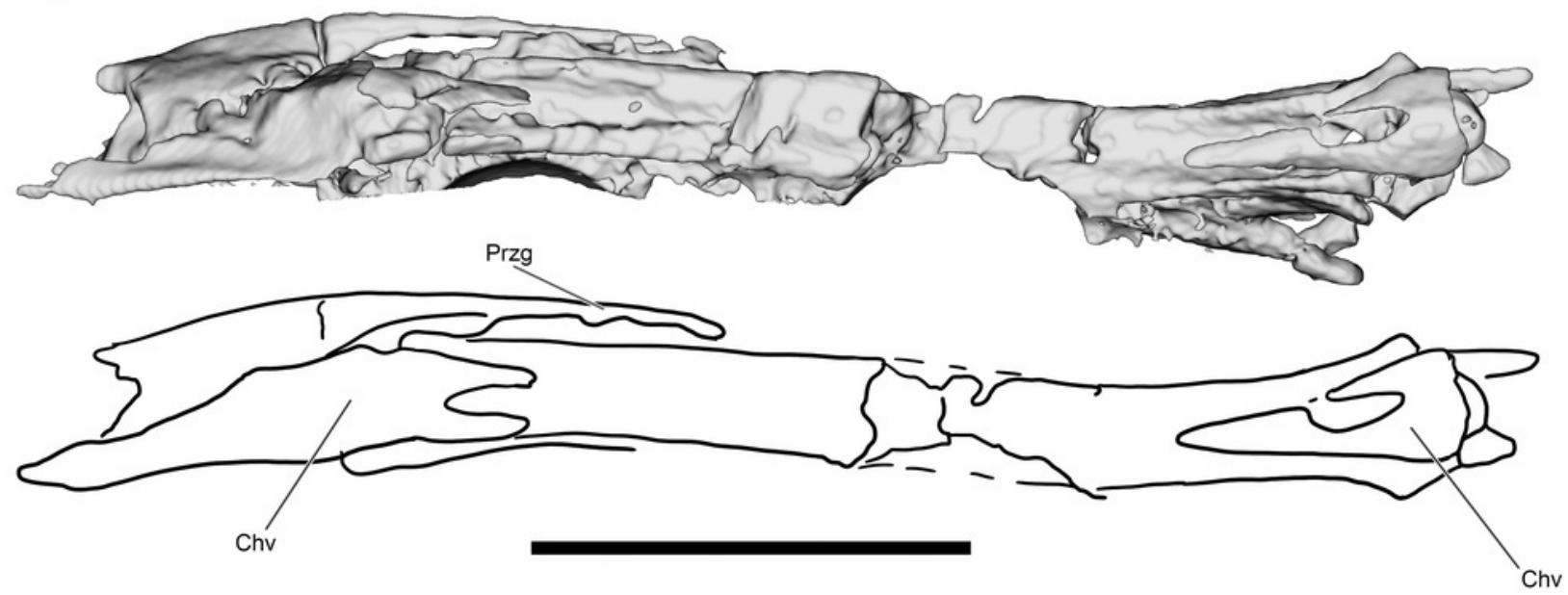


\section{Figure 14}

Forelimb elements of WDC DML-001.

Segmented left carpals and metacarpals in oblique (A) and extensor (B) views. (C) Distal portion of right MCIII in lateral view. (D) Distal end of right humerus in anterior view. Proximal end of left humerus in proximal $(E)$ and lateral view $(F)$. 

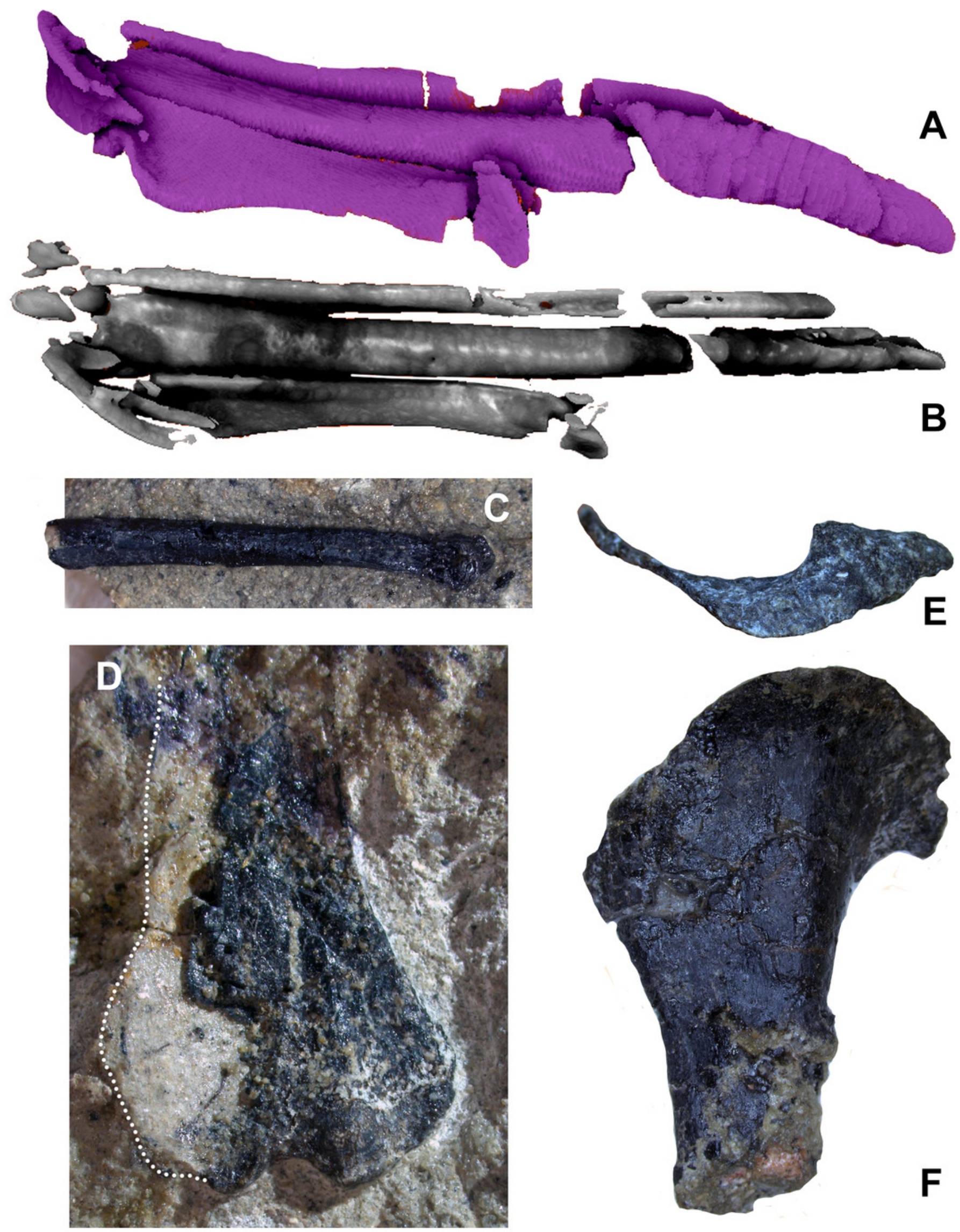


\section{Figure 15}

Unguals of WDC DML-001.

(A) Left manus ungual I in medial view. (B) Left manus ungual II in medial view. (C) Left manus ungual III in medial view. (D) Pes ungual II (mirrored for ease of comparison) with trenchant sickle morphology. Scale bar $=1 \mathrm{~cm}$. 

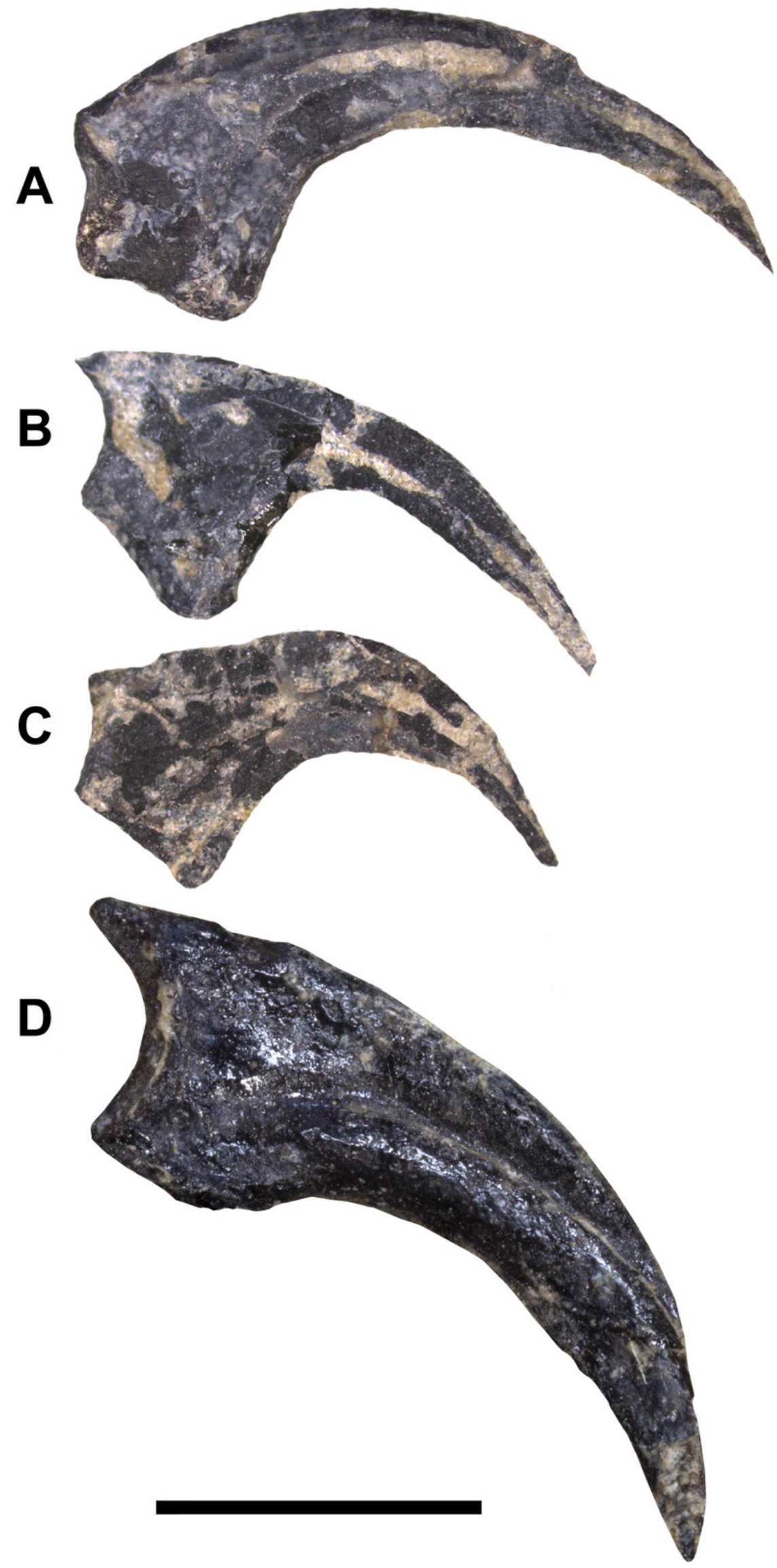


\section{Figure 16}

Select hindlimb elements of WDC DML-001.

Proximal end of left metatarsal packet in posterior (A) and anterior (B) views. (C) Right metatarsal I in medial view. (D) Cross-section through left metatarsals from distal perspective, anterior is to the bottom. (E) Enlarged pes ungual II: red shading is inferred to be preserved sheath material. (F) Cross-section through the left tibia at mid-shaft. 

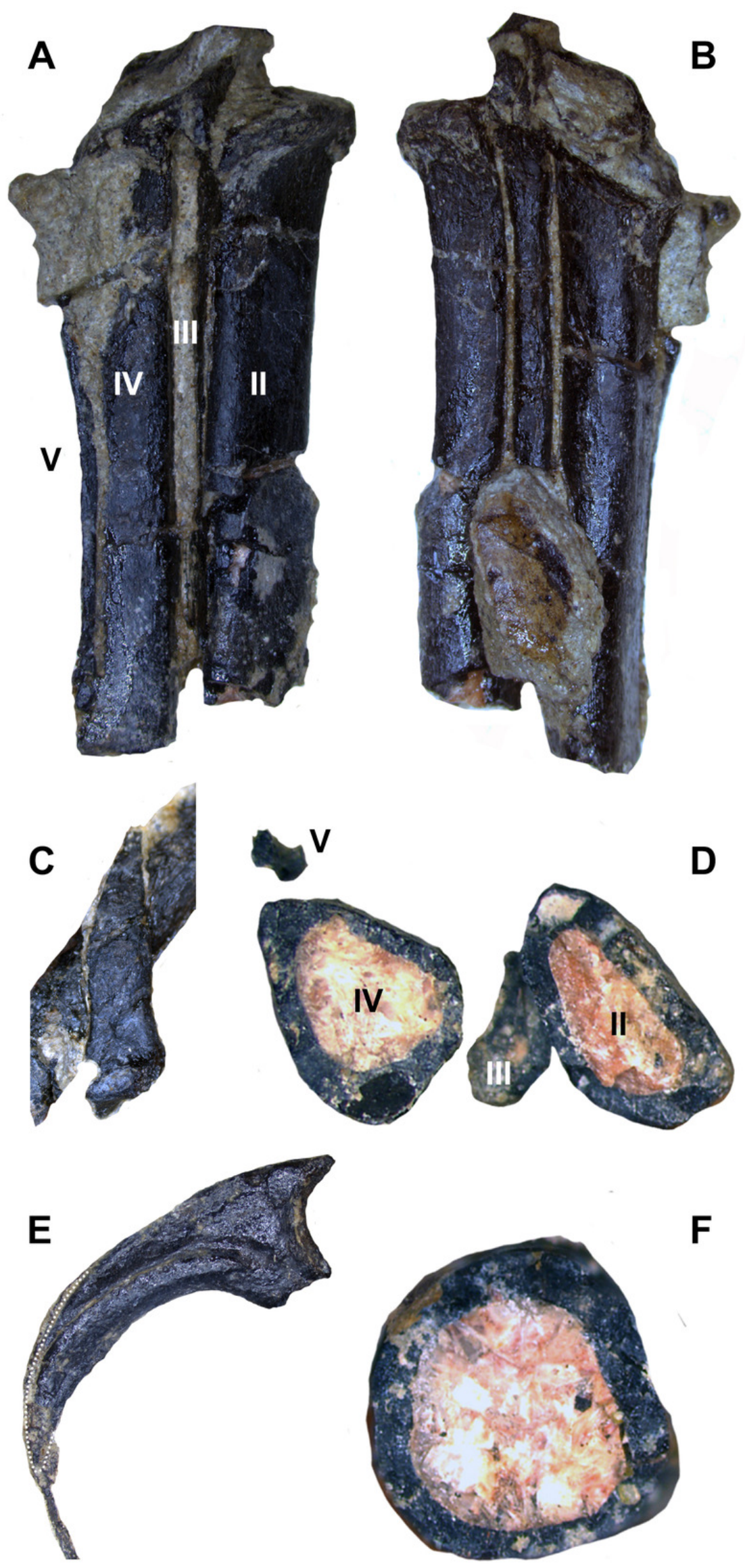

Peer) reviewing PDF | (2018:08:30731:1:2:NEW 20 May 2019) 


\section{Figure 17}

Summary diagram of the findings from this phylogenetic analysis.

Strict consensus tree of maniraptoromorphs after a posteriori pruning with higher level taxa condensed (length $=12123$ ). The uncondensed tree and positions of pruned taxa can be seen in the Supplemental Data. 


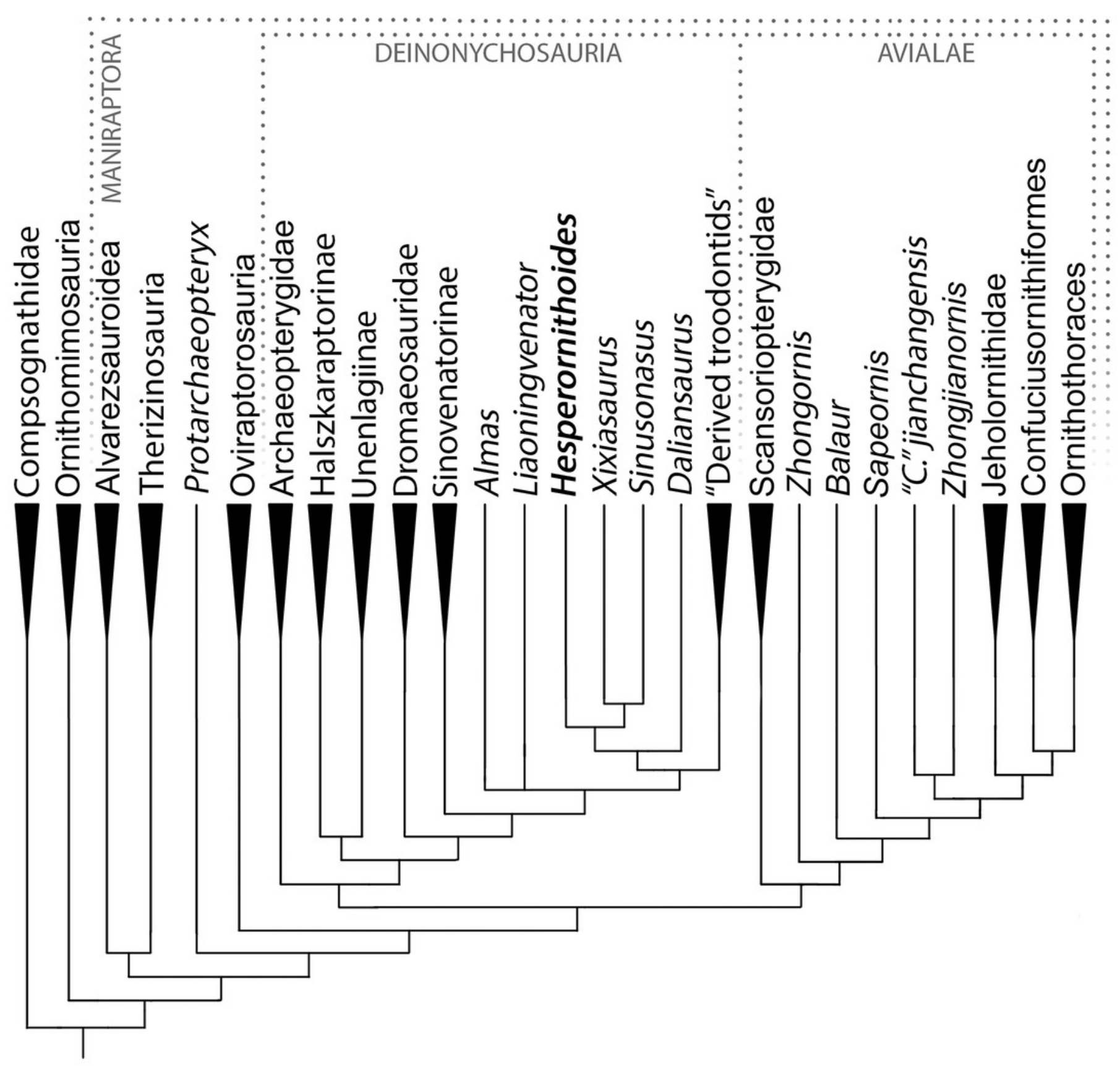




\section{Figure 18}

Partially expanded, time calibrated phylogenetic results.

Clades containing potentially volant taxa (red) are expanded to show their position nested within flightless taxa (black). Taxa exhibiting aerial locomotion directly connected to crown clade Aves are colored blue. Zhongornis is colored purple to reflect the uncertainty revolving around this juvenile specimen. 


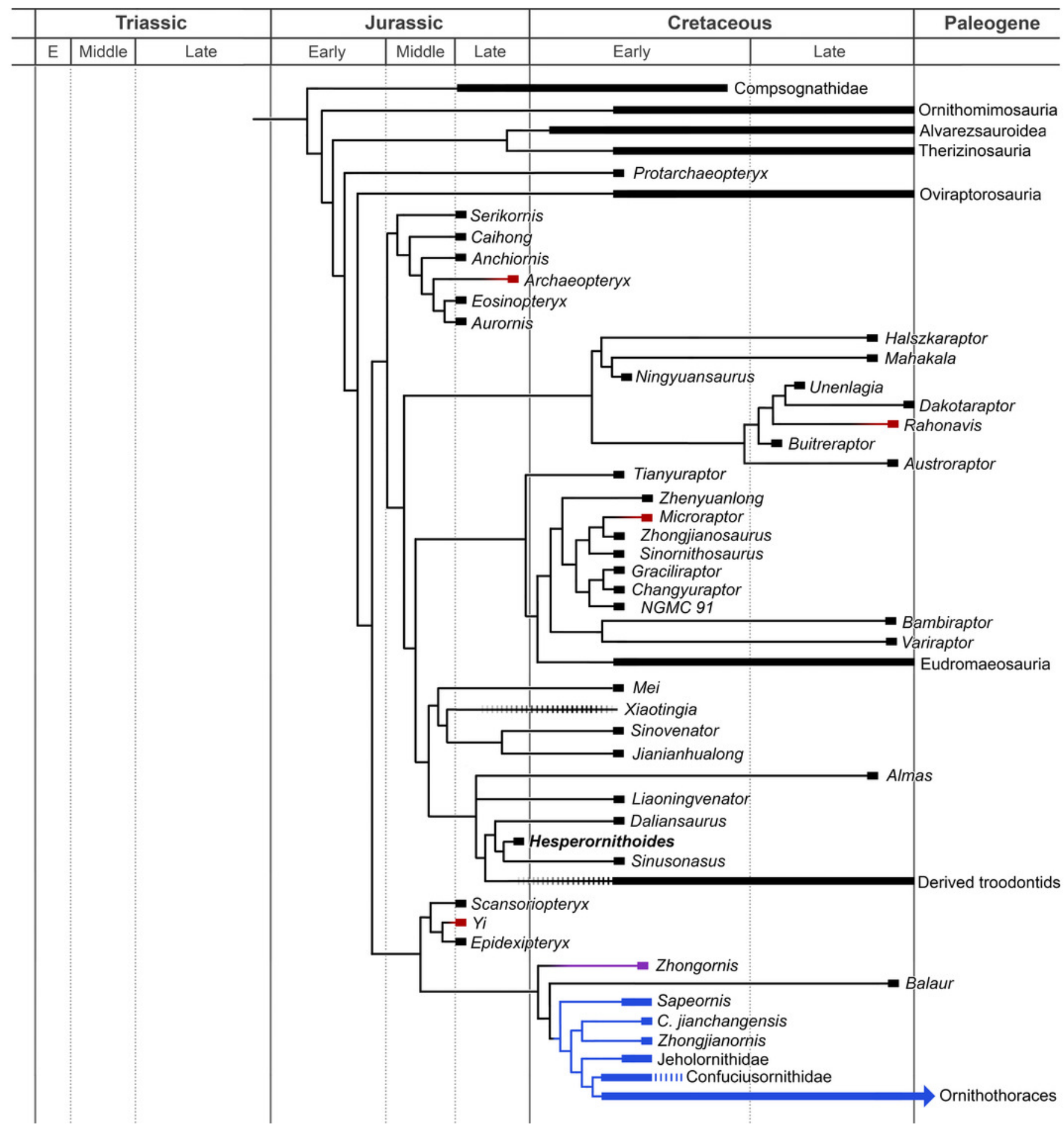




\section{Table 1 (on next page)}

Measurements of the axial skeleton of WDC DML-001.

* Indicates incomplete or partially restored elements. 


\begin{tabular}{|c|c|c|}
\hline Element & Longest Distance (mm) & Additional Measurement (mm) \\
\hline \multicolumn{3}{|l|}{ SKULL } \\
\hline ventral length* (maxilla to quadrate) & 39.5 & \\
\hline longest maxillary tooth crown & 6.4 & \\
\hline shortest erupted tooth crown & 2.1 & \\
\hline mandible* $^{*}$ missing anterior end) & 42.5 & \\
\hline \multicolumn{3}{|l|}{ AXIAL (CENTRA LENGTH) } \\
\hline CV3 & 11.7 & \\
\hline CV4 & est 14 & \\
\hline CV?6 & 14.5 & \\
\hline CV8 & 13.7 & \\
\hline CV9/D1 & 11.7 & \\
\hline proximo/mid caudal & 20.8 & \\
\hline CA B (mid caudal) & 22.2 & max height $=6$ \\
\hline CA C (mid caudal) & 22.3 & \\
\hline CA E (mid caudal)* & 23.6 & max height $=4.9$ \\
\hline $\mathrm{CA} \mathrm{H}$ (distal caudal) & 18.2 & 3.2 \\
\hline CA I (distal caudal) & 17.5 & 2.5 \\
\hline \multicolumn{3}{|l|}{ BODY LENGTH ESTIMATES } \\
\hline Head & 66 & \\
\hline neck & 108 & \\
\hline dorsals & 130 & \\
\hline sacrum & 45 & \\
\hline caudals & 540 & \\
\hline Total & 889 & \\
\hline
\end{tabular}




\section{Table 2 (on next page)}

Measurements of the appendicular skeleton og WDC DML-001.

* Indicates incomplete or partially restored elements. 


\begin{tabular}{|c|c|c|}
\hline Appendicular Element & Longest Distance (mm) & Other Measurement (mm) \\
\hline Coracoid* $^{*}$ & height 21.4 & width 14.6 \\
\hline Left humerus* (proximal portion) & 34.5 & Shaft -32.5 \\
\hline Left ulna/rad & 46.4 & \\
\hline $\mathrm{MCl}$ & 16.9 & \\
\hline MCII + carpals* & 61 & \\
\hline Manus phalanx III-2 & 7 & \\
\hline Manus phalanx III-3 & 18.2 & \\
\hline Manual ungual I & 17.1 & \\
\hline Manual ungual II & 15.5 & \\
\hline Manual ungual III & 14.4 & \\
\hline Left femur* (no proximal end) & 93.9 & \\
\hline Left tibia & 168 & \\
\hline Right tibia* (missing distal end) & 153 & \\
\hline Left MT packet* (proximal) & 55.2 & \\
\hline Left pes phalanx III-1 & 26.3 & \\
\hline Left pes phalanx III-2 & 17.3 & \\
\hline Left pes phalanx IV-2 & 13.2 & \\
\hline Left pes phalanx IV-3* & est 8.5 & \\
\hline Left pes phalanx IV-4 & 6.9 & \\
\hline Pes ungual III & 13.6 & height 3.7 \\
\hline
\end{tabular}




\section{Table 3(on next page)}

Humeral/femoral ratios of paravian theropods.

Data drawn from personal measurements and literature values. 
2

\begin{tabular}{|ll|ll|}
\hline Taxa & H/F Ratio & Taxa & H/F Ratio \\
\hline Ningyuansaurus & 0.56 & Deinonychus & $0.76-0.80$ \\
Protarchaeopteryx & 0.70 & Austroraptor & 0.47 \\
Similicaudipteryx & 0.59 & Buitreraptor & 0.91 \\
Caudipteryx & 0.47 & Unenlagia & 0.72 \\
Mahakala & 0.50 & Dakotaraptor & 0.57 \\
Mei & $0.52-0.55$ & Archaeopteryx & $1.12-1.24$ \\
Sinovenator & 0.68 & Serikornis & 0.90 \\
Xiaotingia & 0.85 & Anchiornis & $0.96-1.04$ \\
Jianianhualong & 0.70 & Eosinopteryx & 0.78 \\
Jinfengopteryx & 0.70 & Aurornis & 0.88 \\
Liaoningvenator & 0.59 & Halszkaraptor & 0.60 \\
Sinornithoides & 0.59 & Scansoriopteryx & $1.06-1.12$ \\
Hesperornithoides & 0.56 & Yandangornis & 0.75 \\
Tianyuraptor & 0.65 & Epidexipteryx & 0.98 \\
Caihong & 0.59 & Zhongornis & 1.04 \\
Zhenyuanlong & 0.63 & Zhongjianornis & 1.48 \\
NGMC 91 & 0.92 & Sapeornis & $1.57-1.88$ \\
Changyuraptor & 0.97 & Jeholornis & $1.40-1.47$ \\
Sinornithosaurus & 0.92 & Jixiangornis & $1.34-1.56$ \\
Microraptor & $0.79-0.92$ & Eoconfuciusornis & $1.11-1.30$ \\
Zhongjianosaurus & 0.73 & Chongmingia & 1.18 \\
Bambiraptor & 0.85 & Confuciusornis & $1.14-1.27$ \\
\hline
\end{tabular}

